Annual Technical Progress Report

\title{
PREFERRED WATERFLOOD MANAGEMENT PRACTICES FOR THE SPRABERRY TREND AREA
}

DOE Contract No.: DE-FC26-01BC15274

Harold Vance Department of Petroleum Engineering

Texas A\& M University

3116 TAMU

College Station, TX 77843-3116

(979) 845-2241

Contract Date:

Anticipated Completion Date:

Program Manager:

Principal Investigator:

Contracting Officer's Representative:

Report Period:
September 1, 2001

September 1, 2003

C. M. Sizemore

Pioneer Natural Resources

David S. Schechter

Harold Vance Department of Petroleum

Engineering

Dan Ferguson

National Petroleum Technology Office

Sept 1, 2001- Sept 31, 2002

US/DOE Patent Clearance is not required prior to the publication of this document. 


\section{DISCLAIMER}

This report was prepared as an account of work sponsored by an agency of the United States Government. Neither the United States Government nor any agency thereof, nor any their employees, makes any warranty, express or implied, or assumes any legal liability or responsibility for the accuracy, completeness, or usefulness of any information, apparatus, product, or process disclosed, or represents that its use would not infringe privately owned rights. Reference herein to any specific commercial product, process, or service by trade name, trademark, manufacturer, or otherwise does not necessarily constitute or imply its endorsement, recommendation, or favoring by the United States Government or any agency thereof. The views and opinions of authors expressed herein do not necessarily state or reflect those of the United States Government or any agency thereof. 


\section{TABLE OF CONTENTS}

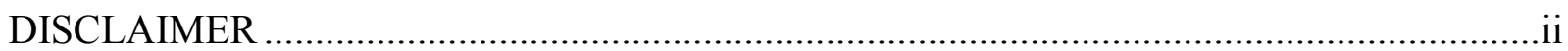

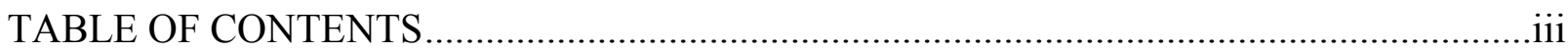

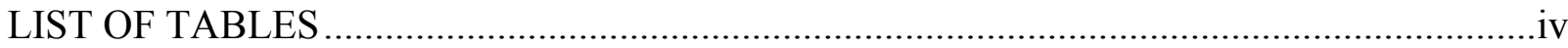

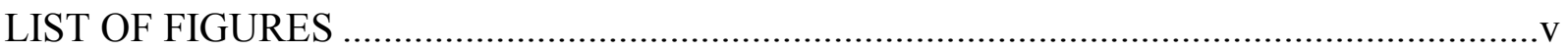

I. Germania Unit Rate Forecasting Based on Other Waterflood Pilots in the Spraberry

Area .1

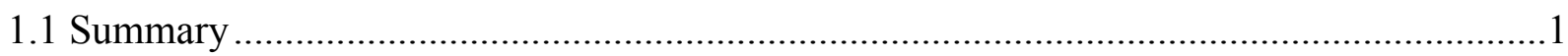

1.2 Waterflood History of Germania Unit .................................................................... 1

1.3 Waterflooding performances in the previous Germania unit and other units ....................4

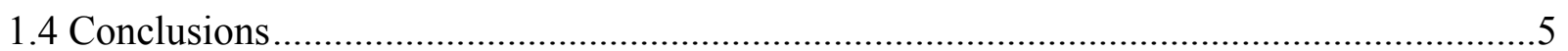

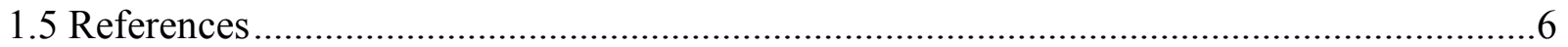

II. Evaluation of Current E.T O'Daniel $\mathrm{CO}_{2}$ Pilot...............................................................30

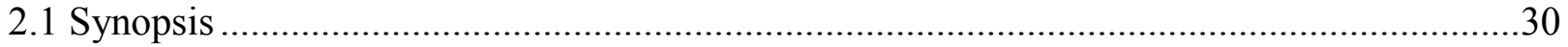

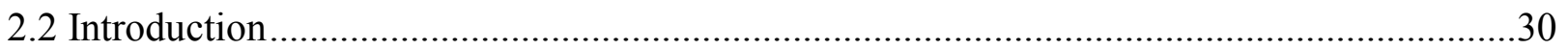

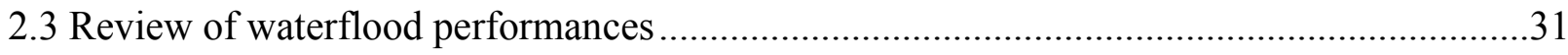

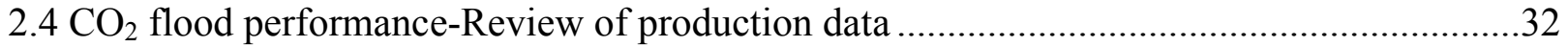

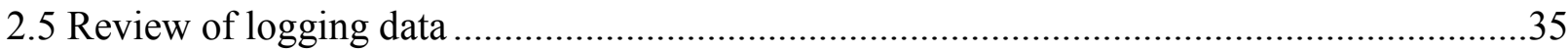

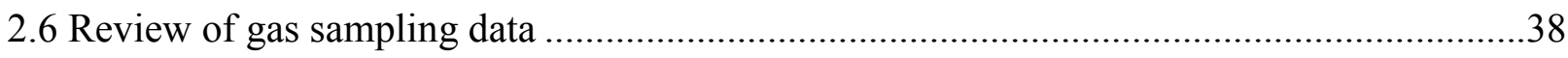

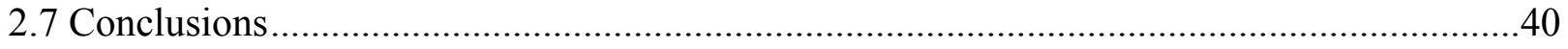

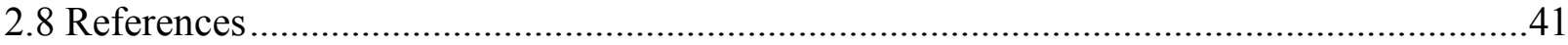




\section{LIST OF TABLES}

Table 1.1 Coupling between injector and producers...................................................

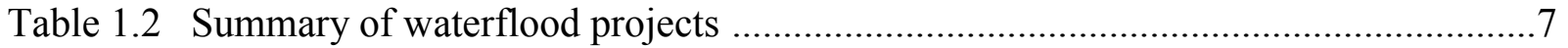




\section{LIST OF FIGURES}

Fig. 1.1 The new and old waterflood patterns applied in Naturally Spraberry Trend

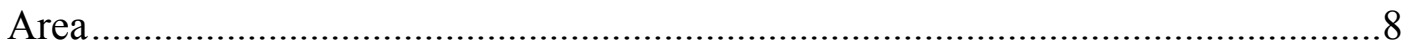

Fig. 1.2 The Germania Unit Layout showing coupling between injectors and producers

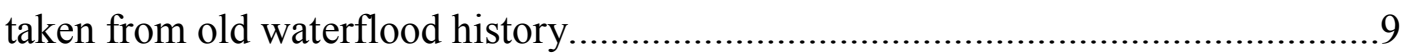

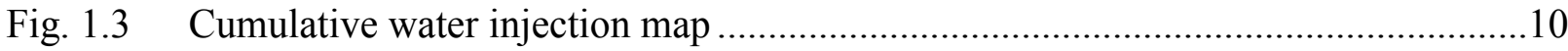

Fig. 1.4 Cumulative oil production map .....................................................................11

Fig. 1.5 Cumulative water oil ratio map.....................................................................12

Fig. 1.6 Cumulative water oil ratio in bubble map......................................................13

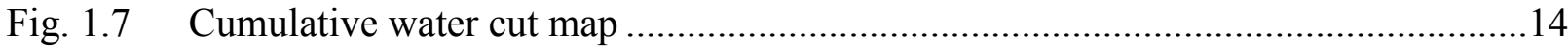

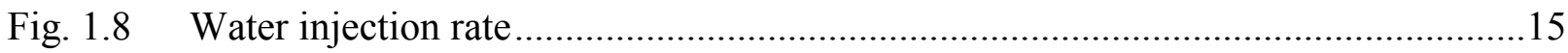

Fig. 1.9 Production summary of Germania Unit ..................................................... 15

Fig. 1.10 Oil production history and decline curve analysis ...........................................16

Fig. 1.11 Comparison of cumulative production between infill wells and waterflood

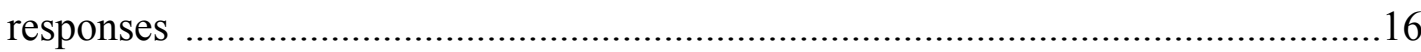

Fig. 1.12 Decline curve analysis taken from all data points and continued with the forecasting incremental oil from current ET O'Daniel waterflood performance.

Fig. 1.13 Decline curve analysis taken from all data points and continued with the forecasting incremental oil from old ET O’Daniel waterflood performance.

Fig. 1.14 Nominal decline rate above and below base case decline curve for current ET O’Daniel waterflood performance

Fig. 1.15 Nominal decline rate above and below base case decline curve for old ET O’Daniel waterflood performance

Fig. 1.16 Decline curve analysis taken from last data points.

Fig. 1.17 Decline curve analysis taken from last data points and continued with the forecasting incremental oil from old and current ET O'Daniel waterflood performance.

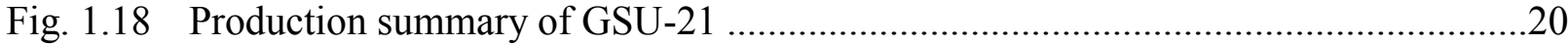

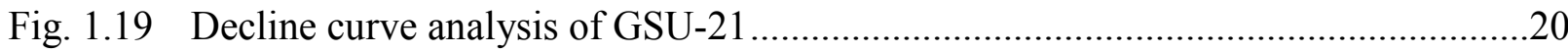

Fig. 1.20 Cumulative oil recovery due to waterflood in the Germania unit ..........................21 
Appendix-A: Production Summary and Decline Analysis of Germania Wells ......................22

Fig. 1.1A Production summary of GSU-10 ………………………....................................23

Fig. 1.2A Decline curve analysis of GSU-10 ....................................................................23

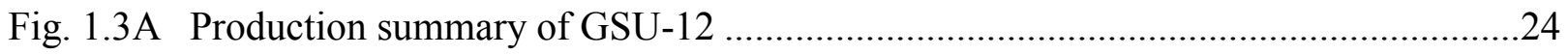

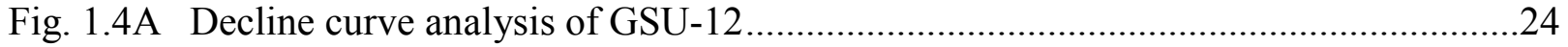

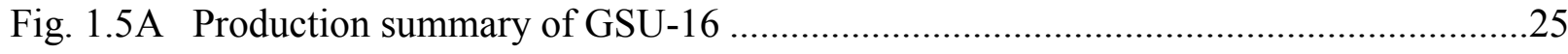

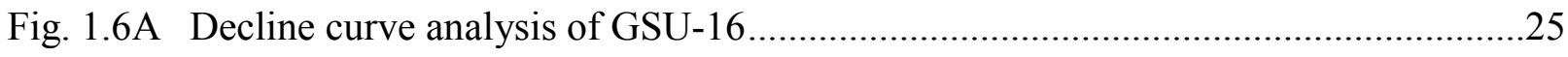

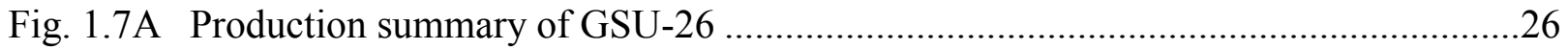

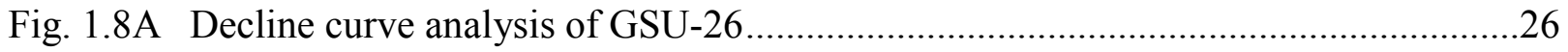

Appendix - B: Production Summary and Decline Analysis of Old ET O'Daniel Unit.........27

Fig. 1.1B Production summary of old ET O'Daniel unit.......................................................28

Fig. 1.2B Incremental oil recovery of old ET O'Daniel unit....................................................28

Fig. 1.3B Cumulative oil production of old ET O'Daniel unit ................................................29

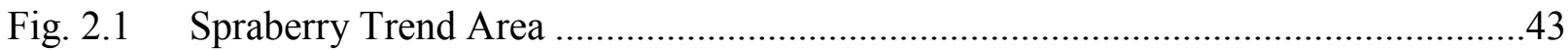

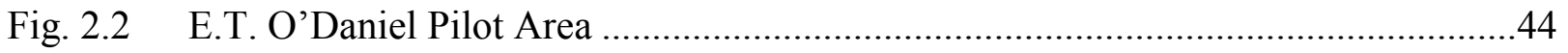

Fig. 2.3 Grid map showing cumulative oil production during 1951-1959 .............................45

Fig. 2.4 Cumulative water cut grid map (1959-1999)..........................................................46

Fig. 2.5 Cumulative oil production (1959-1999) ................................................................47

Fig. 2.6 Cumulative gas production (1959-1999) ………...................................................4

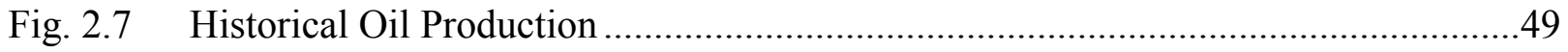

Fig. 2.8 Oil response seen at on-trend wells (1999-2002) ..................................................50

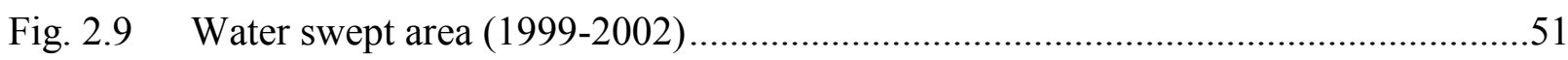

Fig. 2.10 Quickest tracer response (times of response shown in box) .....................................52

Fig. 2.11 Tracer response after 5 days …………….........................................................53

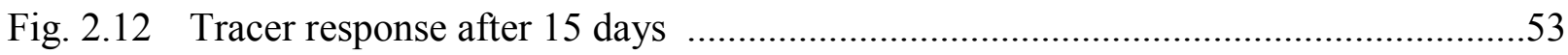

Fig. 2.13 Tracer response after 29 days …………….................................................5

Fig. 2.14 The percentage of $\mathrm{CO}_{2}$ produced at the interior wells and ET O'Daniel A1 ............54

Fig. 2.15 Total water and $\mathrm{CO}_{2}$ injection is maintained in the pilot ......................................55 
Fig. 2.16 Comparison of $\mathrm{CO}_{2}$ injected and produced in the interior producers and ET O’Daniel A1

Fig. 2.17 Cumulative water injection and production profile from ET O'Daniel A1 and

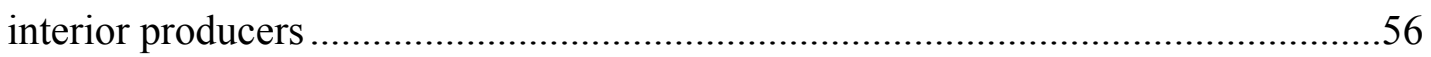

Fig. 2.18 Cumulative production profile from on trend wells ................................................56

Fig. 2.19 Similar production trend in Brunson F1 and O'Brien B1 ......................................57

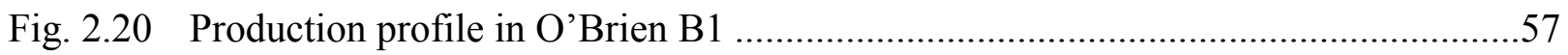

Fig. 2.21 Cumulative $\mathrm{CO}_{2}$ injected ...........................................................................5

Fig. 2.22 Production response at wells due to water injection alone .......................................58

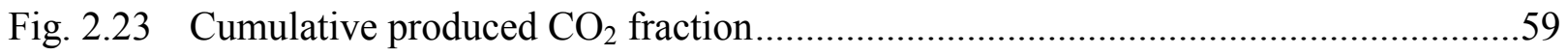

Fig. 2.24 Comparison of oil production between interior producers and ET O'Daniel A1 ......60

Fig. 2.25 Comparison of oil rate and gas rate at ET O'Daniel A1 ………................................60

Fig. 2.26 Water production at the interior producers and ET O'Daniel A1 ..............................61

Fig. 2.27 Oil production profile in ET O'Daniel A1 .........................................................61

Fig. 2.28 Decline curve scenarios when highest oil rate prior to waterflooding is used ..........62

Fig. 2.29 Cumulative oil production for decline in production before waterflooding ..............62

Fig. 2.30 Decline curve analysis after waterflooding was started.............................................63

Fig. 2.31 Cumulative production estimates for different rates after waterflooding …..............63

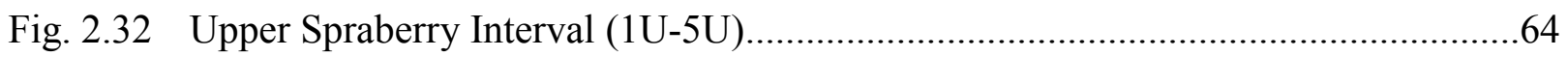

Fig. 2.33 Comparison of neutron response at LOW 49(Jan/Dec 2001) …………...................65

Fig. 2.34 Comparison of neutron response at LOW 50(Feb/Dec 2001) ..................................66

Fig. 2.35 Temperature Log taken in ET O'Daniel 41 ..........................................................67

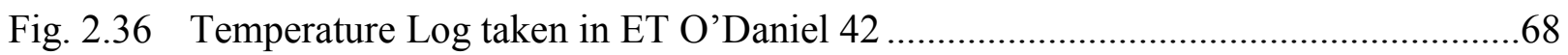

Fig. 2.37 Initial gas compositions recorded in Feb 2001 .......................................................69

Fig. 2.38 Carbon di oxide fractions in on-trend wells............................................................69

Fig. 2.39 Methane fractions in on-trend wells ....................................................................

Fig. $2.40 \mathrm{C} 2, \mathrm{C} 3, \mathrm{n}-\mathrm{C} 4$ and $\mathrm{C} 6+$ fractions in on-trend wells ................................................70

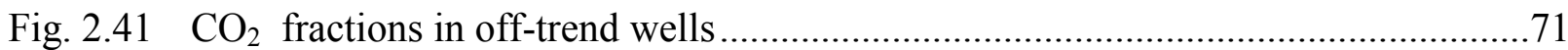

Fig. 2.42 C1 mole fraction in ET O'Daniel A1 compared to interior producers .......................71

Fig. 2.43 Relative enrichment of hydrocarbon fractions at ET O'Daniel A1 and interior

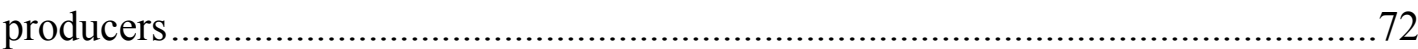




\section{Germania Unit Rate Forecasting Based on Other Waterflood Pilots in the Spraberry Area}

\subsection{Summary}

Due to the favorable results from DOE/NPTO Class III Field Demonstration Project in the E.T. O'Daniel waterflood pilot (Schechter et al, 2002), we have extended our waterflood techniques to the Germania unit. Based on recent technological development and intensive research, both basic and applied, we have gained a new understanding of proper procedures for waterflooding Spraberry reservoirs.

The Germania unit is selected for a waterflood pilot candidate based on several quantitative and qualitative criteria such as history of waterflood (cumulative injection and production per acre), condition and number of existing injection and production wells, source of water injection, surface facilities etc. The Germania unit as well as other waterflood units in the Spraberry Area had been waterflooded with the conventional waterflood techniques applied in natural fractured reservoirs elsewhere, where all injection wells were aligned parallel along major fracture trend in order to force the oil to flow in a direction perpendicular to the fracture trend towards a line of production wells. Based on our experience in this field and responses from successful waterflood projects, the injection wells should be aligned to production wells along the fracture orientation to have fast responses and viable waterfloods. The pattern configuration for both waterflood techniques is presented in Fig. 1.1.

Many wells have been pre-maturely abandoned in the Germania Unit as well as in other units in the Spraberry Trend. Abandonment is the result of either low productivity or casing failures due to corrosive nature of San Andreas water. We catalog all the production and injection wells since casing failures imply that unrecovered reserves are near these wells and should be aligned immediately and directly along the fracture trend to mobilize and sweep this oil to production wells that are still active (Schechter et al., 2000).

The objectives of this report are, thus, to propose the location of new injection wells, to review wellbore status in Germania unit and to forecast the incremental oil recovery based on waterflooding performance in other waterflood pilot area in order to demonstrate the benefit of waterflooding in Germania unit area. We endeavor to develop management practices to rapidly exploit Spraberry waterflood reserves.

\subsection{Waterflood History of Germania Unit}

Figure 1.2 is the Germania unit layout with 31 wells that have available injection and production data. The waterflooding was initiated at the end of 1965 and continued until Jan 1992. We divided the on-trend and off-trend wells based on the location of injection 
wells to the production wells and fracture orientation. For example, water injection GSU6 is in the on-trend location to GSU-12 and off-trend location to GSU-3 and GSU- 13.

Any changes in water, oil and gas production during the waterflood period are classified as waterflood responses. The responses of waterflood to off-trend and on-trend wells are tabulated in Table 1. Sometimes it is difficult to differentiate which injection wells affected the production wells. For example, injection wells GSU-11 and GSU-22 that are located in off-trend direction to the production wells GSU-12 and GSU-21, respectively, seems to be affecting those production wells. By analyzing the response in details, we found that those production wells were affected by on-trend injection wells GSU-6 and GSU-27, respectively.

The line drawn between injection and production wells indicates a communication between those wells (coupling) during waterflood period. Couplings between injection and production wells obtained from this study are oriented to the known fracture orientation in NE-SW direction (Schechter et al, 2002). Not all injection wells affected the offset production wells. Injection wells GSU-8, GSU-11 and GSU-15 did not have significant effect on surrounding oil production wells, either in the on-trend or off-trend production wells. The reasons behind this are still unclear. It may be inadequate volume of water that has been injected or lack of fracture density around this area.

Based on some criteria discussed previously, Germania unit has been chosen as a waterflooding pilot. Pioneer Natural Resources proposed the location of new injection wells as shown in Fig. 1.2. The seven proposed injection wells have a blue circle symbol. From the results of coupling between injection and production wells show that the location of proposed injection wells GSU-408A and GSU-10 should be relocated because they are located on old injector path.

To have a better analysis of production data from Germania Unit and avoid the ambiguity analysis we collected and organized injection and production data followed by developing a database using software donated by Schlumberger (OFM). Using this software, we were able to see the old waterflood performance and identify casing failure due to the corrosive nature of San Andreas water resulting in premature abandonment of Spraberry well bores. This OFM software can also be interfaced with real time data acquisition so that daily analysis of response can be monitored and analyzed from remote location.

Figure 1.3 shows the history of cumulative water injection and the results of water injection on oil production (Fig. 1.4). It shows that wells located in the NE-SW location responded to water injection and water injection improved oil recovery in this area. The water injection not only affected the oil production but also increased the water production. Production wells GSU-10 and GSU-16 had the highest cumulative water production. When we plotted the cumulative water oil ratio (CWOR), it shows that the production wells GSU-1, GSU-315A and GSU-5 had the highest CWOR (Fig. 1.5). The high CWOR indicates that the wells might have casing leaks. Pioneer corroborated same problem in the field. Well GSU-1 has been plugged and abandoned. Well GSU-315A has 
been temporarily abandoned. The leaks in well GSU-5 have been fixed. Near these wells, oil is still unrecovered and should be mobilized to production wells that are still active.

Figure 1.6 shows the CWOR in the bubble plot map. The difference between this map and the previous contour map is that the bubble map shows actual magnitude of the number to identify trends and anomalies in a project while the contour map uses interpolation techniques i.e. kriging, spline and nearest neighbor to create the isopachs, or areas, for a map image.

To identify the location of new wells (infill wells) and oil spot, we can employ the water cut map as our base analysis (Fig. 1.7). It becomes apparent from the map that the Germania unit has un-swept areas. Wells GSU-13, GSU-25 and GSU-17 would be good producers when the new water injection pattern concept is applied since the water cuts around those wells are still low. Low total oil production and insignificant total water injection indicate that the Germania unit is an excellent target for waterflooding. Figure 1.8 shows the water injection history of four injection wells and the cumulative water injection. The total water that had been injected was about $2.5 \mathrm{MMbbls}$ for about 20 years. The production summary and the number of wells in the unit area are shown in Fig. 1.9. The average oil production per well was ranging from 4 to 29 bopd. The infill wells show instantaneous increase in oil production but later the production faded away. In Sep-92, the average production rate was 8.5 bopd and after adding a total of 23 wells in March-93, the production jumped to 28.7 bopd (Fig. 1.10). Similar production response was exhibited at successive infill wells.

The decline curve analysis was conducted to define the baseline of waterflooding so that the excess production due to infill wells and waterflooding can be quantified. Due to the nature of oil production rate from the naturally fractured reservoir, a hyperbolic-type decline curve was used to fit the production trend and forecast the future production rate. The following well-known decline curve equation is presented below:

$$
q_{i}=q_{o}\left(1+n d_{i} T\right)^{\frac{1}{n}}
$$

where $q_{o}$ is the initial rate (bopd), $n$ is the fractional power exponential decline (dimensionless), $d_{i}$ is the nominal decline rate (1/day) and $T$ is cumulative time (day).

Three cases were conducted in decline analysis:

1. Fitting decline curve to data points before the infill wells started to compare the performance of infill wells versus waterflooding.

2. Fitting decline curve to all data points after peak rate to analyze the future waterflood scenarios.

3. Starting decline curve analysis from the last data point.

The first case: Since the waterflooding in this unit was terminated around May-90 and the infill wells were started on Sep-92, thus, all incremental oil was a result of infill wells only. The result of decline curve analysis is depicted in Fig. 1.10. The decline curve was 
fitted until Mar-97 data points in order to take into account the production response due to infill wells. The incremental oil recovery obtained as a result of infill well was compared to the results of waterflooding in the ET O'Daniel Pilot. We divided two successful waterflood performances, old ET O'Daniel performance (Guidroz, 1967) and current ET O’Daniel waterflood pilot performance (1995-now) (Schechter et al, 2002). These two production performances were added on Sep-02 by assuming that the Germania unit would behave with a similarly response during water injection. The abrupt change shown in decline curve on Sep-02 was conducted to take into account the losing production rate due to conversion of 5 producers to injectors.

The cumulative oil comparisons between infill well and waterflooding scenarios are demonstrated in Fig. 1.11. The incremental oil due to 15 infill wells is similar at about 1100 days with incremental oil due to waterflood response from current ET O'Daniel performance. Meanwhile, the waterflood response from old ET O'Daniel performance needs only 400 days to reach the same production response due to infill wells. Even before conducting the economic calculation, we can justify that the waterflooding would be more economical than the incremental rate obtained from infill wells.

The second case: Again, we fitted the decline curve to all data points to analyze the future waterflood scenarios as shown in Figs. 1.12 and 1.13. We also used the old and current ET O'Daniel waterflood performance for our prediction. We did a sensitivity study to forecast the resulting incremental oil rate by changing nominal decline rate above and below base case decline as the case may be used for running project economics (Figs. 1.14 and 1.15).

As our last case, we did the decline analysis from the last data point as shown in Fig. 1.16. The old and current ET O'Daniel waterflood performances were also included for forecasting our incremental oil. We used current ET O'Daniel data as our best and pessimistic guesses and old ET O'Daniel data as our optimistic guess. This case also includes a 14 bopd oil rate reduction due to the negative impact of converting three known existing producers to injectors (Fig.1.17). If this unit follows the incremental oil recovery from ET O'Daniel waterflood, either old or current waterflood performances, we justify that the waterflooding would be economical and competing with other secondary projects.

\subsection{Waterflooding performances in the previous Germania unit and other units}

Waterflooding in the naturally fractured Spraberry Trend Area reservoirs has always been scorned resulting from ambiguity of performance data after water injection or results that did not conform to previously conceived notions. However, upon closer inspection, Spraberry water injection projects have all responded in a similar manner. Indeed, incremental oil was always recovered and production rates increased (Schechter et al., 2000). 
In order to analyze the old waterflood performances in Germania unit and other units, we gathered and compiled all production and injection data. Then reconstructed and developed injection/production data using Oil Field Manager (OFM) database. The example of production data from GSU-21 that was used as an input parameter for OFM database is presented in Fig. 1.18. A decline analysis was conducted to quantify the waterflood response (Fig. 1.19). All production wells in this unit have been analyzed and the waterflood response has been quantified (Appendix-A). A total of 120,000 bbls oil has been recovered due to waterflooding in this area over 25 years with total injection of 2.5 MMbbls (Fig. 1.20). The waterflood response in this unit resulted in a lack of confidence in water injection as a result many wells face abandonment. The small amount of oil that has been recovered due to waterflooding and negligible amount of water that has been injected for 25 years warrant that this unit would be potential for recovering oil with proper management practices during water injection.

We have reviewed waterflood performance in other units in order to demonstrate the benefit of waterflooding in this area and to reach a stage of development of management practices that could eventually help for conducting successful water injection in Germania Unit. The previous summary of waterflood projects in other units is summarized in Table 2 and can be found in PUMP semi annual report (Putra and Schechter, 2002). Waterflood performance in the E.T. O'Daniel has been reviewed in PUMP proposal (Schechter and Putra, 2000) and Guidroz's paper (1967). We provide a production summary and decline analysis for this area as found in Appendix-B. An updated review of current E.T. O'Daniel pilot is presented in the next section.

\subsection{Conclusions}

1. Proposed injection wells GSU-408A and GSU-10 should be relocated because they are located along old injector paths.

2. Based on the high WOR map, production wells GSU-1, GSU-315A and GSU-5 may have casing leaks.

3. Waterflooding in the Germania Unit would be economical and compete favorably with other secondary projects.

4. Spraberry water injection projects in other waterflood units increased oil production rates and improved ultimate recovery.

5. The amount of historical water injection in Germania unit was very low compared to the water injection rate in other waterflood units. Based on the injection rate in other pilots and by aligning the water injection parallel to production wells along the fracture orientation, this unit could be successfully flooded with total injection rates between 2000 and 2500 bwpd. 


\subsection{References}

McDonald, P., Lorenz, J. C., Sizemore, C., Schechter, D.S., and Sheffield, T.: "Fracture Characterization Based on Oriented Horizontal Core From the Spraberry Trend Reservoir: A Case Study" paper SPE 38664 presented at the 1997 Annual Technical Conference and Exhibition, San Antonio, Tx, 5-8 October.

Guidroz, G.M.: “E.T. O’Daniel Project - A Successful Spraberry Flood,” paper SPE 1791 presented at the 1967 Sixth Permian Basin Oil Recovery Conference, Midland, 8-9 May.

Schechter, D.S., Putra, E. and Knight, W: "Preferred Waterflood Management Practices for the Spraberry Trend Area," Proposal submitted to DOE contract No.: DE-FC2295BC14942 (August 2000).

Schechter, D.S.: "Advanced Reservoir Characterization and Evaluation of $\mathrm{CO}_{2}$ Gravity Drainage in the Naturally Fractured Spraberry Trend Area," Final Technical Report, DOE contract No.: DE-FC22-95BC14942 (June 2002).

Putra, E. and Schechter, D.S.: "Preferred Waterflood Management Practices for the Spraberry Trend Area," Semi Annual Technical Report, DOE Contract No.: DE-FC2601BC15274 (Mar 2002) 
Table 1 - Coupling between injector and producers

\begin{tabular}{|c|c|c|c|c|c|c|}
\hline Injector & $\begin{array}{l}\text { Waterflood } \\
\text { period }\end{array}$ & $\begin{array}{l}\text { On-trend } \\
\text { well }\end{array}$ & Responding & $\begin{array}{l}\text { Off-trend } \\
\text { well }\end{array}$ & Responding & Remarks \\
\hline G.S.U. \#6 & $01 / 72-05 / 89$ & GSU\#12 & $\begin{array}{l}\text { Oil, gas and } \\
\text { water }\end{array}$ & $\begin{array}{l}\text { GSU\#3 } \\
\text { GSU\#13 }\end{array}$ & $\begin{array}{l}\text { None } \\
\text { None }\end{array}$ & \\
\hline G.S.U. \#8 & $08 / 71-02 / 77$ & GSU\#2 & None & $\begin{array}{l}\text { GSU \#1 } \\
\text { GSU \#7 } \\
\end{array}$ & $\begin{array}{l}\text { Water } \\
\text { None }\end{array}$ & \\
\hline G.S.U. \#11 & $\begin{array}{l}12 / 65-01 / 68 \\
02 / 70-02 / 75\end{array}$ & $\begin{array}{l}\text { GSU\#31 } \\
\text { GSU\#13 } \\
\text { GSU\#3 } \\
\text { GSU\#20 } \\
\text { GSU\#19 } \\
\end{array}$ & $\begin{array}{l}\text { None } \\
\text { None } \\
\text { None } \\
\text { None } \\
\text { None } \\
\end{array}$ & $\begin{array}{l}\text { GSU\#10 } \\
\text { GSU\#17 } \\
\text { GSU\#12 } \\
\text { GSU\#7 } \\
\end{array}$ & $\begin{array}{l}\text { None } \\
\text { None } \\
\text { Oil, gas and } \\
\text { water } \\
\text { None } \\
\end{array}$ & $\begin{array}{l}\text { \#19 was } \\
\text { converted to } \\
\text { WIW } \\
\# 12 \text { was affected } \\
\text { by WIW\#6 }\end{array}$ \\
\hline G.S.U. \#15 & $09 / 71-01 / 92$ & GSU\#14 & $\begin{array}{l}\text { None } \\
\text { None }\end{array}$ & $\begin{array}{l}\text { GSU\#13 } \\
\text { GSU\#16 }\end{array}$ & $\begin{array}{l}\text { None } \\
\text { None }\end{array}$ & \\
\hline G.S.U. \#19 & $06 / 70-01 / 77$ & GSU\#10 & $\begin{array}{l}\text { Oil, gas and } \\
\text { water }\end{array}$ & $\begin{array}{l}\text { GSU\#20 } \\
\text { GSU\#9 }\end{array}$ & $\begin{array}{l}\text { None } \\
\text { Oil, gas and } \\
\text { water??? }\end{array}$ & \\
\hline G.S.U. \#22 & $06 / 70-01 / 76$ & $\begin{array}{l}\text { GSU\#16 } \\
\text { GSU\#26 }\end{array}$ & $\begin{array}{l}\text { Oil, gas and } \\
\text { water } \\
\text { Oil, gas and } \\
\text { water }\end{array}$ & $\begin{array}{l}\text { GSU\#21 } \\
\text { GSU\#23 } \\
\text { GSU\#17 } \\
\text { GSU\#25 } \\
\end{array}$ & $\begin{array}{l}\text { Water } \\
\text { None } \\
\text { None } \\
\text { None }\end{array}$ & $\begin{array}{l}\# 21 \text { was affected } \\
\text { by WIW\#27 }\end{array}$ \\
\hline G.S.U. \#27 & $06 / 70-01 / 77$ & GSU\#21 & water & $\begin{array}{l}\text { GSU\#26 } \\
\text { GSU\#20 }\end{array}$ & $\begin{array}{l}\text { None } \\
\text { None }\end{array}$ & \\
\hline
\end{tabular}

Table 2 - Summary of waterflood projects

\begin{tabular}{|c|c|c|c|}
\hline Pilot area & $\begin{array}{c}\text { Duration of } \\
\text { waterflooding }\end{array}$ & $\begin{array}{c}\text { Cumulative water } \\
\text { injection/No. of } \\
\text { injection wells }\end{array}$ & $\begin{array}{c}\text { Cumulative oil } \\
\text { production/No. of } \\
\text { production wells }\end{array}$ \\
\hline Germania unit & $\sim 19$ & $\begin{array}{c}\sim 2,500,000(4) \\
(\sim 1000 \text { bwipd })\end{array}$ & $\sim 80,000(5)$ \\
\hline Current E.T O'Daniel & $\sim 3$ & $\begin{array}{c}\sim 1,600,000(6) \\
(\sim 2000 \text { bwipd })\end{array}$ & $\sim 110,000(4)$ \\
\hline Old E.T O'Daniel & $\sim 26$ & $\begin{array}{c}\sim 17,600,600 \\
(\sim 2500 \text { bwipd })\end{array}$ & $\sim 2,200,000$ \\
\hline Midkiff "Mc Donald" unit & $\sim 2$ & $\begin{array}{c}\sim 1,400,000^{*}(4) \\
(\sim 2000 \text { bwipd })\end{array}$ & $\sim 40,000(15)$ \\
\hline Midkiff "Heckman" unit & Since 1996 & - & $\sim 60,000(18)$ \\
\hline
\end{tabular}

*) injected only in Upper Spraberry layer 


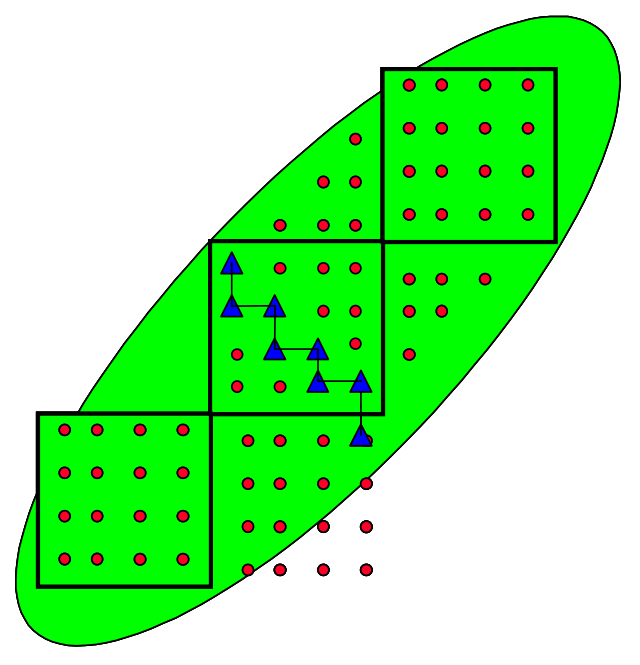

a. New waterflood technique

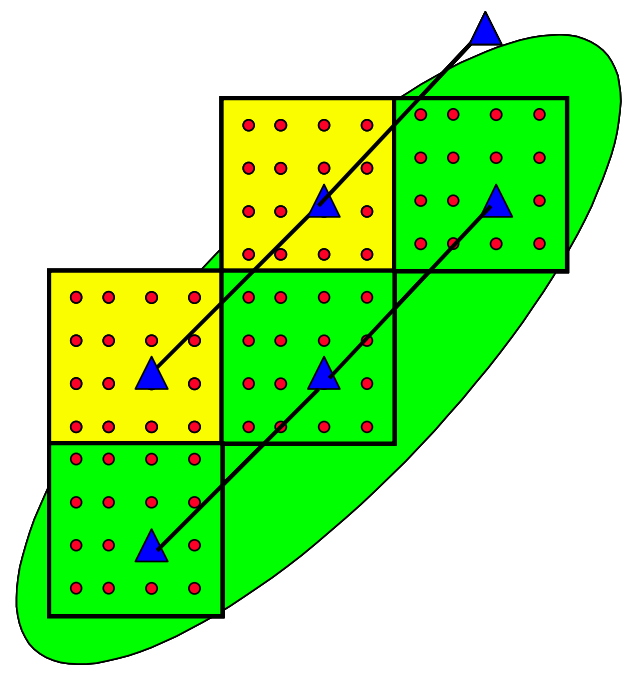

b. Old waterflood technique

Fig. 1.1 - The new and old waterflood patterns applied in Naturally Spraberry Trend Area. 


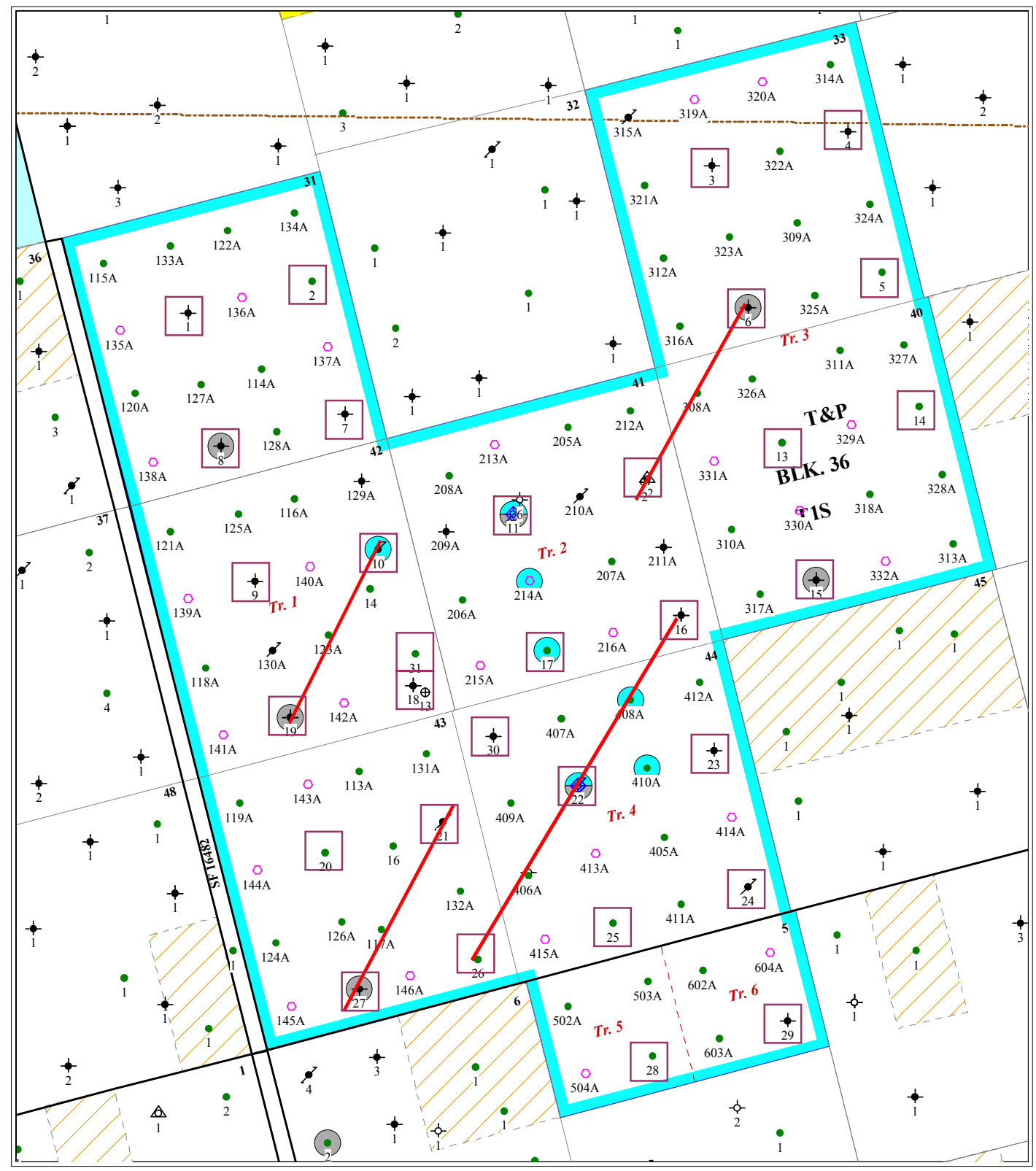

Fig. 1.2 - The Germania Unit Layout showing couple between injectors and producers taken from old waterflood history. 


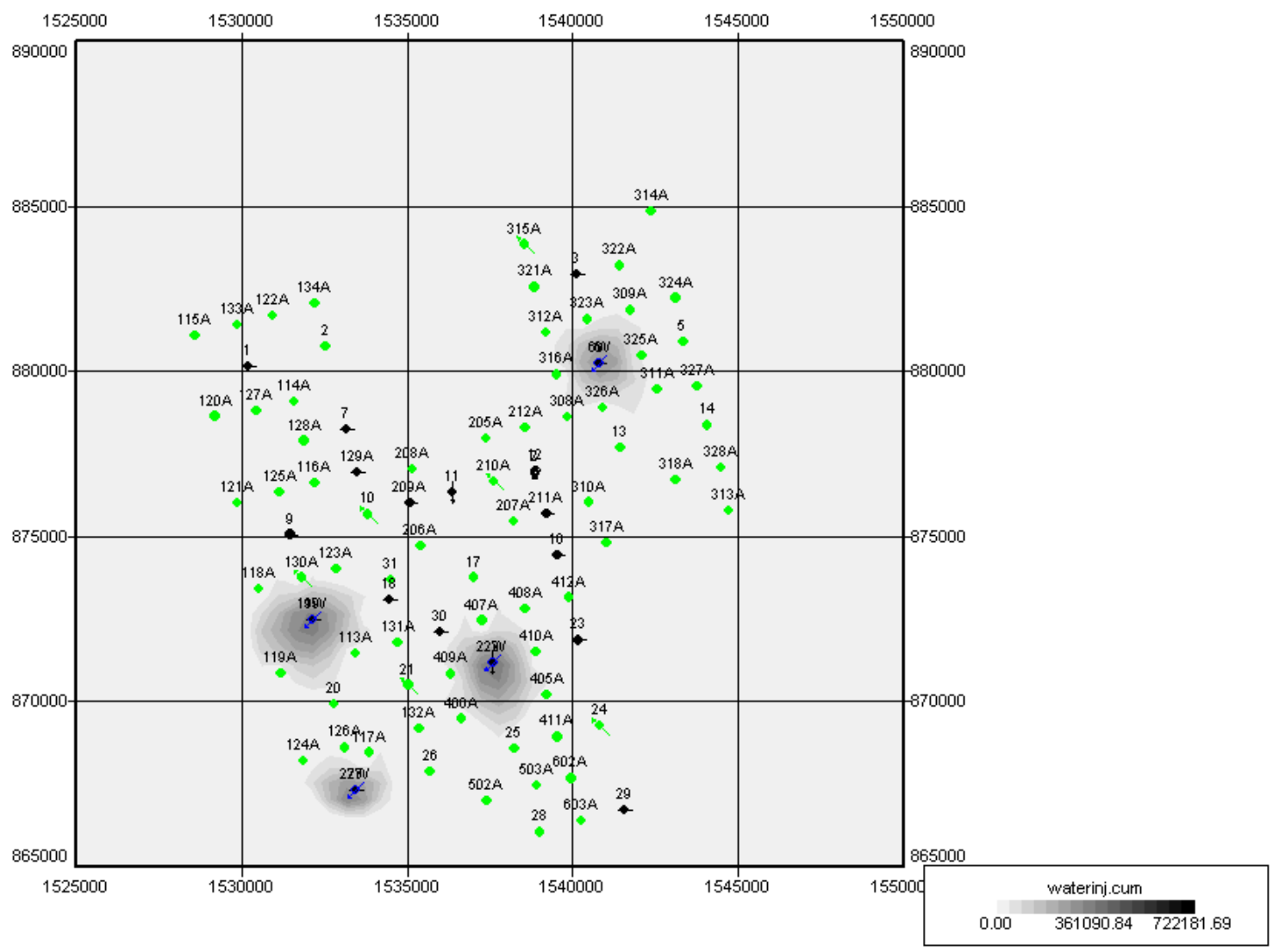

Fig. 1.3 - Cumulative water injection map in the Germania Unit. 


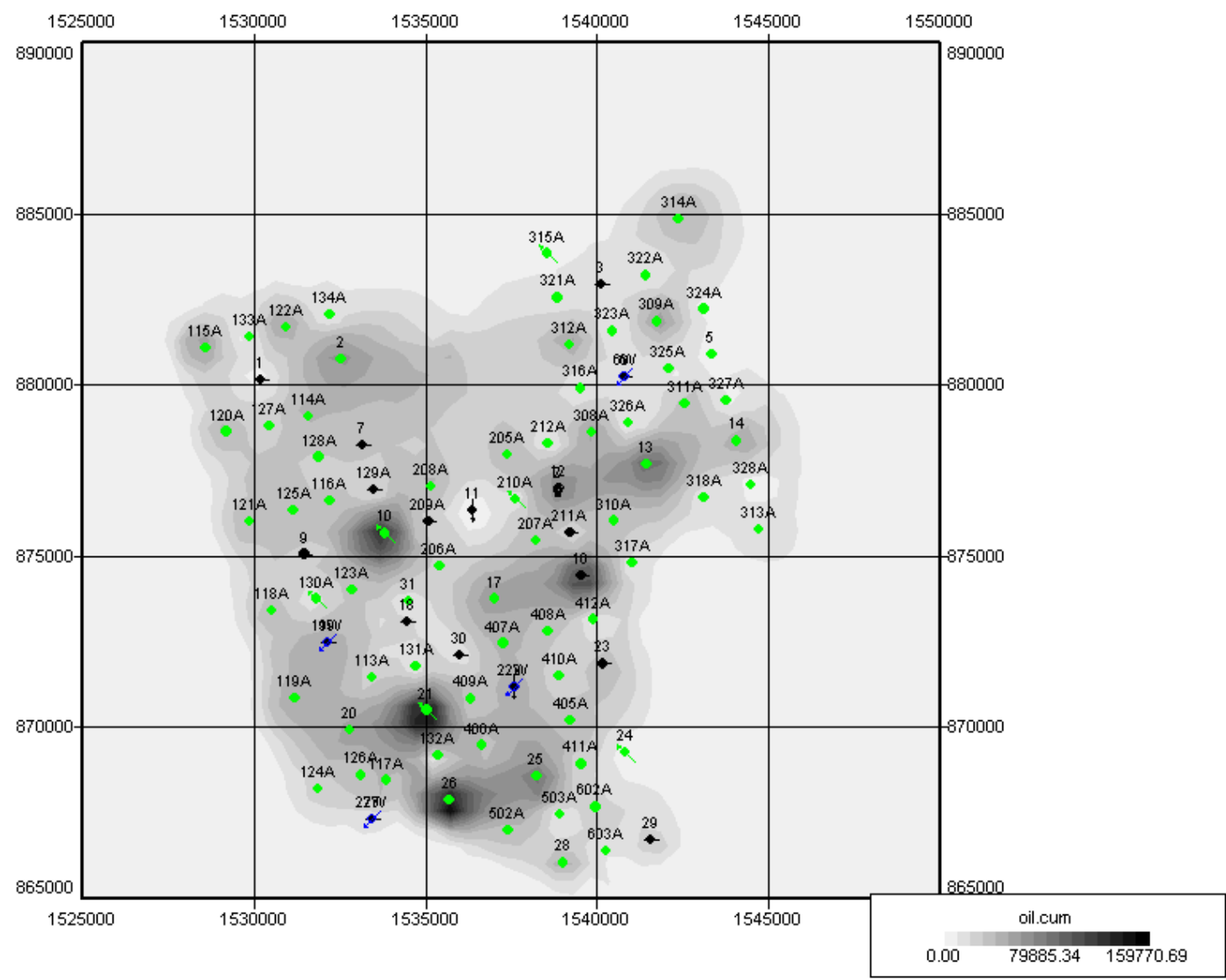

Fig. 1.4 - Cumulative oil production map in the Germania Unit. 


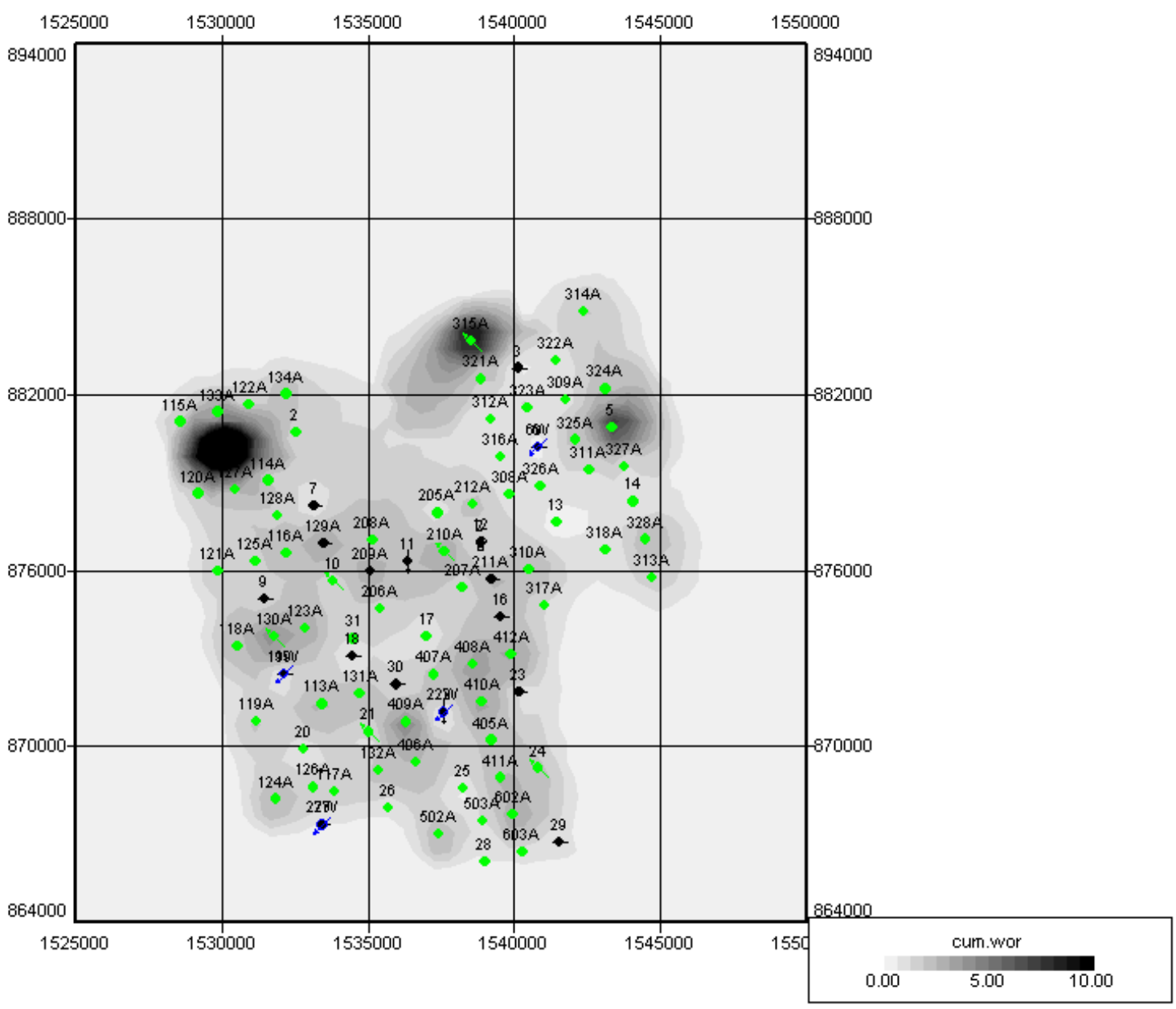

Fig. 1.5 - Cumulative water oil ratio map in the Germania Unit. 


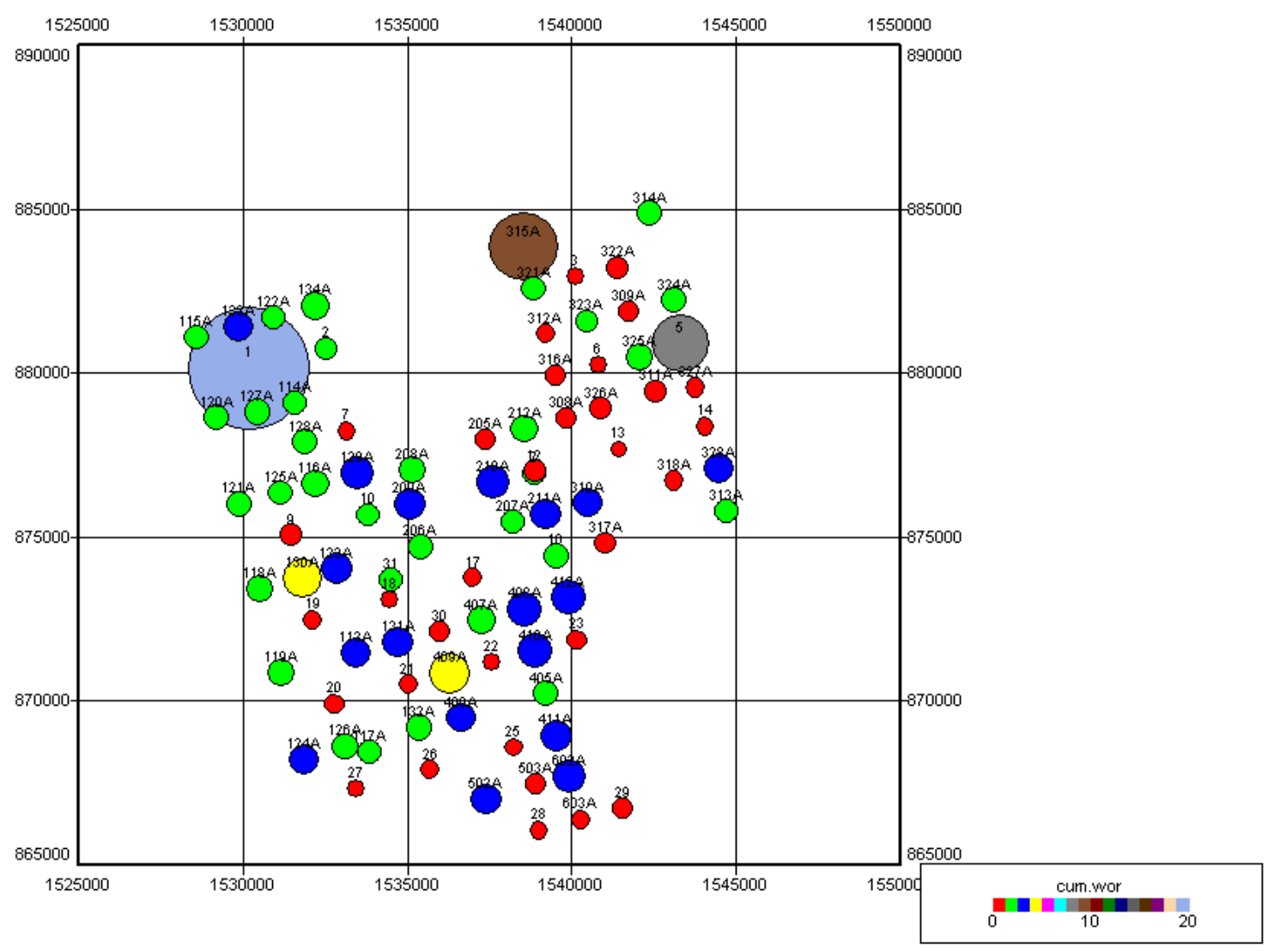

Fig. 1.6 - Cumulative water oil ratio bubble map in the Germania Unit. 


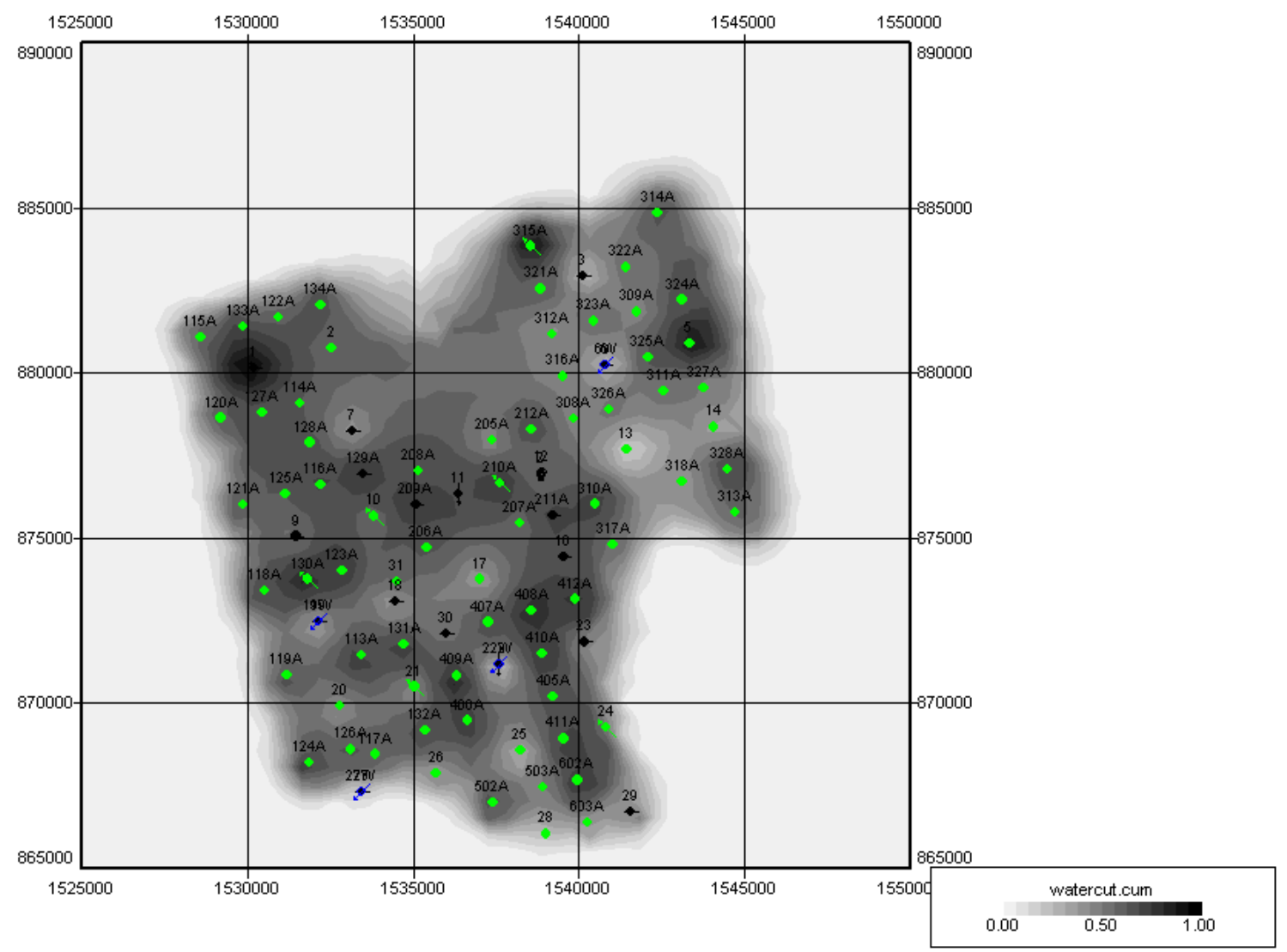

Fig. 1.7 - Cumulative water cut map in the Germania Unit. 


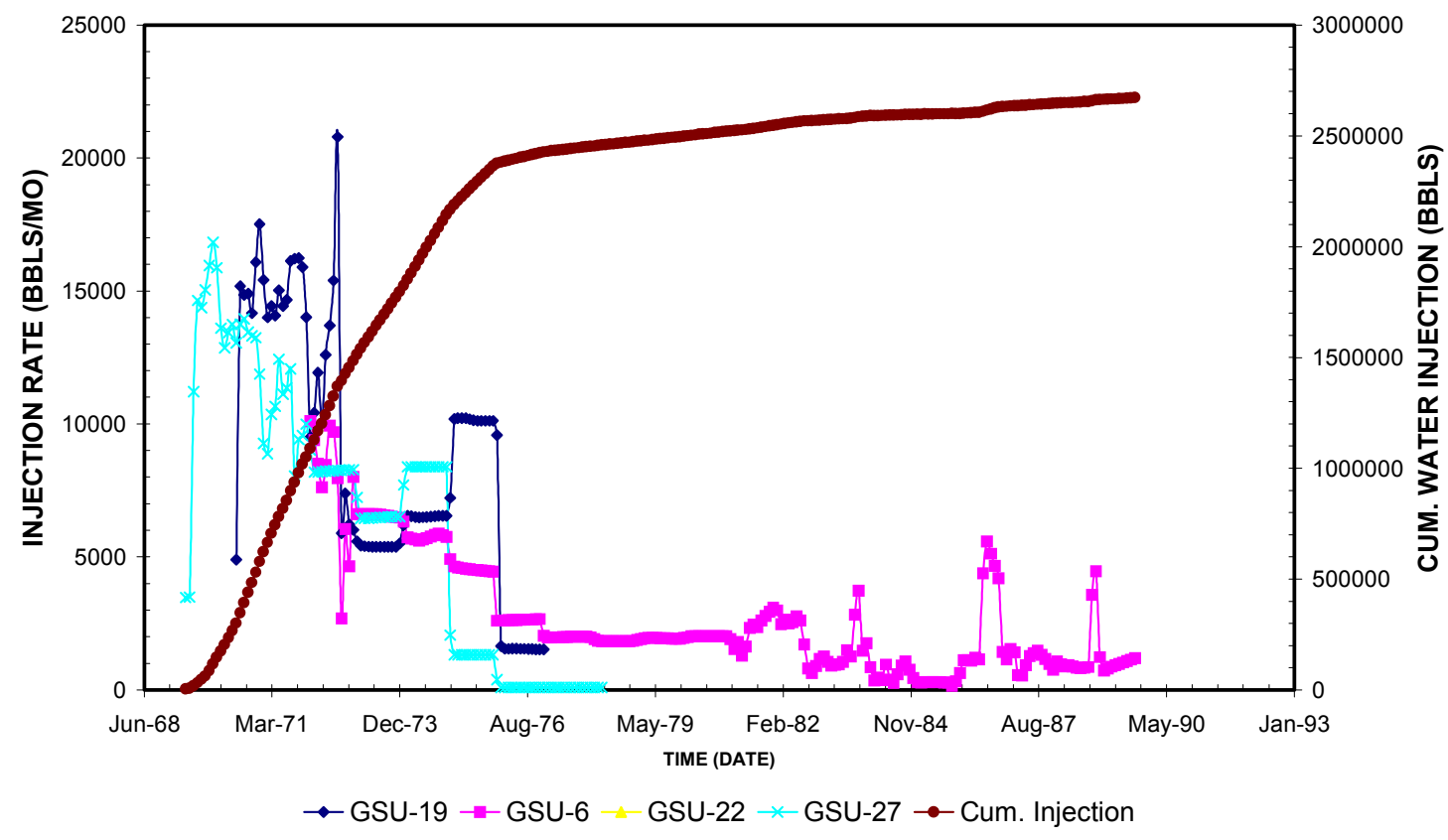

Fig. 1.8 - Historical water injection rate in the Germania Unit .

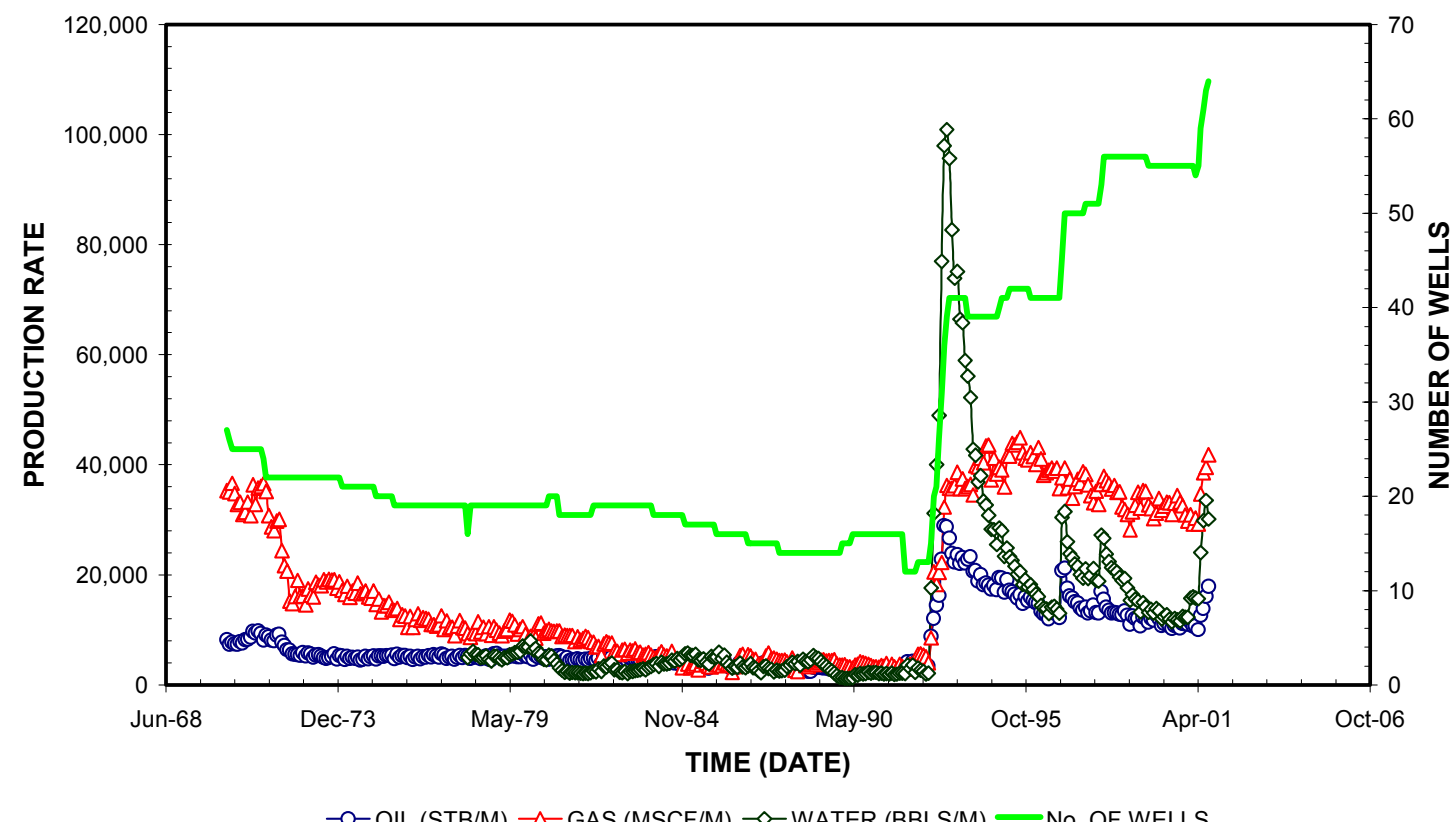

Fig. 1.9 - Production summary of the Germania Unit. 


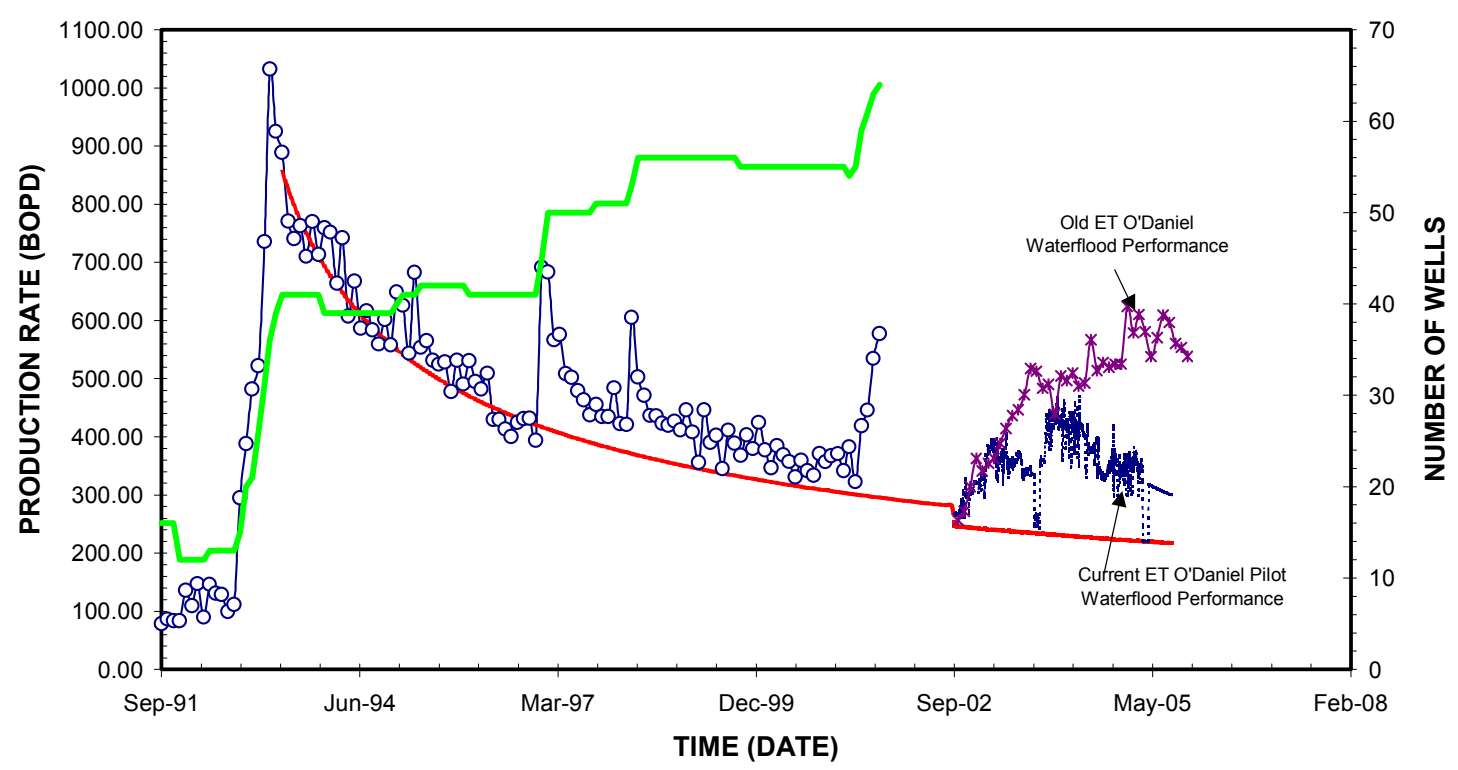

Fig. 1.10 - Oil production history and decline curve analysis for the Germania Unit .

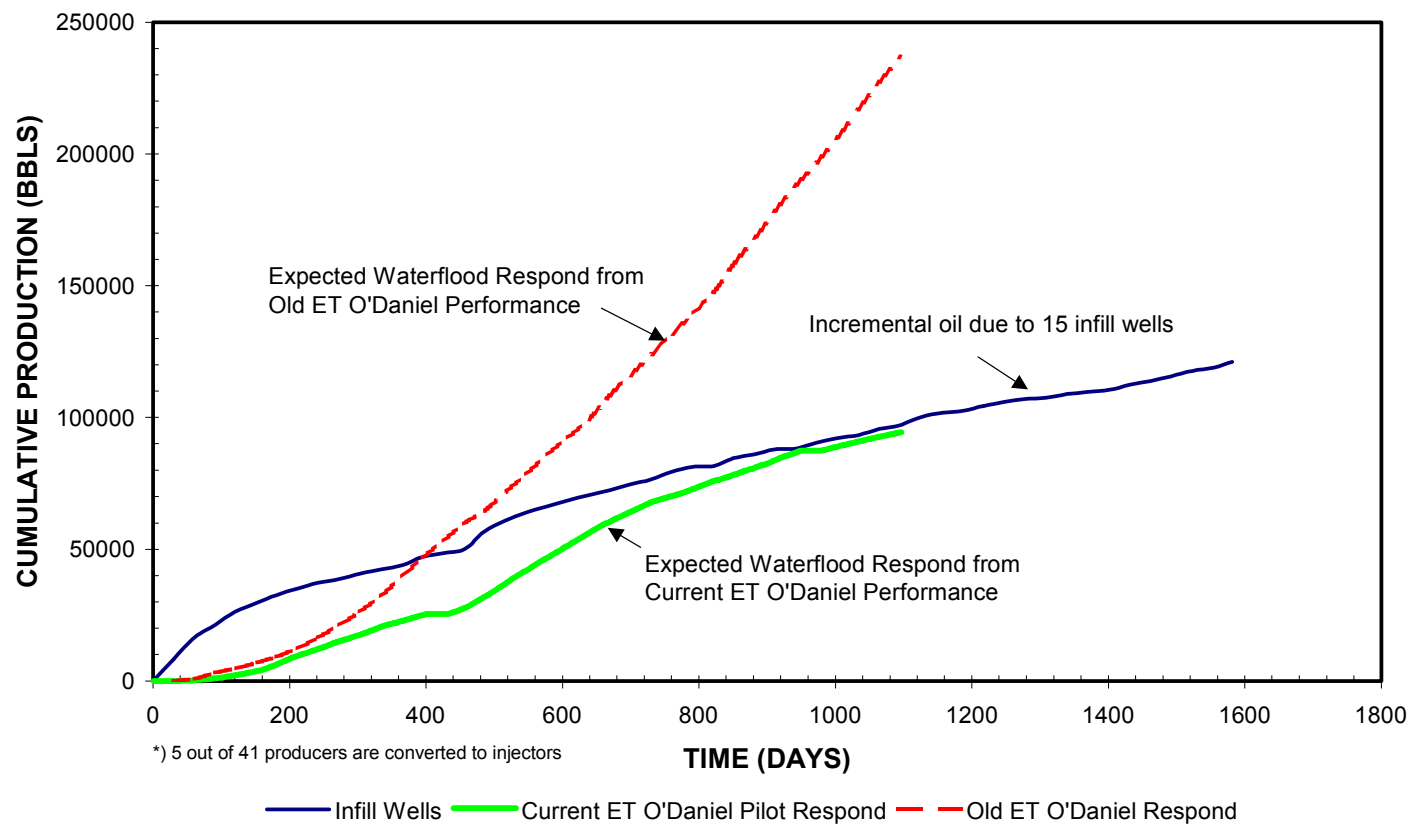

Fig. 1.11 - Comparison of cumulative production between infill wells and waterflood responses in the Germania Unit. 


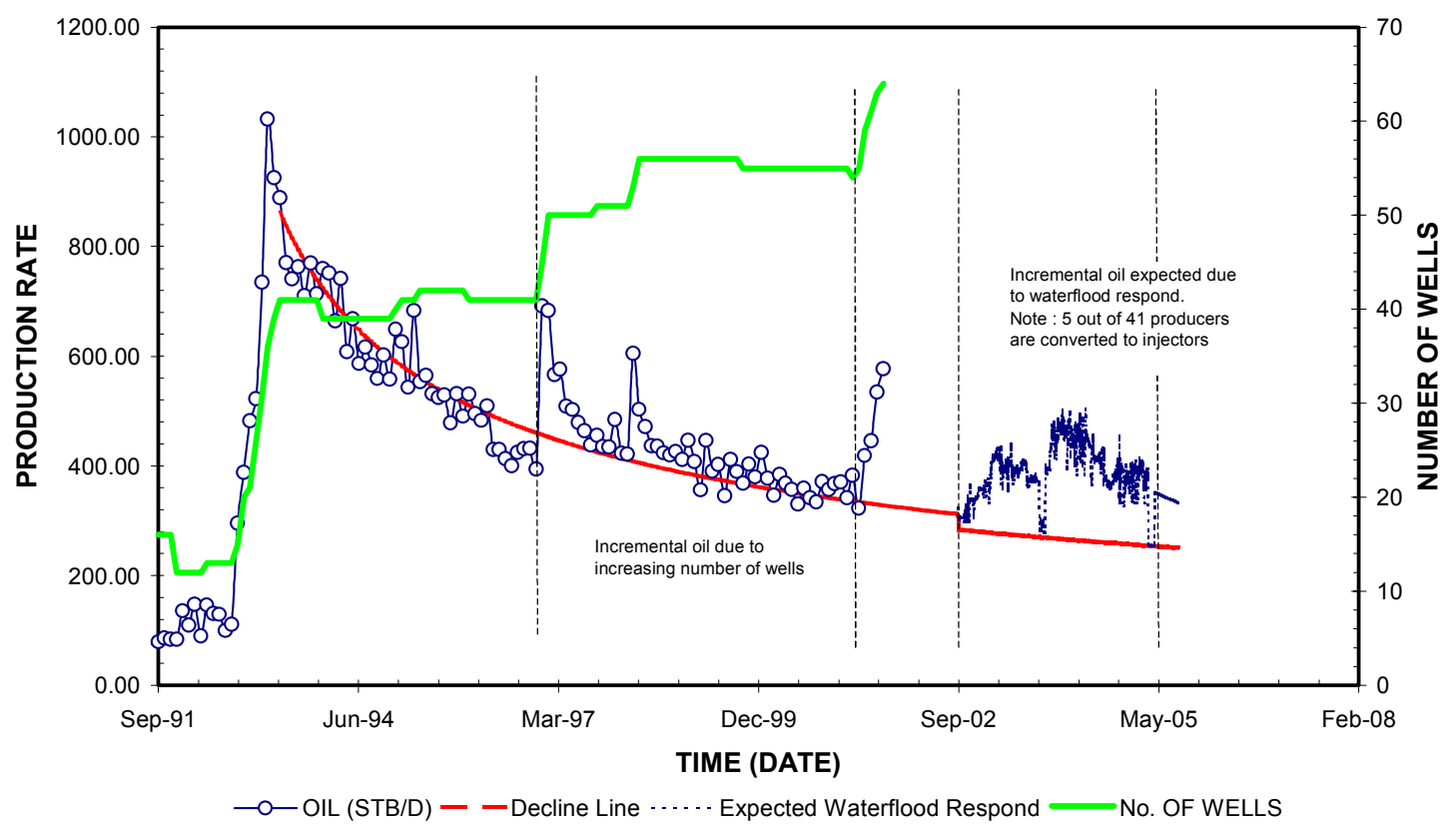

Fig. 1.12 - Decline curve analysis taken from all data points and continued with the forecasting incremental oil from current E.T.'O'Daniel waterflood performance.

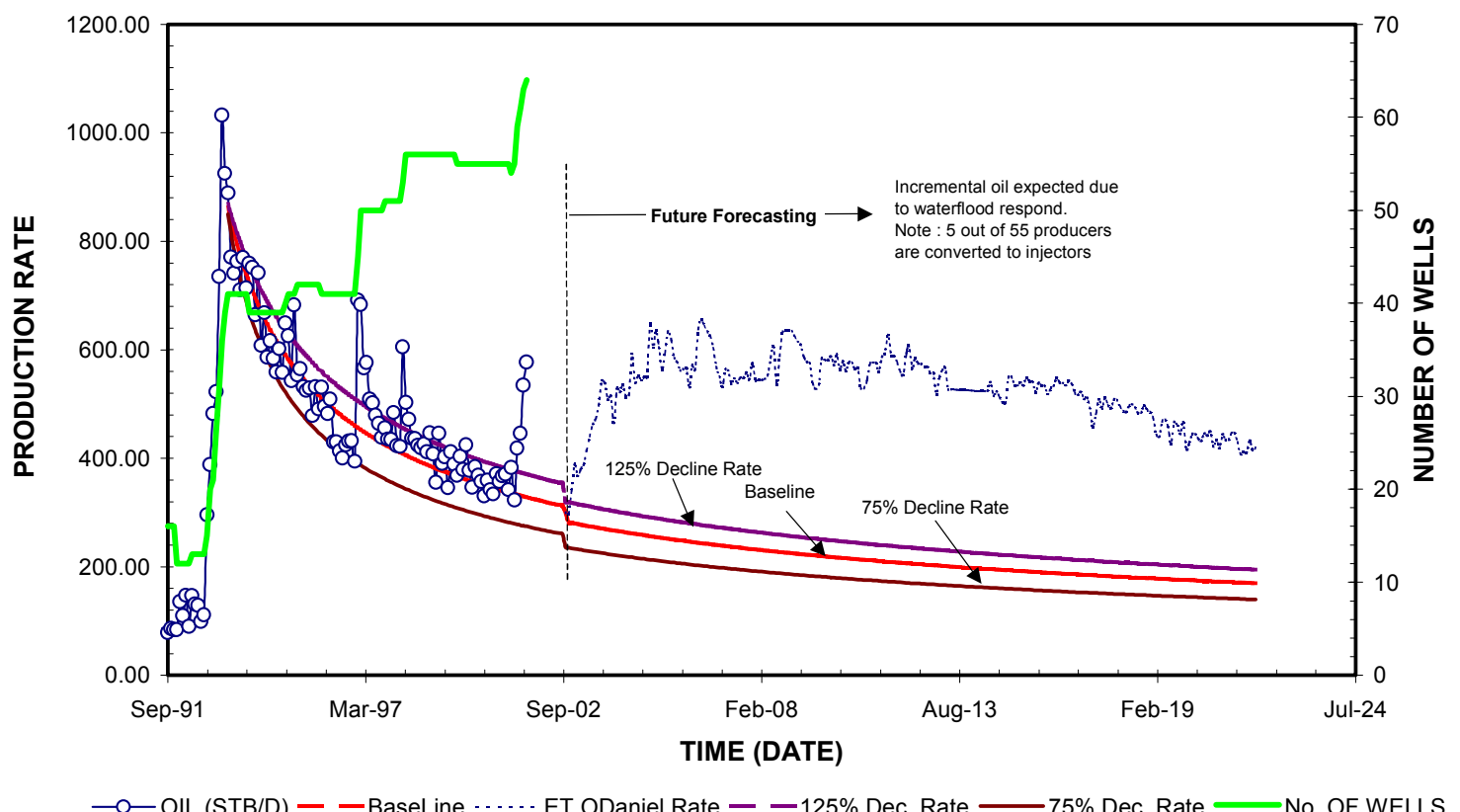

Fig. 1.13 - Decline curve analysis taken from all data points and continued with the forecasting incremental oil from old ET'O'Daniel waterflood performance. 


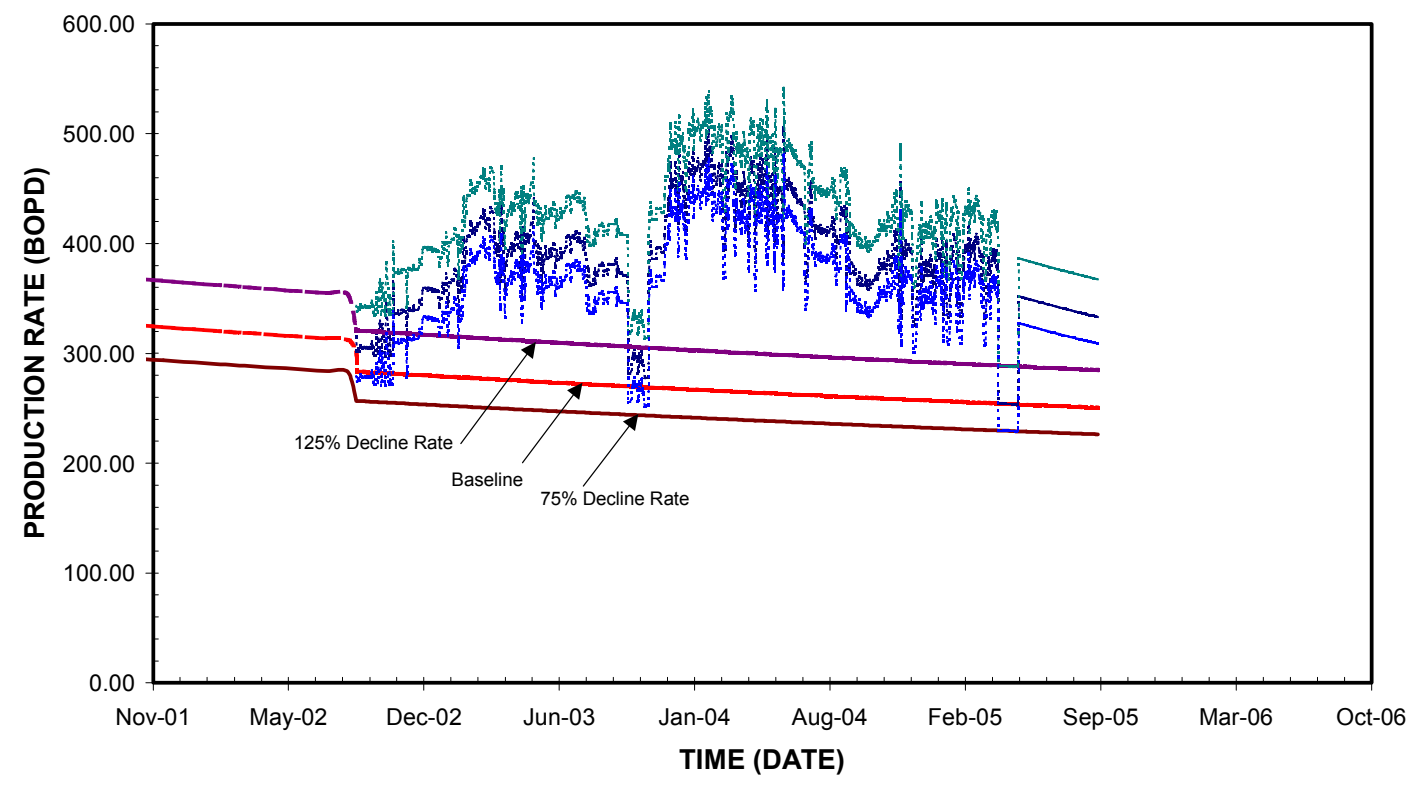

Fig. 1.14 - Nominal decline rate above and below base case decline curve for current E.T. O'Daniel waterflood performance.

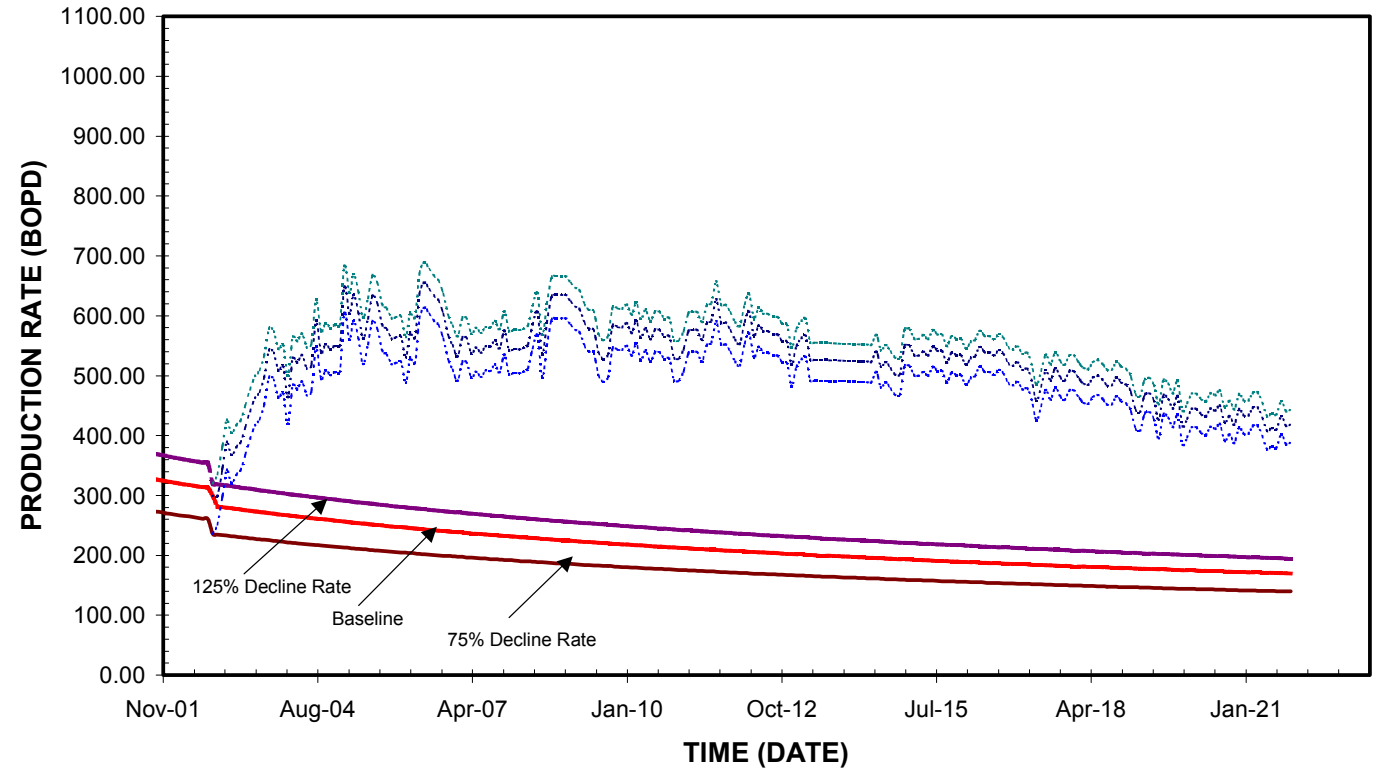

Fig. 1.15 - Nominal decline rate above and below base case decline curve for old E.T.O'Daniel waterflood performance. 


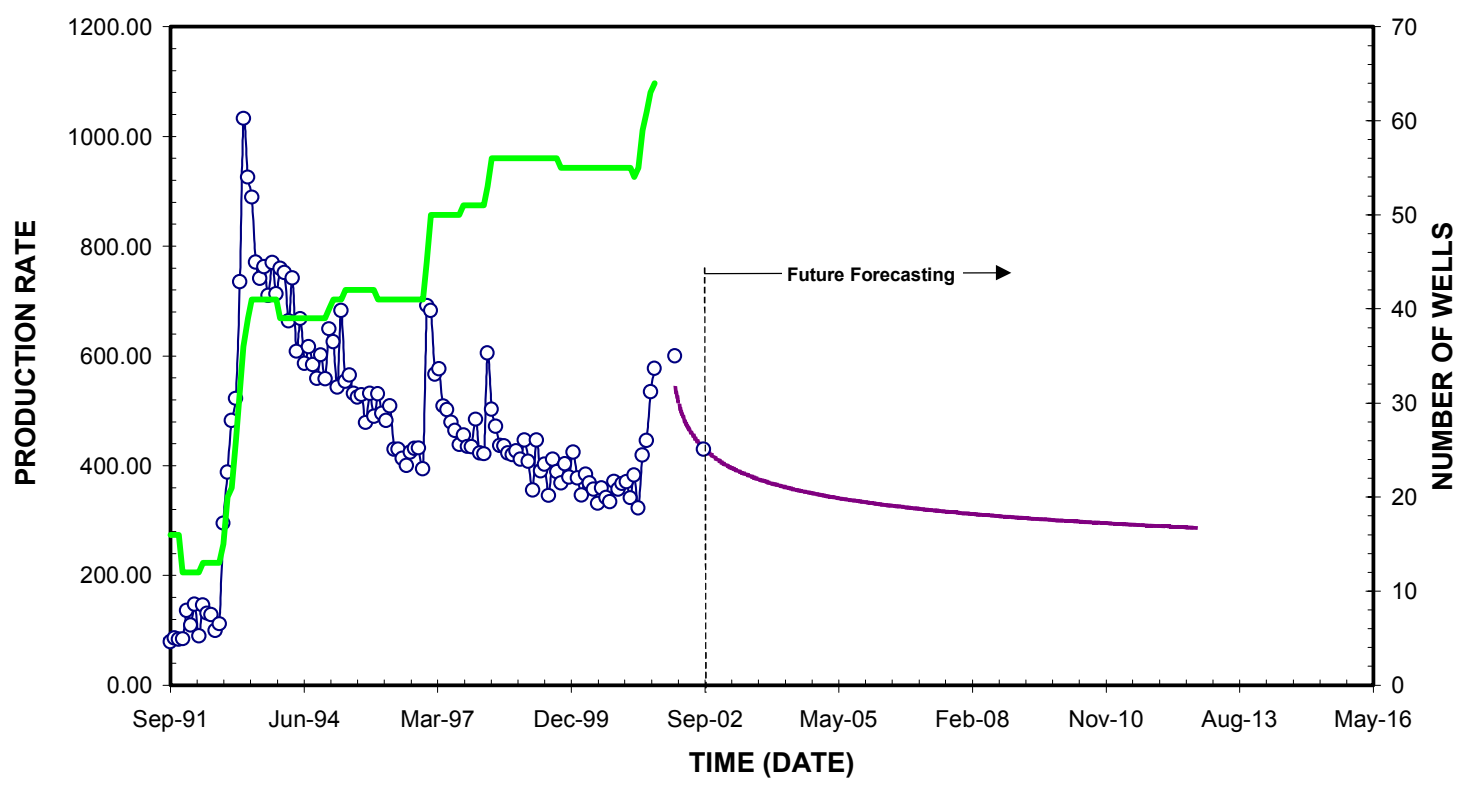

$\multimap$ - OIL (STB/D) - -Without doing anything —No. OF WELLS

Fig. 1.16 - Decline curve analysis taken from last data points.

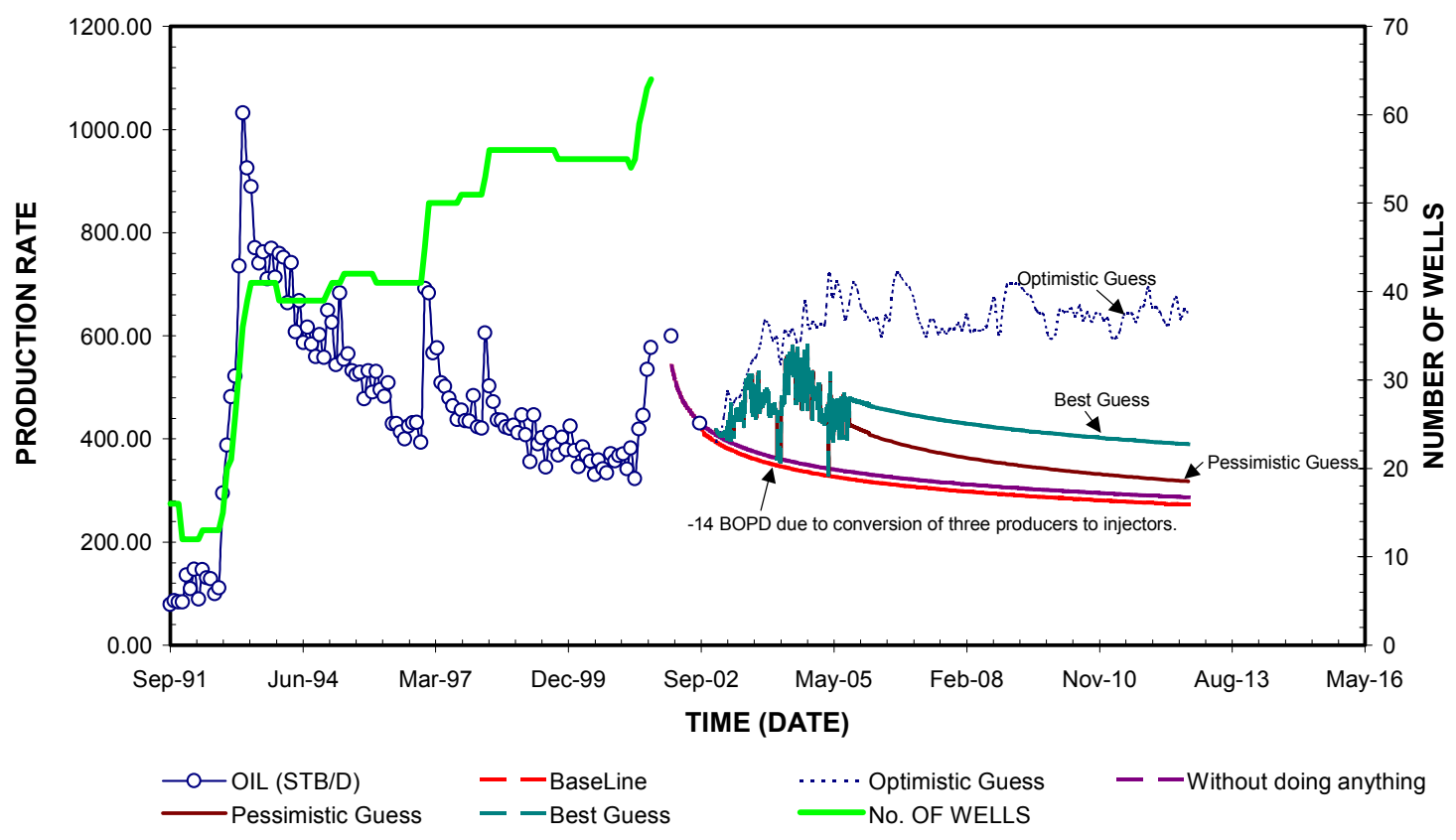

Fig. 1.17 - Decline curve analysis taken from last data points and continued with the forecasting incremental oil from old and current ET'O'Daniel waterflood performance. 


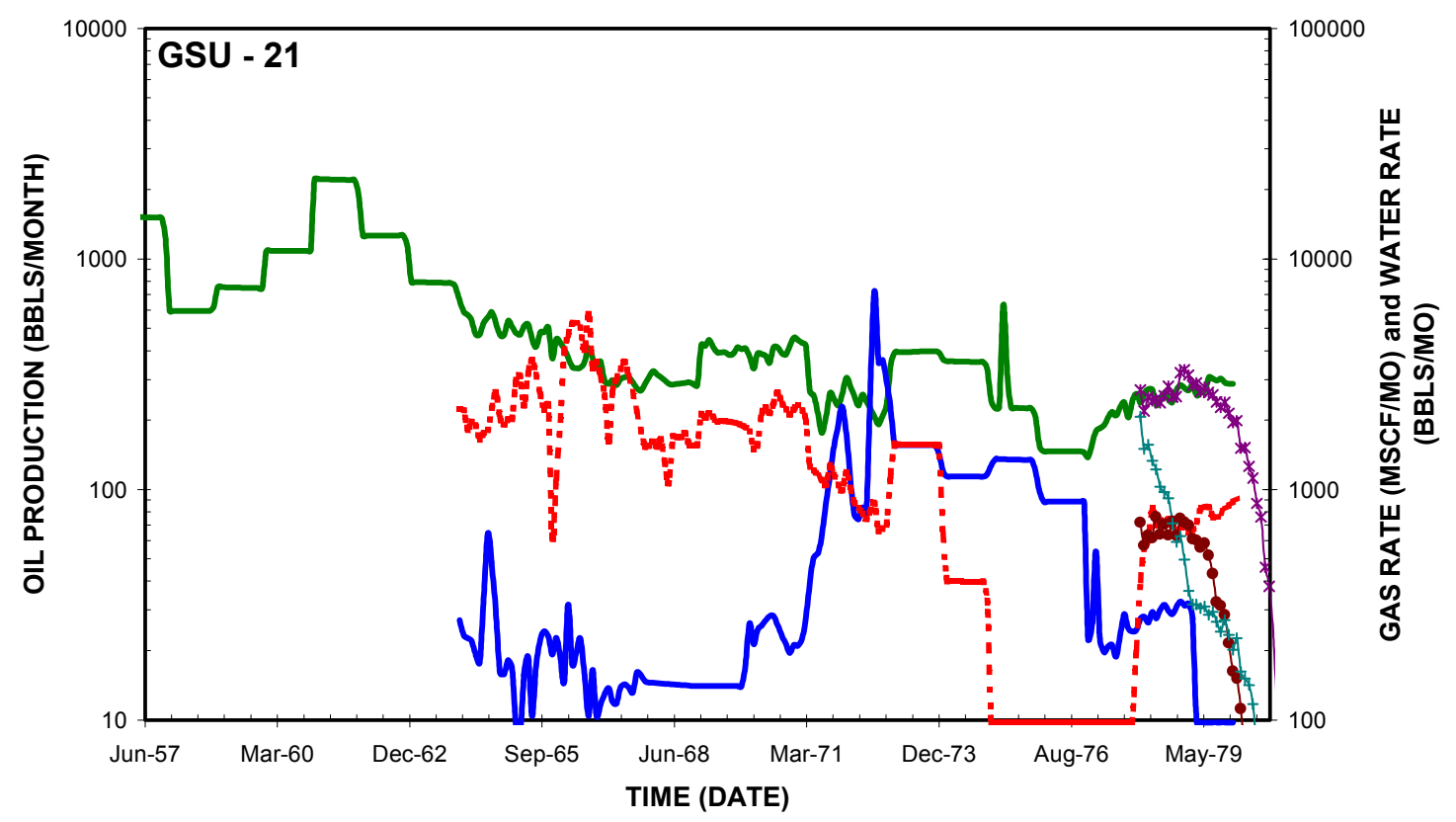

Fig. 1.18 - Production summary of GSU-21.

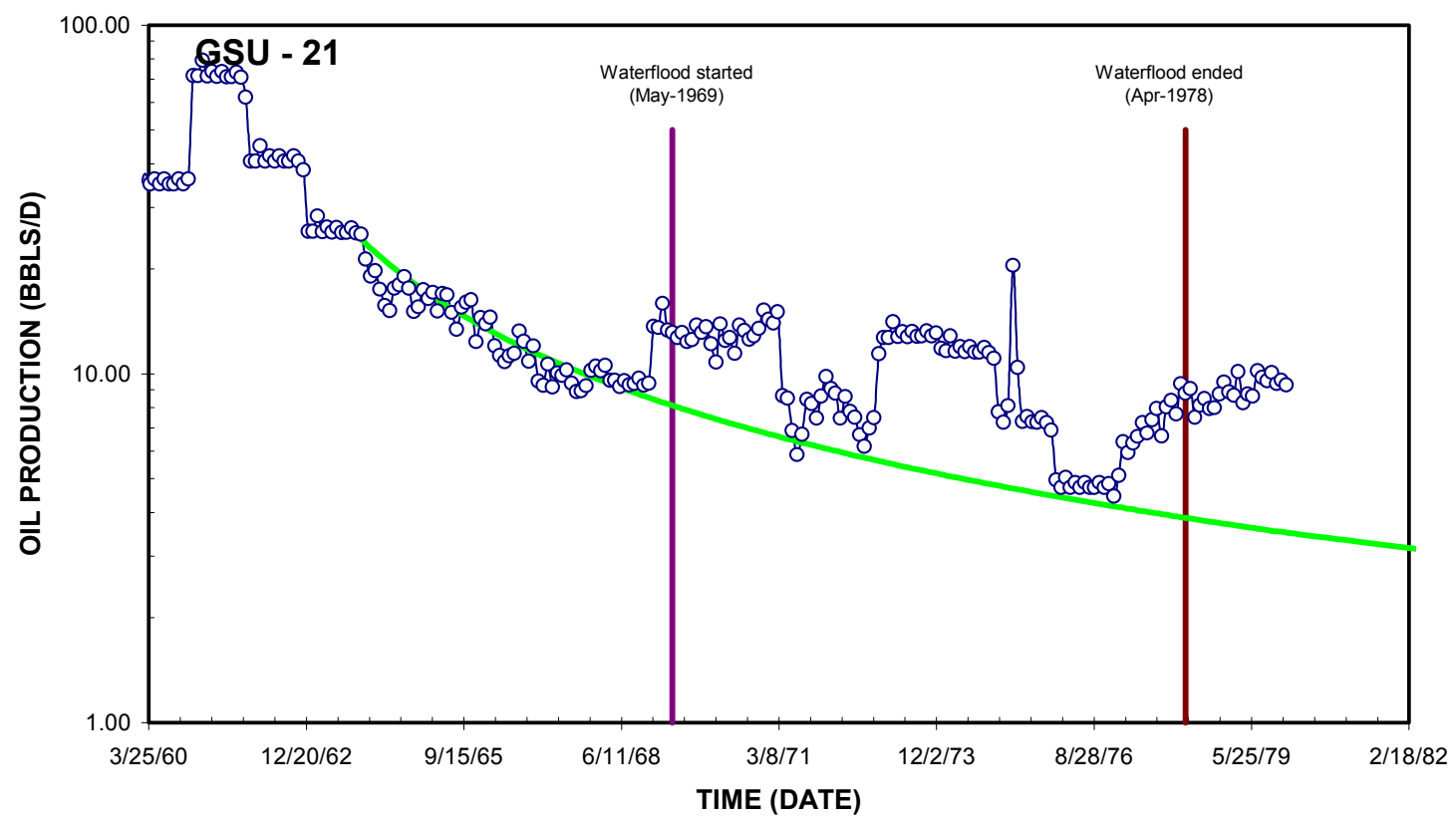

Fig. 1.19 - Decline curve analysis of GSU-21. 


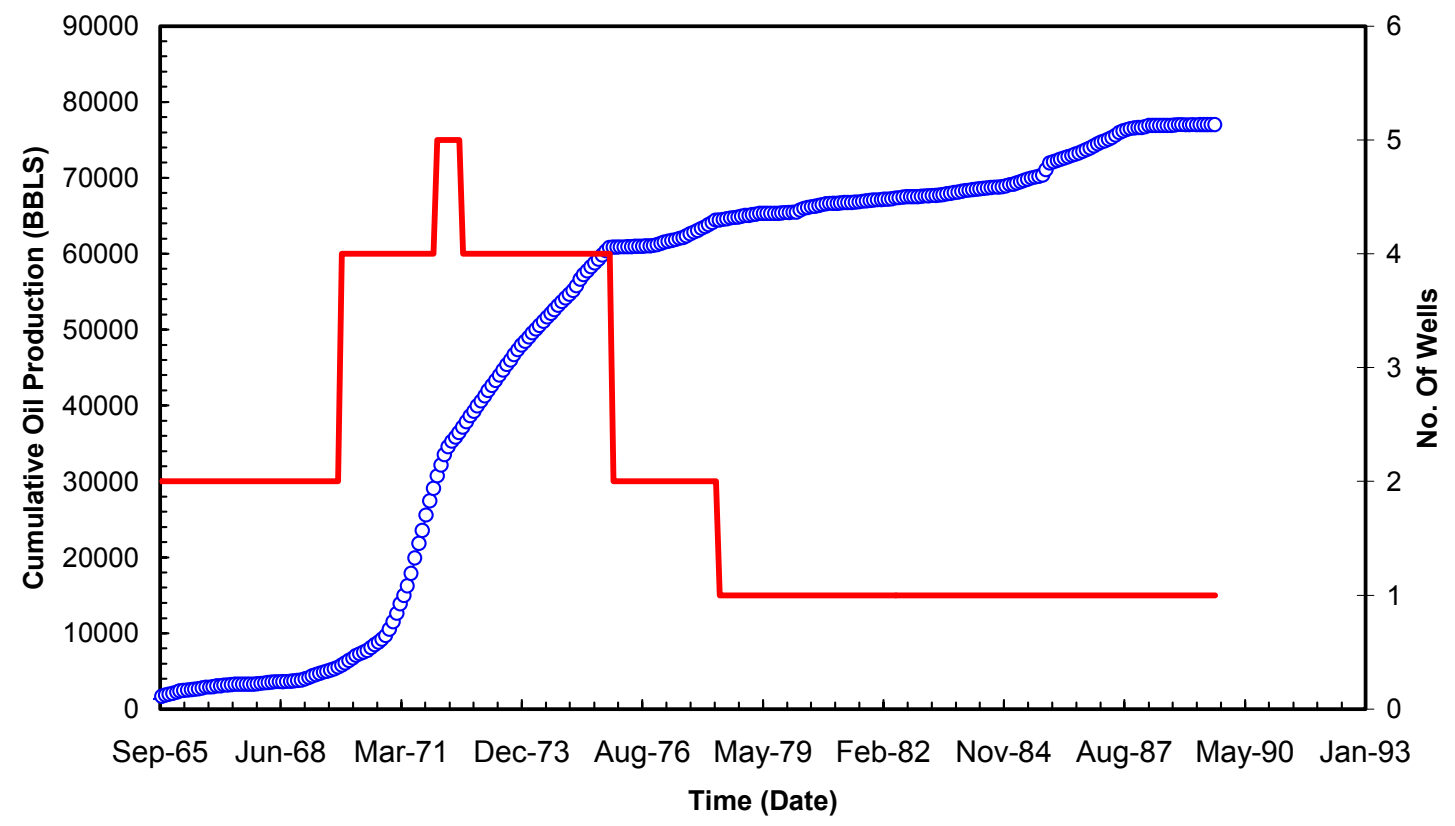

Fig. 1.20 - Cumulative oil recovery due to waterflood in the Germania unit. 
Appendix-A

Production Summary and Decline Analysis of Germania Wells 


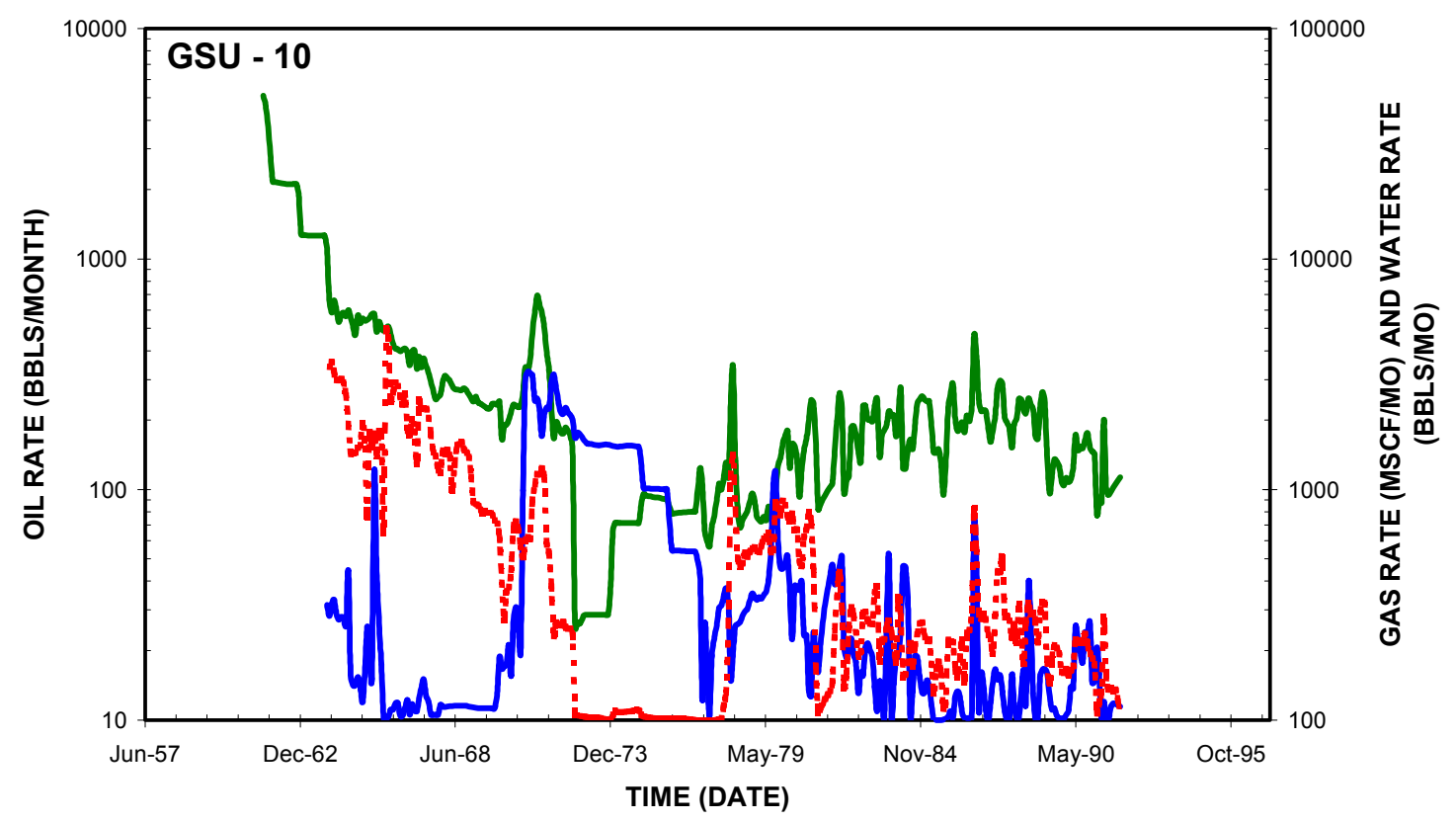

Fig. 1.1 A - Production summary of GSU-10.

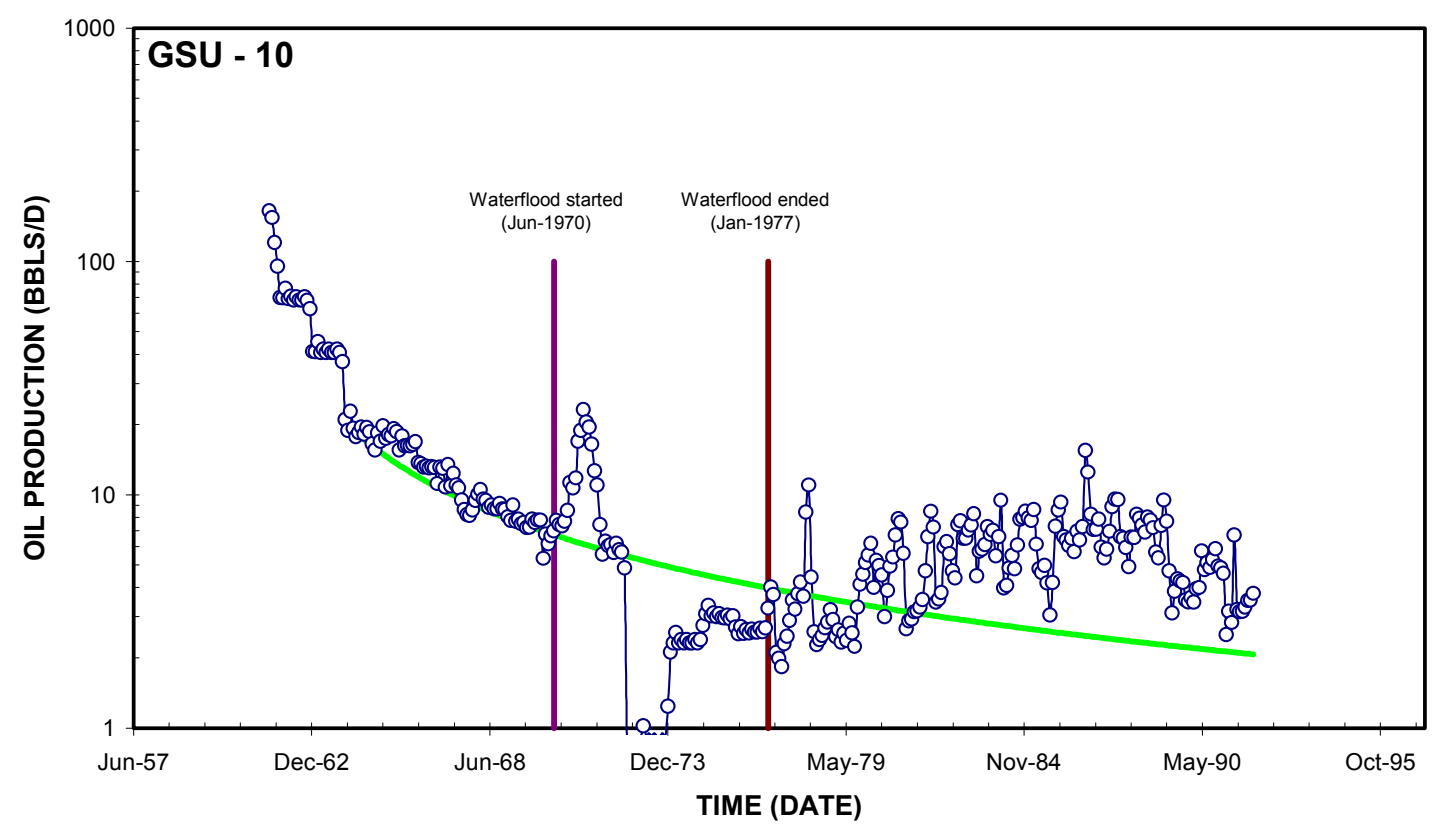

Fig. 1.2A - Decline curve analysis of GSU-10. 


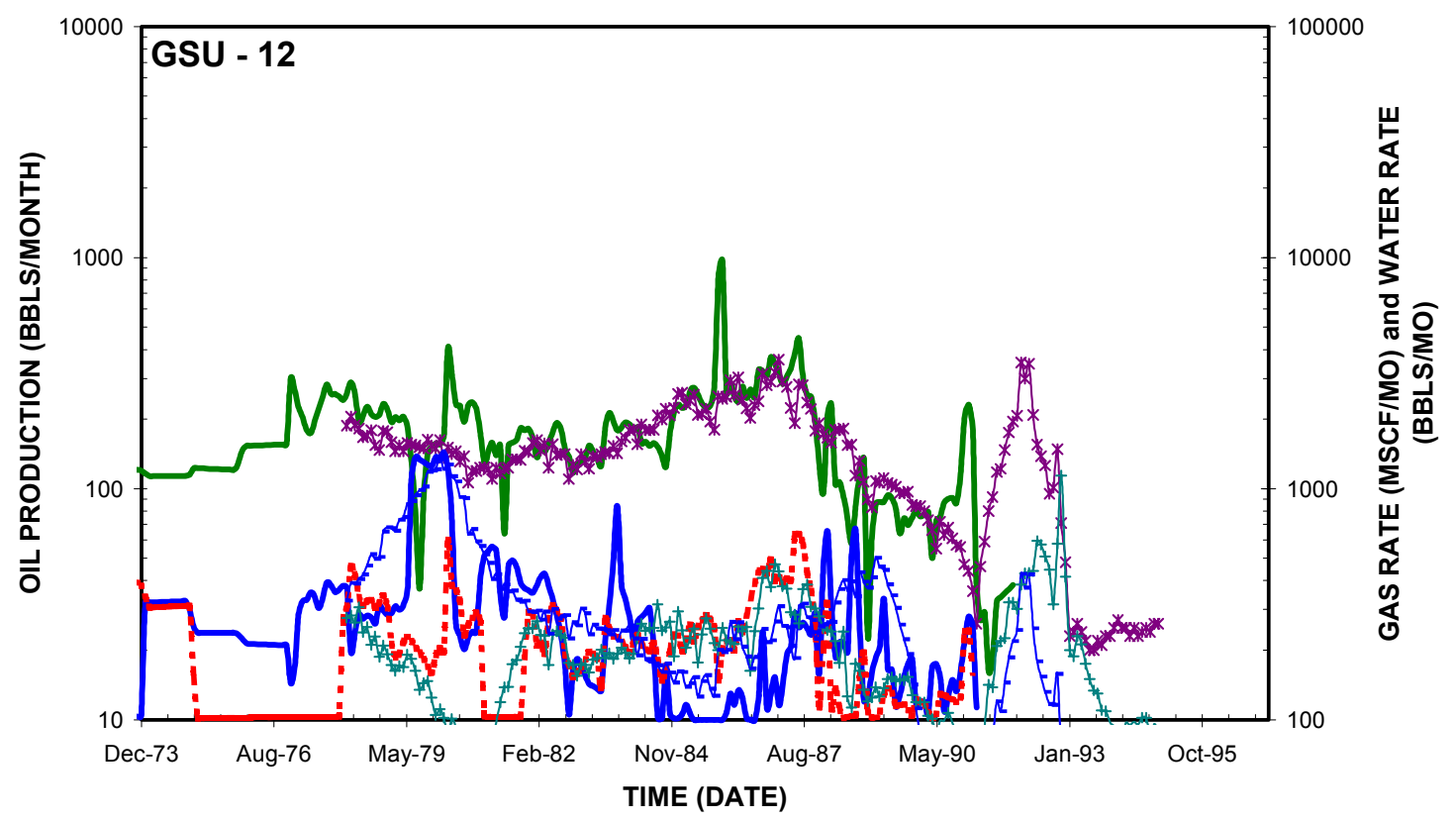

Fig. 1.3A - Production summary of GSU-12.

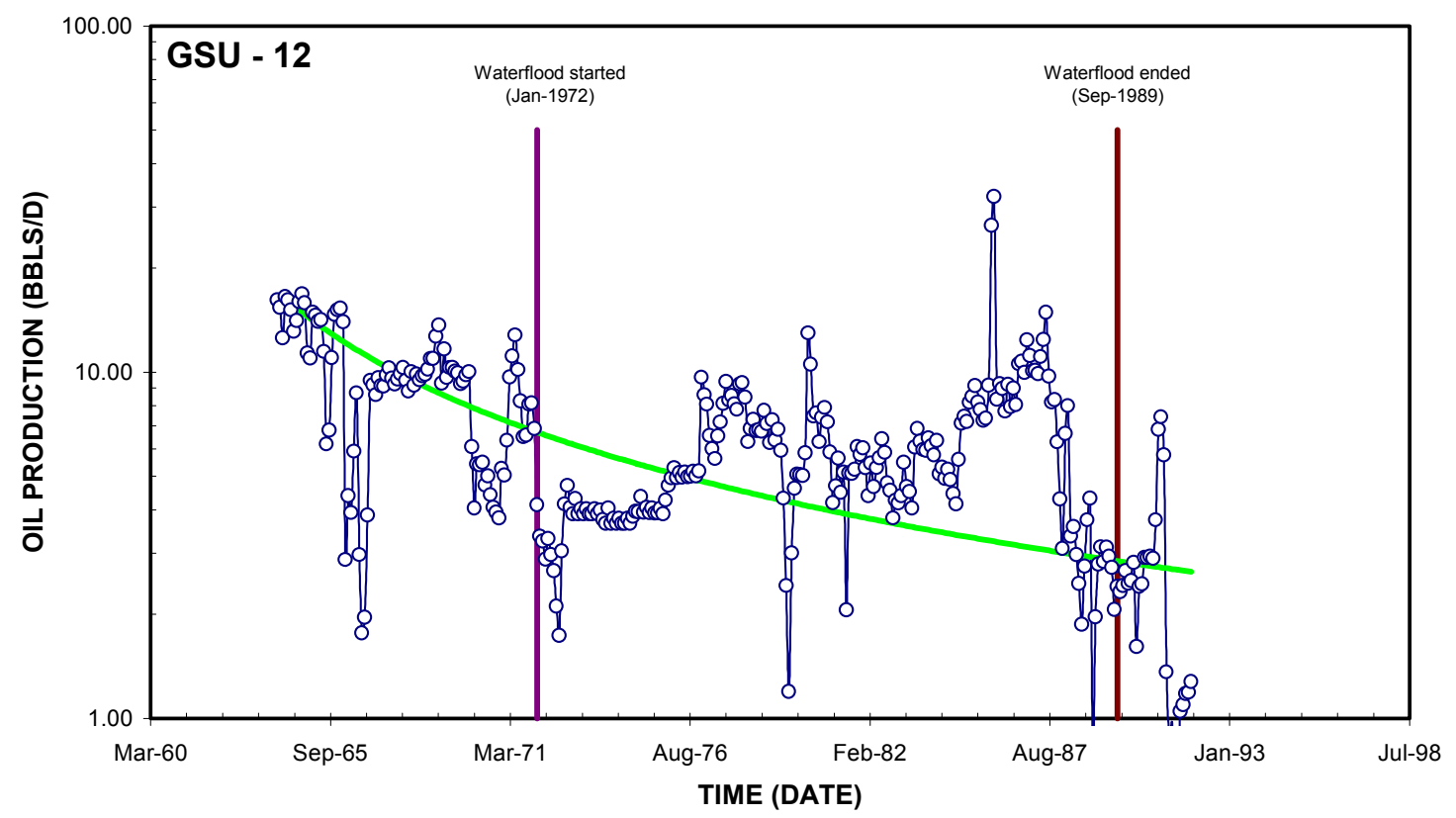

Fig. 1.4A - Decline curve analysis of GSU-12. 


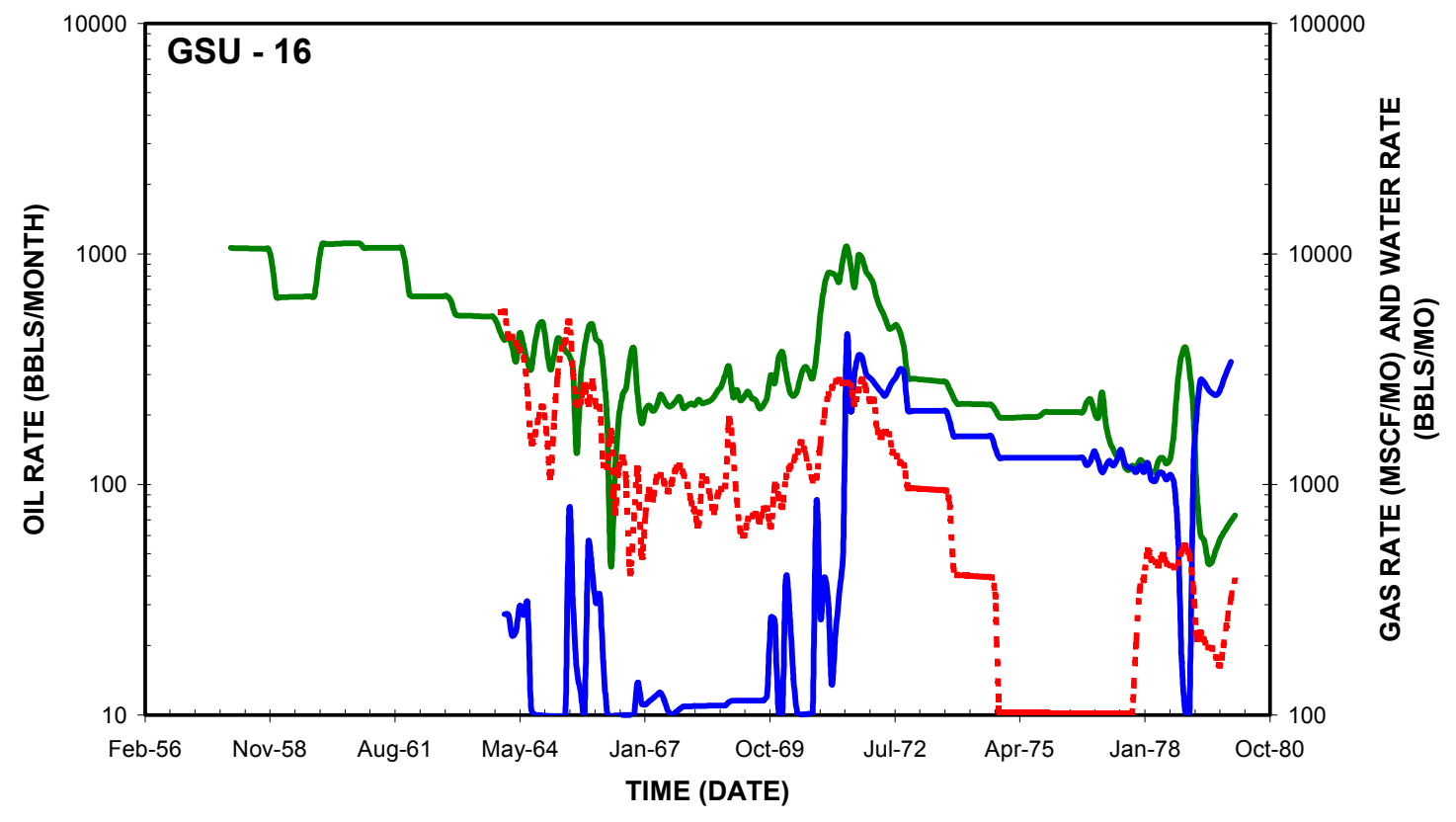

Fig. 1.5A - Production summary of GSU-16.

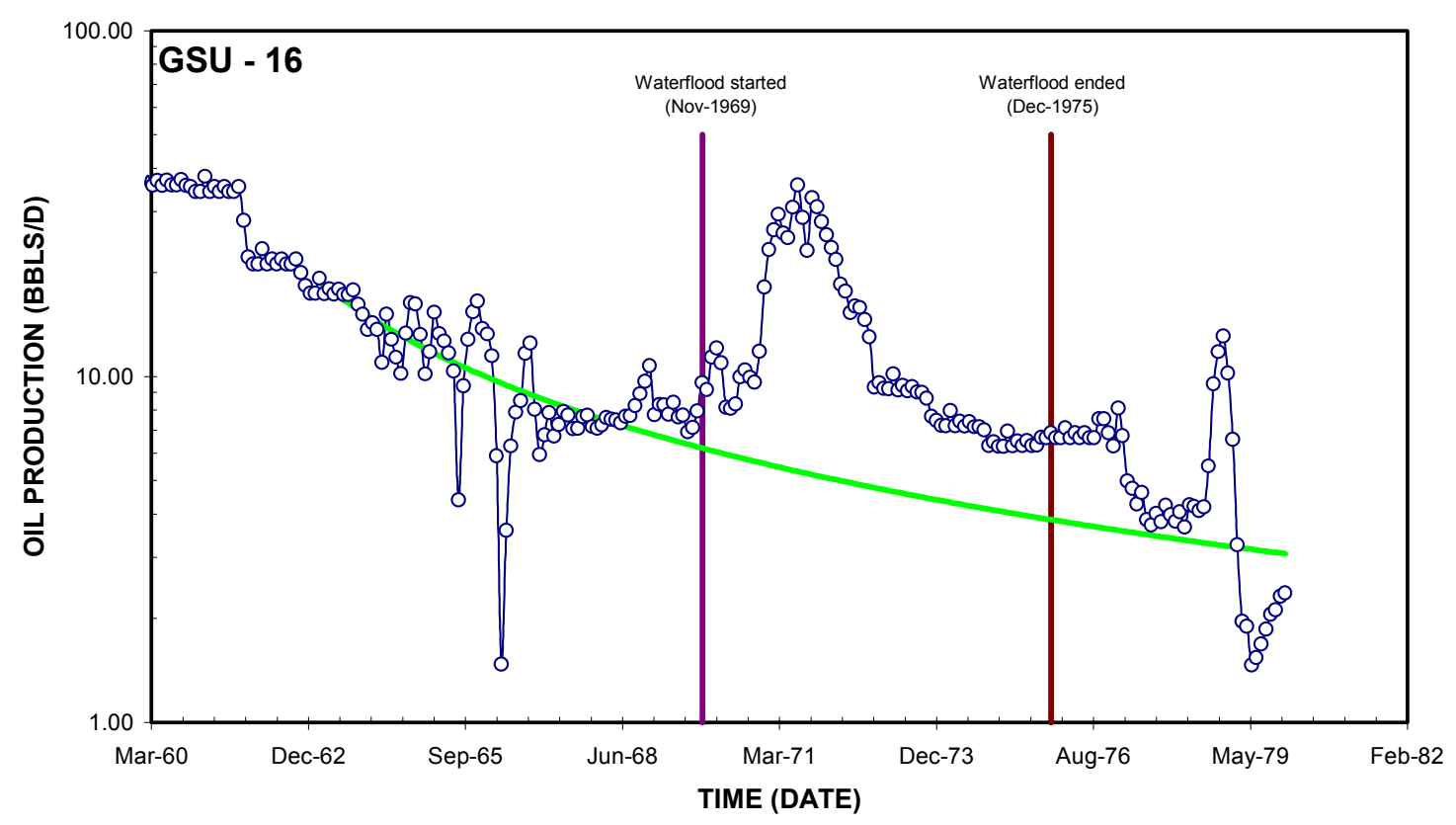

Fig. 1.6A - Decline curve analysis of GSU-16. 


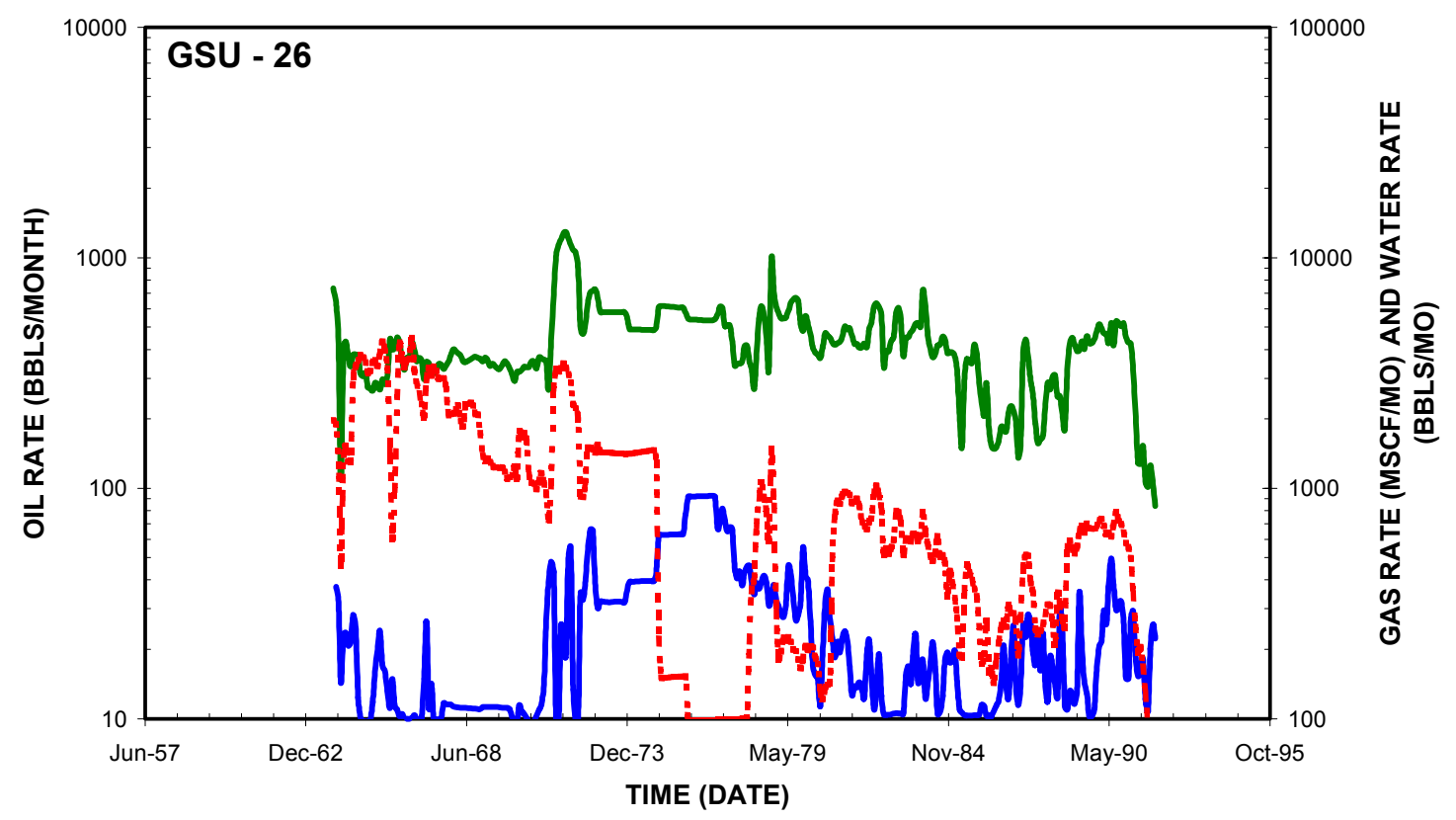

Fig. 1.7A - Production summary of GSU-26.

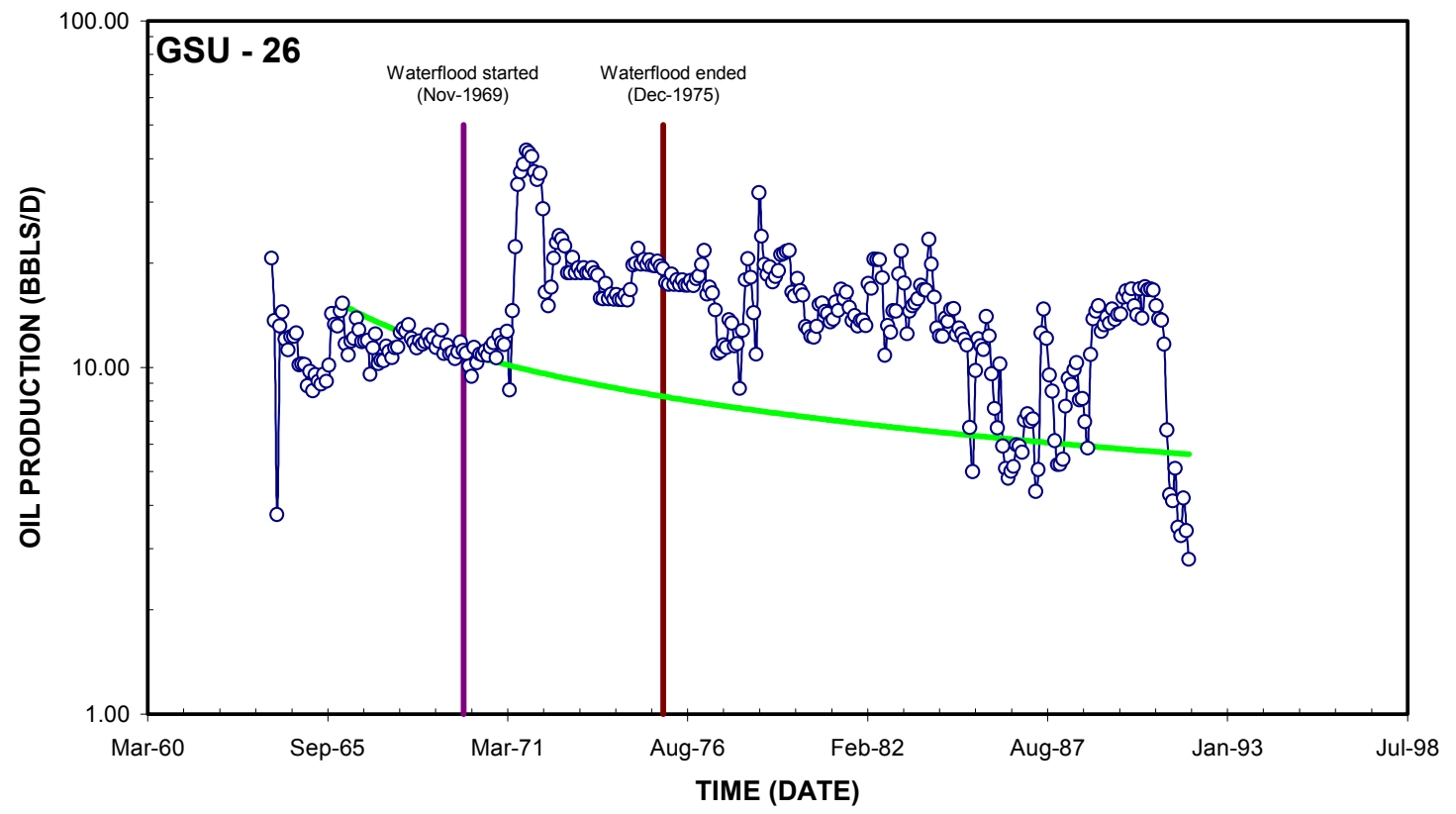

Fig. 1.8A - Decline curve analysis of GSU-26. 


\section{Appendix - B}

Production Summary and Decline Analysis of the Historical E.T. O'Daniel Unit Waterflood 


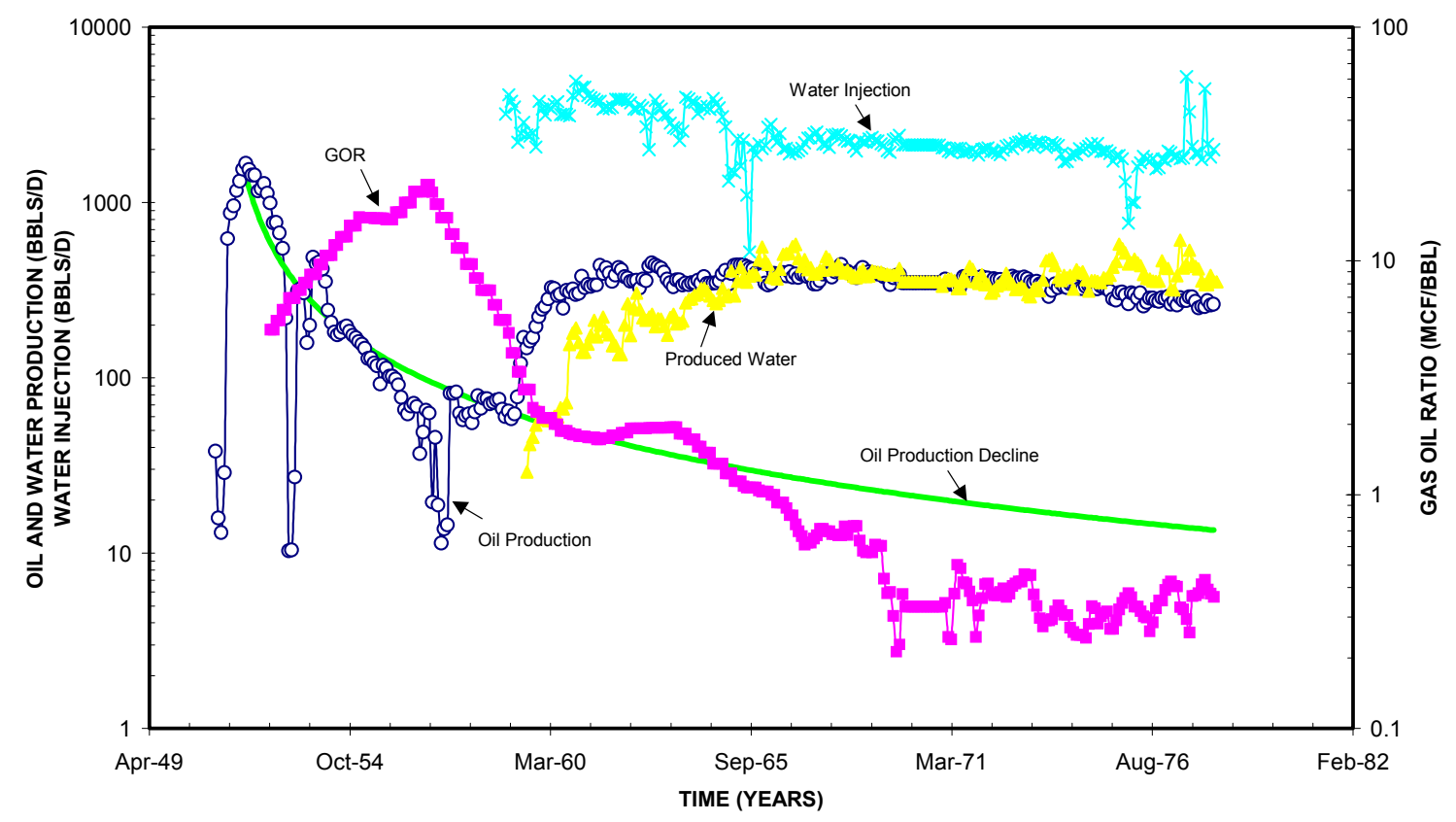

Fig. 1.1B - Production summary of old E.T. O’Daniel unit.

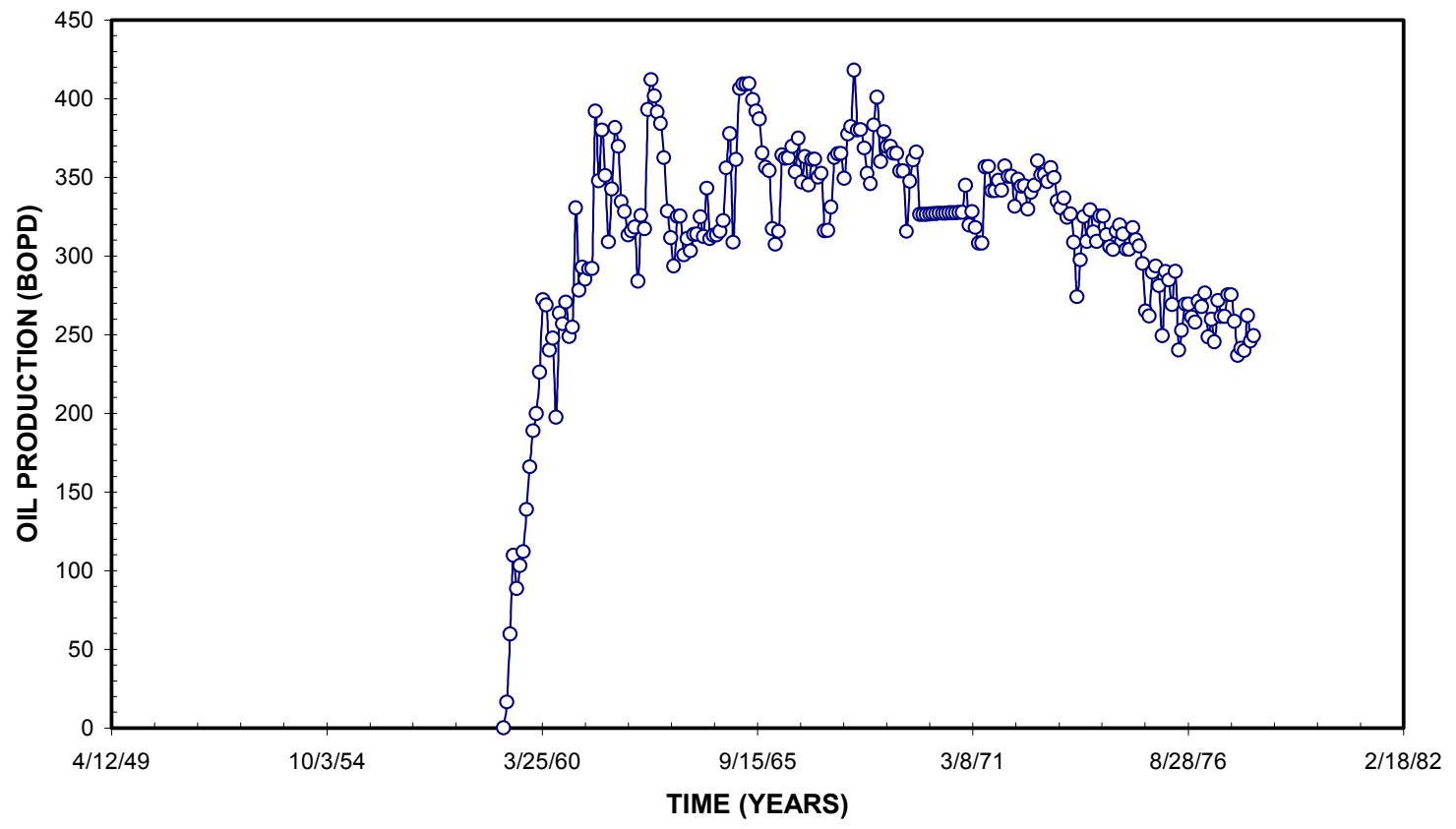

Fig. 1.2B - Incremental oil recovery of old E.T. O'Daniel unit. 


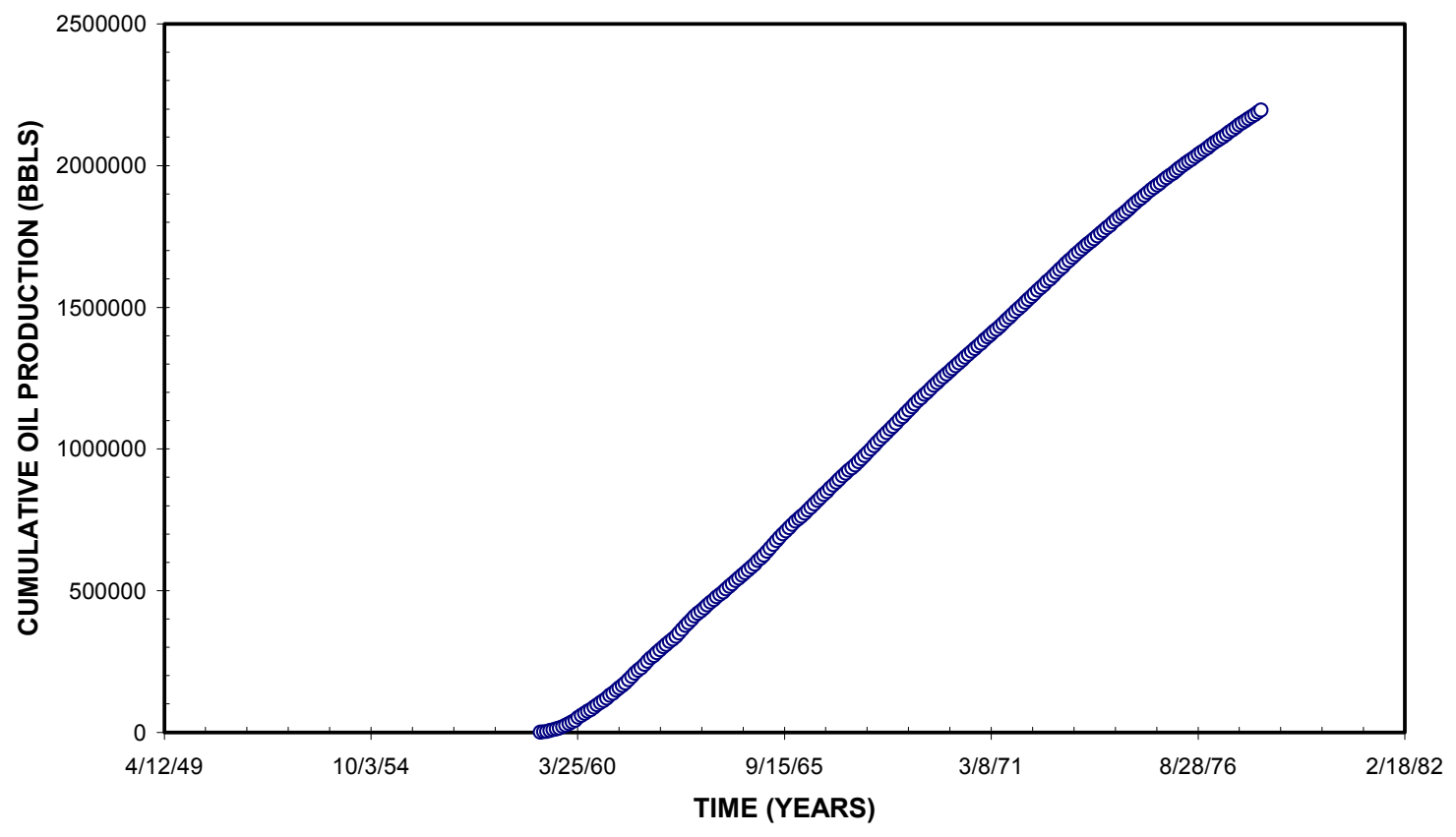

Fig. 1.3B - Cumulative oil production of old E.T. O'Daniel unit. 


\section{EVALUATION OF CURRENT E.T O'DANIEL $\mathrm{CO}_{2}$ PILOT}

\subsection{Synopsis}

The operational philosophy of this project is to test the technical and economical feasibility of using Carbon-di-Oxide $\left(\mathrm{CO}_{2}\right)$ for recovering the tertiary oil in the Spraberry reservoir.

The site chosen was the ET O'Daniel Lease, which had a successful waterflooding history ${ }^{1,2}$ and was most appropriate for conducting a tertiary recovery program. The project was initiated in 1994 but actual injection of $\mathrm{CO}_{2}$ flooding commenced on February $26^{\text {th }}$ 2001. Extensive characterization studies extending from laboratory experiments to field tests ${ }^{3-6}$ were carried out in the preceding seven year period.

The evaluation of the project performance from 1999 to 2002 is presented here. We have developed a database by incorporating injection, production, tracer and gas sample data into $\mathrm{OFM}^{\mathrm{TM}}$ (software donated by Schlumberger) for generating contours, grid maps and plots to evaluate and visualize the flood performance in greater detail. This chapter diagnoses the response of the pilot starting from the waterflooding and subsequent $\mathrm{CO}_{2}$ flooding by interpreting information collected from the following sources:

1. Production data from the interior, on-trend and off-trend producers

2. Tracer tests

3. Well logs from logging observation wells (LOW)

4. Temperature Logs

In addition, a method to determine the waterflood baseline to quantify $\mathrm{CO}_{2}$ incremental oil recovery using decline curves is presented.

\subsection{Introduction}

The ET O'Daniel lease shown in Fig. 2.1 is located in Midland County, West Texas and forms a part of the Spraberry Trend area. Geologically, the reservoirs are part of the Permian Basin and comprise of typically low porosity, low permeability fine sandstones and siltstones that are interbedded with shaly non-reservoir rocks. Natural fractures existing over a regional area have long been known to dominate all aspects of performance in the Spraberry Trend Area ${ }^{7}$.

It has been mentioned ${ }^{1}$ that Section 4 T2S Block 37 of the E.T. O'Daniel lease was responsible for more than $50 \%$ of the production due to waterflooding. This area was chosen for the location of the pilot both for its excellent production history as wells as the regional structure height, which could assist in gravity drainage. The pilot area as shown in Fig. 2.2 comprised of six peripheral water injectors, three producers, two observation wells and four $\mathrm{CO}_{2}$ injectors. The hexagonal pattern was found to effect maximum conformance. 
In order to visualize and understand the performance of the ET O'daniel lease during the $\mathrm{CO}_{2}$ flood pilot project in an effective manner, a brief summary of the lease performance in the preceding years, from 1959-1999 is explained in the following paragraphs.

The cumulative oil production grid map during the primary depletion period (Fig. 2.3) indicates that ET O'Daniel 1 produced a very high amount of oil as compared to the other wells in the surrounding areas.

The extent of water swept areas is shown in Fig. 2.4. From the cumulative water cut contours it is evident that water is moving through the fractures in a northeasterly direction. The darkened areas are quite uniformly spread implying that most of the area has been waterflooded. The cumulative oil and gas production (Figs. 2.5 and 2.6) during the corresponding period shows high production in the on-trend wells indicating good communication between wells lying along the main fracture trend.

The overall performance of the lease both during primary depletion and the subsequent waterflooding in 1959 is illustrated in Fig. 2.7 with peak production reaching close to 1000 bopd in 1952 and then receding to about 90 bopd in 1959. This receding production prompted the operators to intiate a waterflood and in the next 42 years, the ET O'Daniel Lease as well the surrounding areas were continously depleted by injecting water.

\subsection{Review of waterflood performance}

The objective of the pre- $\mathrm{CO}_{2}$ flood water injection was to raise the pressure of $\mathrm{E} T$ O'Daniel pilot area from 480 psia (1999 estimate) to a pressure above 1550 psia, which was the minimum miscibility pressure (MMP), found from experimental analysis. A $250 \mathrm{bbl} / \mathrm{d}$ water slug was injected into each of the six wells to prepare the area for $\mathrm{CO}_{2}$ injection by maintaining the pressure to form protective ring around the pilot area during the $\mathrm{CO}_{2}$ injection inside the pilot area.

Waterflooding started in October 1999 and the three central production wells, the O'Daniel \#38, \#39, and \#40 have shown little or no response to water injection as anticipated earlier since this is a 40 -year-old waterflood area. It was assumed there would be minimal response from water injection and the area was at residual oil saturation.

However, a rapid increase in oil production was noted in several wells directly along an $\mathrm{N} 32^{\circ} \mathrm{E}$ orientation (Fig. 2.8). Some wells located over one mile from the injection wells responded within days of initiation of water injection whereas wells oriented perpendicular to injection wells at a fraction of the distance from injection wells have shown little or no response. The counter-current and co-current imbibition mechanisms along with high permeability anisotropy facilitated the oil production rate to increase on the on-trend wells during high water injection. Due to weakly water wet and low matrix permeability, the off-trend wells continued to produce at low rate similar to pre-injection rates. It might be possible that the off-trend wells will respond in the future. 
Rapid increase in oil production rate at on-trend wells, Brunson C-2, O'Brien B-1 and Brunson G-1, Brunson F-1 and water-out at Brunson A-1 located far away from the pilot area clearly indicates the presence of un-swept oil (Figs. 2.8 and 2.9). This shows that the injected water can spread towards the Brunson field in a matter of few days indicating that the permeability ratio is highly anisotropic. It also indicates that the fractures are continuous and might have multiple orientations.

To throw more light on the oil production at far away wells, a scrutiny of the water movement patterns needed to be studied. A tracer injection program was initiated in Aug 1999 in order to understand the fracture network in this area. Six different chemical tracers were injected into each of the water injectors and the response was recorded continously at 29 surrounding wells. Of the 29 wells sampled, 15 wells showed tracer breakthrough within the first two days after tracer injection started, indicating that the fracture system had very high permeability. The fracture system facilitates transport of fluids through long distances in short times (more than 3,000 ft in two days), reaching from Floyd "B1" to Brunson "D1". The tracer response in Fig. 2.10 shows that the fracture network is highly interconnected and the quickest response is seen in the on trend wells.

Detailed analysis of the tracer patterns revealed that the tracers were moving through two paths. This is elaborated by noticing the response at ET O'Daniel A1, the first slug reaches A1 in 5 days and another slug after 29 days. This delayed response could indicate that the first slug of tracer moves through the shortest fracture path via $1 \mathrm{U}$ and the next slug moves through a longer path via 5U. Figs. 2.11-2.13 illustrate these findings, a close look at the bubble map response at ODA1 indicates two samples of high tracer concentration reaching $\mathrm{A} 1$ at different times.

The result also reveals that placement of production wells along the fracture orientation could significantly increase oil production if water injection could be optimized. The results oppose the previous belief that on trend injection wells channel via fractures and rapidly water out production wells.

\section{4 $\mathrm{CO}_{2}$ Flood Performance- Review of production data}

$\mathrm{CO}_{2}$ injection into the Spraberry formation was started on Monday, February $26^{\text {th }} 2001$ after remedial action was taken on cement problems at one of the logging observation wells.

In order to maintain a target of $200 \mathrm{RVB} / \mathrm{D}$ of $\mathrm{CO}_{2}$ injection, the water injection rate was revised from 280 to $245 \mathrm{BWPD}$. A few minor glitches such as the $\mathrm{CO}_{2}$ turbine meters getting clogged with debris were encountered.

Each $\mathrm{CO}_{2}$ injector experienced some unique problem during start-up but there hasn't been a problem, which has warranted serious remedial action. The battery monitoring the four wells closest to the pilot shows that the interior producers (wells \#38, \#39 and \#40) have experienced increased percentage of $\mathrm{CO}_{2}$ in about 3 weeks of $\mathrm{CO}_{2}$ injection. 
Surprisingly, well O'Daniel A1 (Fig. 2.14), which lies directly along the NE-SW fracture orientation, has observed a moderate $\mathrm{CO}_{2}$ break-through till March 2002. This might be due to high pressure around the six-ring fence that restricts the movement of $\mathrm{CO}_{2}$ outside the pilot area. The line of production wells experiencing high $\mathrm{CO}_{2}$ fraction are along the natural fracture trend and perpendicular to the $\mathrm{CO}_{2}$ injection wells. This clearly indicates that a direct communication exists between injection wells and production wells due to induced fractures that may have been created during step rate or pulse testing periods.

The sudden rise in $\mathrm{CO}_{2}$ production at ET O'Daniel A1 can be attributed to a change in injection pattern, which came into effect in March 2002. The change in injection pattern wherein two producers (O'Daniel 38 and O'Daniel 39) were closed, two CO2 injectors (O’Daniel 42 and O'Daniel 44) were closed and one water injection well (O'Daniel 48) was closed. These changes in the pilot were made to observe $\mathrm{CO}_{2}$ incremental oil recovery at wells O'Daniel A1 and Brunson F1.

Due to high rate of gas production at the interior wells, a cyclic injection scheme of water alternating gas (WAG) was initiated in order to retain the injected $\mathrm{CO}_{2}$ inside the reservoir for a longer period of time and thereby facilitate extraction of oil. The $\mathrm{CO}_{2}$ injectors were converted to water injectors periodically while keeping up the total injection volume intact to keep up the reservoir pressure in-between that of minimum miscibility pressure and minimum parting pressure (Fig. 2.15).

A closer look at the rate of gas production at the interior wells reveal that at the end of every $\mathrm{CO}_{2}$ injection cycle, the gas production rate at the producers decreased but the next $\mathrm{CO}_{2}$ cycle produced $\mathrm{CO}_{2}$ at a higher rate than the previous one and the cyclic progression of $\mathrm{CO}_{2}$ injection reveals that O'Daniel A-1 also started producing the gas from a later period (Fig. 2.14). The fall in gas production at the interior producers after March 2002 is due to the closure of the two producers (O'Daniel 38 and O'Daniel 39). But this closure along with the injection of $\mathrm{CO}_{2}$ from the two injectors has increased the production at $\mathrm{A} 1$ as more and more $\mathrm{CO}_{2}$ is being channeled through the fractures.

In spite of $\mathrm{CO}_{2}$ breakthrough, no immediate oil response was observed in the interior production wells until the injection pattern was changed as shown in Fig. 2.14. Earlier, the $\mathrm{CO}_{2}$ from \#43 and \#44 was just moving straight to the producers without affecting any sweep, moreover, the stoppage of water injection \#48 has eased the pressure in the pilot area a little bit and $\mathrm{CO}_{2}$ has become more mobile, thus showing evidence of movement to A1. This could be due to the movement of $\mathrm{CO}_{2}$ in the shale layers or movement of $\mathrm{CO}_{2}$ above the pay zones (1U and $5 \mathrm{U}$ ) as concluded from the logging observation wells and temperature log analyses.

Even though the rate of gas production has been high at the interior wells the total volume of $\mathrm{CO}_{2}$ produced is still less compared to the amount of $\mathrm{CO}_{2}$ remaining in the reservoir (Fig. 2.16). The difference between the amount of $\mathrm{CO}_{2}$ injected and produced shows that $60 \%$ of the $\mathrm{CO}_{2}$ still remains in the reservoir and we could expect mobilization of extracted oil to the production wells at a later period. 
In addition, Fig. 2.17 shows that only $17 \%$ of the total water has been produced which further strengthens our premise that more oil could be produced at a later date.

The response from the injected water and $\mathrm{CO}_{2}$ can be best illustrated by comparing the oil production rates of four wells, Brunson A1, Brunson C2, Brunson G1 and O'Brien A1. Figure 2.18 indicates a linear increase in production in each of the four wells, since water injection started in 1999 and is confirmed by the darkened areas in the contour shown in Fig. 2.7.

Recently, the oil production from O'Brien A1 came into a strong debate as some sources contested that increase in production was due to lease electrification carried out in Jan 2001(Fig. 2.19) and the $\mathrm{CO}_{2}$ was not responsible for the increase in production. But the production trend followed by four wells coupled by a comparison between oil rates (Fig. 2.20) in Brunson F1 and O'Brien B1 shows that this is not true and even the $\mathrm{CO}_{2}$ /water injection should be considered while evaluating the response at the debated well.

In order to get a good response from a multiple contact $\mathrm{CO}_{2}$ miscible displacement, a good proportion of $\mathrm{CO}_{2}$ has to be injected. As of September 2002, the volume of $\mathrm{CO}_{2}$ injected is still very small (about $122700 \mathrm{MSCF}$ ) when compared to the volume of water injected. The small area covered by $\mathrm{CO}_{2}$ illustrated in Fig. 2.21.

Wells such as Brunson F-1, Brunson C-2 and Brunson G-1 located at distances more than 5,000 feet away from the pilot area along naturally fractured trend started responding only after a water volume at least equivalent to about three times that of $\mathrm{CO}_{2}$ volume was injected (Fig. 2.22). A grid map of cumulative $\mathrm{CO}_{2}$ fraction produced indicates that apart from the three internal producers only Brunson F-1 has actually "seen" $\mathrm{CO}_{2}$ (Fig. 2.23). This shows that more $\mathrm{CO}_{2}$ has to be injected in order to produce oil at far off wells. Most of the oil (other than the interior wells) produced is mostly from O'Daniel A-1 (Fig. 2.24). The effect of incremental oil recovery due to $\mathrm{CO}_{2}$ is seen by the production response after March 2002. The cumulative oil production at the interior wells is reduced because of the closure of the two producers and the gas injected is now moving towards O'Daniel A-1 and extracting the oil out. Fig. 2.25 shows the comparison between the oil rate and gas rate observed at O'Daniel A1. Each time there has been an increase in gas production rate, the oil production rate has simultaneously increased. This shows that that there is unrestricted movement of $\mathrm{CO}_{2}$ through the fracture towards $\mathrm{A} 1$.

But an increase in water rate at O'Daniel A-1 (Fig. 2.26) has produced less oil in O'Daniel A-1 if both Figs. 2.23 and 2.24 are compared at the same time periods.

The effect of closing down one water injector on the water rate profile of the interior producers and O' Daniel A1 is shown in Fig. 2.25. The effect of a change in injection pattern from 03/16/2002 reveals that less water is being produced at O'Daniel A1 as seen in Fig. 2.25. 
In order to obtain a sound basis for determining the production of oil due to $\mathrm{CO}_{2}$ alone, a decline curve analysis was carried out. The best indicator of $\mathrm{CO}_{2}$ flood response until now at Spraberry reservoir has been at O' Daniel A1. Figure 2.27 shows an increase in oil recovery after the $\mathrm{CO}_{2}$ injection was started as compared to the earlier years of waterflood. Figs. 2.28 and 2.29 show the depletion of Spraberry reservoir before the waterflooding was started. The date at which the oil production was the highest was chosen and the subsequent decline in production for various scenarios $(50 \%, 20 \%, 150 \%$, and $200 \%$ ) were evaluated.

Here, the cumulative oil production from the different decline scenarios reveals that a combined recovery in the range of 1500-4000 bbls was projected with $\mathrm{CO}_{2}$ flooding conducted in the time period between Feb 2001 and Jul 2002.

Continuing on the decline curve analysis, the depletion of the reservoir due to waterflooding of the pilot area alone is depicted in Figs. 2.30 and 2.31. Again a similar set of decline rates have been used to project the performance of $\mathrm{CO}_{2}$ flood in the pilot area. The range of recovery estimated is around 2400 to $4200 \mathrm{bbls}$ in the stipulated period between Feb 2001 and Jul 2002. The sharp rise in production forecasts after March 2002 is due to change in injection pattern and brings out the importance of understanding the communication between the wells and its location with respect to the main fracture trend.

\subsection{Review of logging data}

Two wells ET O'Daniel 49 and ET O'Daniel 50 were specifically utilized for running logs and were classified as logging observation wells (LOW). Logging runs were frequently conducted to survey the vertical distribution of $\mathrm{CO}_{2}$ inside the upper Spraberry interval.

The upper Spraberry interval consists of 5 zones, of which, two are pay zones (1U and $5 \mathrm{U}$ ) and the remaining are branded as non-pay zones. The pay zones have a combined thickness of $30 \mathrm{ft}$ and their locations are shown in the Fig. 2.32.

Earlier studies ${ }^{8}$ show that there are three basic groups of rock in the Upper Spraberry: one with porosity $<7 \%$ and shale volume $>15 \%$ (mostly mudstones and siltstones), one with porosity $<7 \%$ and shale volume $<15 \%$ (dolostones and dolomitic siltstones), and the reservoir pay zones that have shale volume of $<15 \%$ and porosity $>7 \%$.

\section{Evaluation}

The location of the logging observation wells inside the pilot area was important; ET O'Daniel 49 was placed near a producer (ET O'Daniel 39) and in line with a water injector (See Fig. 2.2), whereas ET O'Daniel 50 was placed in between that of a $\mathrm{CO}_{2}$ injector and a producer (ET O’Daniel 40).

The main idea of running logs in these wells were two fold:

1. To detect the presence of carbon dioxide in the formation

2. To evaluate the distribution of $\mathrm{CO}_{2}$ in the formation.

Logs were run at frequent intervals and their frequency is shown below: 


\begin{tabular}{|c|c|c|c|}
\hline \multirow{3}{*}{$\begin{array}{c}\text { Date } \\
\text { Conducted }\end{array}$} & & \multicolumn{2}{|c|}{ Type of Logs Used for Study } \\
\hline & $\begin{array}{l}\text { Runs } \\
\text { Runing }\end{array}$ & & \\
\hline & & Well\#49 & Well\#50 \\
\hline Jan 312001 & 1 & $\mathrm{AIT}^{*}, \mathrm{GR}, \mathrm{CNL}^{* *}$ & $\mathrm{AIT}^{*}, \mathrm{GR}, \mathrm{CNL}^{* *}$ \\
\hline Feb15 2001 & 2 & $\mathrm{AIT}^{*}, \mathrm{GR}, \mathrm{CNL} * *$ & $\mathrm{AIT}^{*}, \mathrm{GR}, \mathrm{CNL} * *$ \\
\hline Feb18 2001 & 3 & $\mathrm{AIT}^{*}, \mathrm{GR}, \mathrm{CNL} * *$ & $\mathrm{AIT}^{*}, \mathrm{GR}, \mathrm{CNL}^{* *}$ \\
\hline Mar16 2001 & 4 & $\mathrm{AIT}^{*}, \mathrm{GR}, \mathrm{CNL} * *$ & $\mathrm{AIT}^{*}, \mathrm{GR}, \mathrm{CNL}^{* *}$ \\
\hline Apr 162001 & 5 & AIT*, GR, CNL** & AIT*, GR, CNL** \\
\hline Jun 122001 & 6 & $\mathrm{AIT}^{*}, \mathrm{GR}, \mathrm{CNL} * *$ & $\mathrm{AIT}^{*}, \mathrm{GR}, \mathrm{CNL} * *$ \\
\hline Aug 182001 & 7 & AIT*, GR, CNL & AIT*, GR, CNL \\
\hline Dec 32001 & 8 & $\mathrm{AIT}^{*}, \mathrm{GR}, \mathrm{CNL} * *$ & $\mathrm{AIT}^{*}, \mathrm{GR}, \mathrm{CNL} * *$ \\
\hline
\end{tabular}
$\mathrm{AIT}^{*}=$
AO 10, 20, 30, 60, 90
AT $10,20,30,60,90$
AF 10, 20, 30, 60, 90
(AT 90 HAS BEEN USED AS THE DEEP RESISTIVITY READING $\left(\mathrm{R}_{\mathrm{t}}\right)$ FOR ALL CALCULATIONS
$\mathrm{CNL} * *=\quad \mathrm{NPHI}$

\section{AHFCO 60, AHTCO 90}

The logs specifically used for study were the resistivity, gamma ray and the compensated neutron log. Primarily, evaluation of gas bearing formations is done by using porosity log responses. In the literature it has been explained that two porosity logs (sonic, neutron or density) are required to evaluate gas formations, provided that the shale content, $\mathrm{V}_{\text {sh }}$, can be reasonably estimated from the gamma ray log. The density/neutron combination usually is recommended for the evaluation. The sonic log is not recommended because, in addition to gas and shale effects, compaction and secondary porosity effects can be present.

The response from a neutron porosity log alone is used for evaluation in our case and the presence of gas affecting the neutron response is explained in the following paragraphs.

\section{Gas Effect}

When gas is present in a zone, the effect is to show an erroneously low porosity. At first glance, this is due to the reduced hydrogen content or hydrogen index of the gas. While this is true, the observed porosities are too low, even when the lower hydrogen index is taken into account. The reason is that when gas is present, the neutron cloud is significantly larger, causing more neutrons than expected to appear at the far detector. This results in a lower than expected ratio, and lower than expected porosity indication. 


\section{Response in shales}

Shales have hydrogen both as water in the pore space and as hydroxyl $(\mathrm{OH})$ radicals attached to the matrix (bound water). This excessive amount of hydrogen results in an erroneously high indication of porosity in shales. In short, shales are rocks with a lot of hydrogen content not related to porosity.

\section{Gas effect in Logging Observation Wells 49 and 50}

Of the two wells, LOW 49 and 50, LOW 49 gives the best indication of gas movement throught the formation. To illustrate this case more clearly, a base log (Jan 31 2001) was selected, this $\log$ was run before the $\mathrm{CO}_{2}$ injection started (Feb $26^{\text {th }} 2001$ ) and the neutron porosity of the subsequent logging runs were compared with the base log. Fig. 2.33 shows the comparison of the porosity between the base log and Dec $3^{\text {rd }} 2001$ logging run (the last log taken). There is decrease in porosity at nearly all depths and the shaded portion reveals the gas effect. This dispersion of $\mathrm{CO}_{2}$ into all the layers explains the cause of low oil production at the interior producers.

The response at LOW 50 is not consistent with LOW 49 and Fig. 2.34 shows the gas dispersion at LOW 50. The gas effect is not as prominent as in LOW 49. The pay zones $1 \mathrm{U}$ and $5 \mathrm{U}$ do not seem to be invaded by gas at all.

To give more emphasis on the presence of gas in the formation, temperature logs were run during the months of May 2001, October 2001 and November 2001. A preview of the interpretation of these logs is shown below.

\section{Temperature Logs}

The idea of using a temperature log is to locate fluid flows in the casing or in the annular space surrounding the casing. It is used during the injection or production to locate the points of inflow of the fluid.

In an injection well, the fluid injected is generally colder than the temperature of formations. If the injection rate is increased and retention time of fluid inside the casing is longer, it leads to a cooling effect inside the casing and this reduces the temperature as depicted by the curves.

Temperature logs were run in ET O'Daniel 41, 42, 43 and 44 to track the regions into which the fluid $\left(\mathrm{CO}_{2}\right)$ injected is moving into the formation.

Fig. 2.35 shows that $\mathrm{CO}_{2}$ is moving in all zones from $1 \mathrm{U}$ to $5 \mathrm{U}$ as seen by the cooling effect. This further strengthens our observations from the LOW responses, which also show movement of $\mathrm{CO}_{2}$ in all spraberry zones.

The temperature log taken at ET O'Daniel 42 (Fig. 2.36) reveals that $\mathrm{CO}_{2}$ is moving in both $1 \mathrm{U}$ and $5 \mathrm{U}$ and this is prominent by the shape of the curve at these two regions. 


\subsection{Review of gas sampling data}

Continuing the tracking of $\mathrm{CO}_{2}$ using lateral movement of the gas is presented here. The focus of our observations is to understand the movement of gas in the on trend and off trend wells. Samples from a set of 23 on trend, 7 off trend and interior producers were analyzed. These samples were taken at regular intervals at these wells with the basic objective of observing the relative enrichment of $\mathrm{HC}$ fractions by Carbon dioxide $\left(\mathrm{CO}_{2}\right)$. The gas sampling data is classified by the responses obtained at the on trend and off trend wells.

Most of the wells in Fig. 2.37 show a high fraction of methane and similar quantities of ethane/propane and about $8 \%$ of n-butane. These were values recorded just prior to the commencement of the $\mathrm{CO}_{2}$ flooding and the trends to be observed is a composition change. The tracer study conducted has given us the general directions of fluid movement around the pilot area and the tracer responses are best at on trend wells than off trend wells. Hence those wells lying on the on trend wells should exhibit greater composition changes than those wells situated off trend of the main fracture orientation.

It was anticipated that trends emerging from the gas sampling analysis would corroborate with the tracer results, and the best responses would be from on trend wells lying in the northeast-southwest direction.

A quick look at the $\mathrm{CO}_{2}$ fraction reaching on trend wells (Fig. 2.38) reveal that apart from the interior producers, only Brunson F1 and O'Daniel A1 were "seeing" $\mathrm{CO}_{2}$.

Both these wells lie on the northeast - southwest direction and inline with the main fracture trend. In lieu of the above observation, the next question coming to our minds is whether the $\mathrm{CO}_{2}$ reaching these wells were actually successful in producing hydrocarbons. A snapshot of the $\mathrm{C} 1$ mole fraction in the samples collected in the on trend wells is shown in Fig. 2.39. The data on the right hand side is due to relative enrichment of $\mathrm{C} 1$ by $\mathrm{CO}_{2}$ because there is more $\mathrm{CO}_{2}$ coming out of these wells than the data from other wells on the left hand side of the figure.

Figure 2.40 shows the performance of $\mathrm{CO}_{2}$ in extracting the other gas fractions. The profiles of $\mathrm{C} 2, \mathrm{C} 3$ and $\mathrm{n}-\mathrm{C} 4$ with respect to $\mathrm{CO}_{2}$ show a flat profile over the entire period. This implies that there is no change in hydrocarbon composition and $\mathrm{CO}_{2}$ is not extracting these fractions.

But the heavy oil fraction, C6+ shows variation and an increasing trend is observed particularly in the interior producers. There is more heavy oil coming out along with the carbon dioxide.

In a nutshell, a good $\mathrm{CO}_{2}$ fraction is observed at two wells ET O'Daniel A1 and Brunson $\mathrm{F} 1$ with a high $\mathrm{C} 1$ fraction extraction. $\mathrm{CO}_{2}$ has no impact on the other wells outside of the pilot area and on trend with the main fracture orientation. Furthermore, a progressively increasing extraction of heavy oil is observed at the interior producers. 
As previously mentioned the tracer study revealed that wells perpendicular to the main fracture trend did not show good response, a similar trend was observed by analyzing gas samples in these wells (Fig. 2.41). All the gas fractions from off trend wells show a $\mathrm{CO}_{2}$ mole fraction of less than $1 \%$ and clearly $\mathrm{CO}_{2}$ has not swept these areas. The other fractions $\left(\mathrm{C} 1, \mathrm{C} 2, \mathrm{C} 3, \mathrm{C} 4, \mathrm{C} 5\right.$ and $\left.6{ }^{+}\right)$observed from samples collected at these wells also were very small.

From the above summary on the gas sampling analysis from the on trend and off trend wells it is evident that $\mathrm{CO}_{2}$ is reaching very few wells and the impact of it reaching these wells is best illustrated by the response got from O'Daniel A1. Fig. 2.42 shows that the $\mathrm{C} 1$ fraction obtained at O'daniel A1 was greater than those at the interior wells. From this scenario we can assume that $\mathrm{CO}_{2}$ from the injectors is moving outwards in a southwesterly direction and along with it carrying all the light fractions outside the pilot area. This argument is further strengthened by the response got at O'daniel A1 after the injection pattern was changed in March 2002. From the review of production data earlier, an increasing trend in oil production was observed and moreover a high fraction of oil was produced everytime a $\mathrm{CO}_{2}$ injection cycle started.

From Fig. 2.43, a higher fraction of intermediates (C3 and n-C4) and heavy fractions $\left(\mathrm{C}^{+}+\right)$are produced at the interior wells than at O'Daniel A1. This shows that most of the light fractions are being purged out of the pilot area by the incoming $\mathrm{CO}_{2}$. As the pressure buildup is greater inside the pilot area, more oil would eventually be produced at ET O'Daniel A1 and a greater amount of intermediates and heavy fractions would eventually be seen at O'Daniel A1.

A culmination of reviews from logging data, gas sampling data, tracer data and production data from this pilot reveal a strong picture of the direction of fluid movement and a substantial oil production is observed only if the wells are situated on the main fracture trend. 


\subsection{Conclusions}

A diagnosis of the vertical and lateral distribution of $\mathrm{CO}_{2}$ in the Spraberry interval was shown in this study. A summary of the conclusions from this study is presented below:

1. Incremental recoveries in Brunson F-1, ET O'Daniel A-1, O'Brien B-1, Brunson $\mathrm{C}-2$ and Brunson G-1 indicate that $\mathrm{CO}_{2}$ has been successful in mobilizing oil.

2. Production at O'Brien B-1 is not due to lease electrification alone.

3. Tracer injection study confirms there are continuous fracture path from injection wells to O'Daniel A1 and Brunson F1 wells.

4. The use of mapping techniques using OFM has improved our interpretation and visualization of waterflooding and $\mathrm{CO}_{2}$ flooding performance.

5. Gamma Ray/Induction/Neutron porosity response from LOW \#49 show that that there is a decrease in compensated neutron density (NPHI) and increase in resistivity logs at different depths hinting the presence of a hydrocarbon gas or $\mathrm{CO}_{2}$.

6. WAG method has not been very effective in sweeping the oil in the Spraberry reservoir as evident by the responses.

7. Since the cumulative amount of $\mathrm{CO}_{2}$ produced is still small compared to the amount injected, a delayed recovery of hydrocarbons is expected.

8. The observations from LOW\#50 do not mirror the observations obtained from LOW \#49.

9. Even though $\mathrm{CO}_{2}$ is entering all layers as indicated by the changes in resistivity and density logs, those changes are not magnified. More $\mathrm{CO}_{2}$ volume needs to be injected and more logging runs need to be carried out.

10. The temperature logs also show that there is movement of $\mathrm{CO}_{2}$ in all layers.

11. A study of gas samples from on-trend and off-trend wells suggest that:

a There is no indication of $\mathrm{CO}_{2}$ presence at the off- trend wells

- Only two on- trend wells Brunson F1 and O'daniel A1 have 'seen' $\mathrm{CO}_{2}$

- Heavy oil fractions are being produced at the interior wells

- Light oil and middle oil fractions are dominant in Brunson F1 and O'daniel A1.

- A greater amount of $\mathrm{C} 1$ is recorded at O'Daniel A1 than the interior producers. This implies that all the light fractions are being driven outside the pilot area and every time a WAG cycle has started, more oil is produced at O'Daniel A1. 


\subsection{References}

1) Guidroz, G.M.: "E.T. O’Daniel Project - A Successful Spraberry Flood," paper SPE 1791 presented at the 1967 Sixth Permian Basin Oil Recovery Conference, Midland, 8-9 May.

2) Schechter, D.S., McDonald, P., Sheffield, T. and Baker, R.: "Reservoir Characterization and $\mathrm{CO}_{2}$ Pilot Design in the Naturally Fractured Spraberry Trend Area," SPE paper 35469, presented at the SPE Permian Basin Oil and Gas Recovery Conference, Midland, Texas, March 27 - 29, 1999.

3) Schechter, D.S., "Advanced Reservoir Characterization and Evaluation of $\mathrm{CO}_{2}$ Gravity Drainage in the Naturally Fractured Spraberry Trend Area," First Annual Technical Progress Report to DOE under Contract No. DE-FC22-95BC14942, Dec. 17, 1996, (b).

4) Schechter, D.S., "Advanced Reservoir Characterization and Evaluation of $\mathrm{CO}_{2}$ Gravity Drainage in the Naturally Fractured Spraberry Trend Area," Second Annual Technical Progress Report to DOE under Contract No. DE-FC22-95BC14942, Oct. 1997.

5) Schechter, D.S.: "Advanced Reservoir Characterization and Evaluation of $\mathrm{CO}_{2}$ Gravity Drainage in the Naturally Fractured Spraberry Trend Area," Third Annual Technical Progress Report, Contract No. DE-FC22-95BC14942, U.S. DOE, (Dec 1998).

6) Schechter, D.S: "Advanced Reservoir Characterization and Evaluation of $\mathrm{CO}_{2}$ Gravity Drainage in the Naturally Fractured Spraberry Trend Area," Fourth Annual Technical Progress Report to DOE under contract No.: DE-FC22-95BC14942, U.S. DOE (October 1999).

7) Schechter, D.S: "Advanced Reservoir Characterization and Evaluation of $\mathrm{CO}_{2}$ Gravity Drainage in the Naturally Fractured Spraberry Trend Area," Final Annual Technical Progress Report to DOE under contract No.: DE-FC22-95BC14942, U.S. DOE (June 2002).

8) Banik, A.K., and Schechter, D.S.: "Characterization of the Naturally Fractured Spraberry Trend Shaly Sands Based on Core and Log Data," paper SPE 35224 
presented at the SPE Permian Basin Oil \& Gas Recovery Conference, Midland, Texas, 27-29 March 1996. 


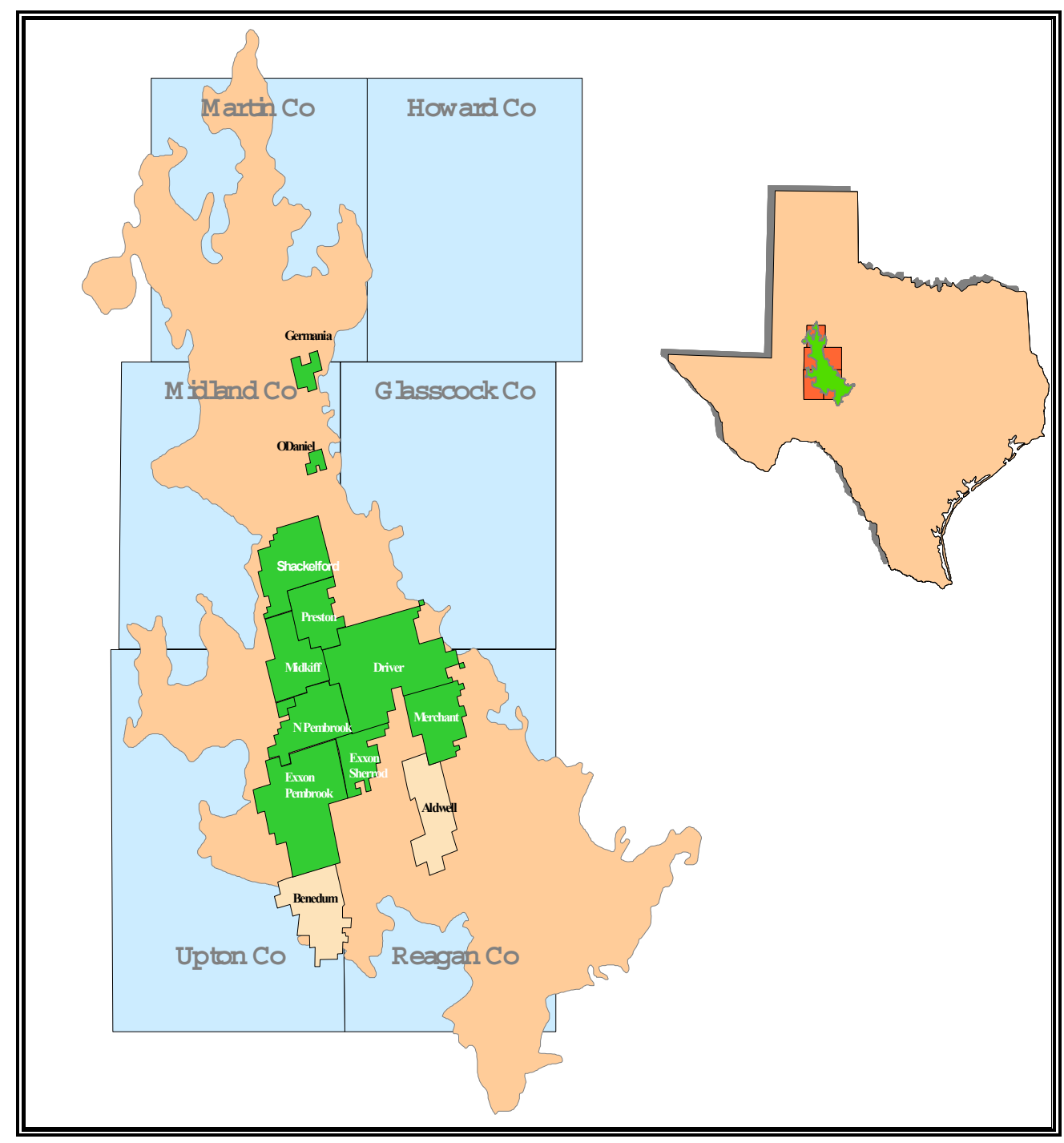

Fig. 2.1 Spraberry Trend Area 


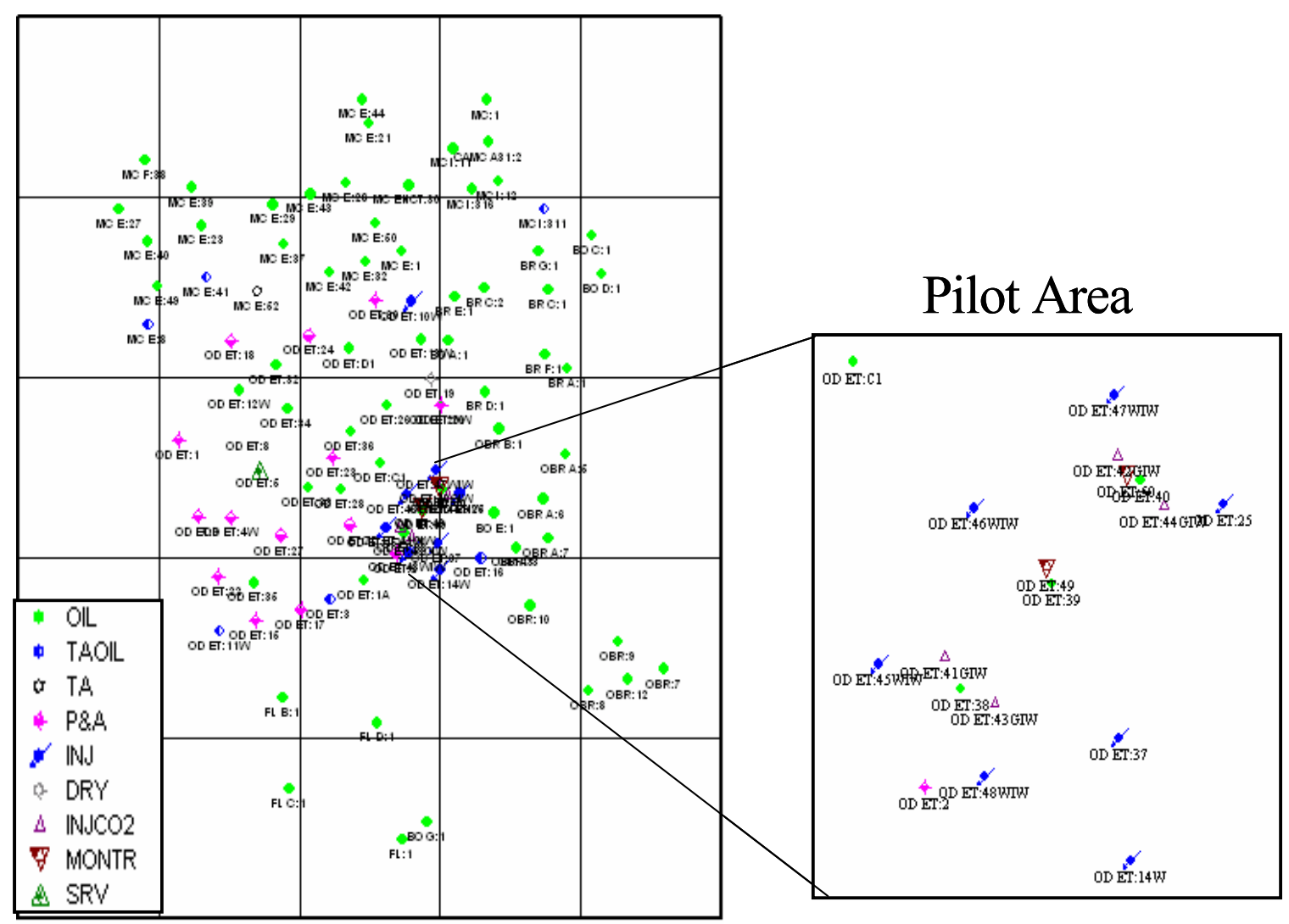

Fig. 2.2 - E.T. O’Daniel Pilot Area 


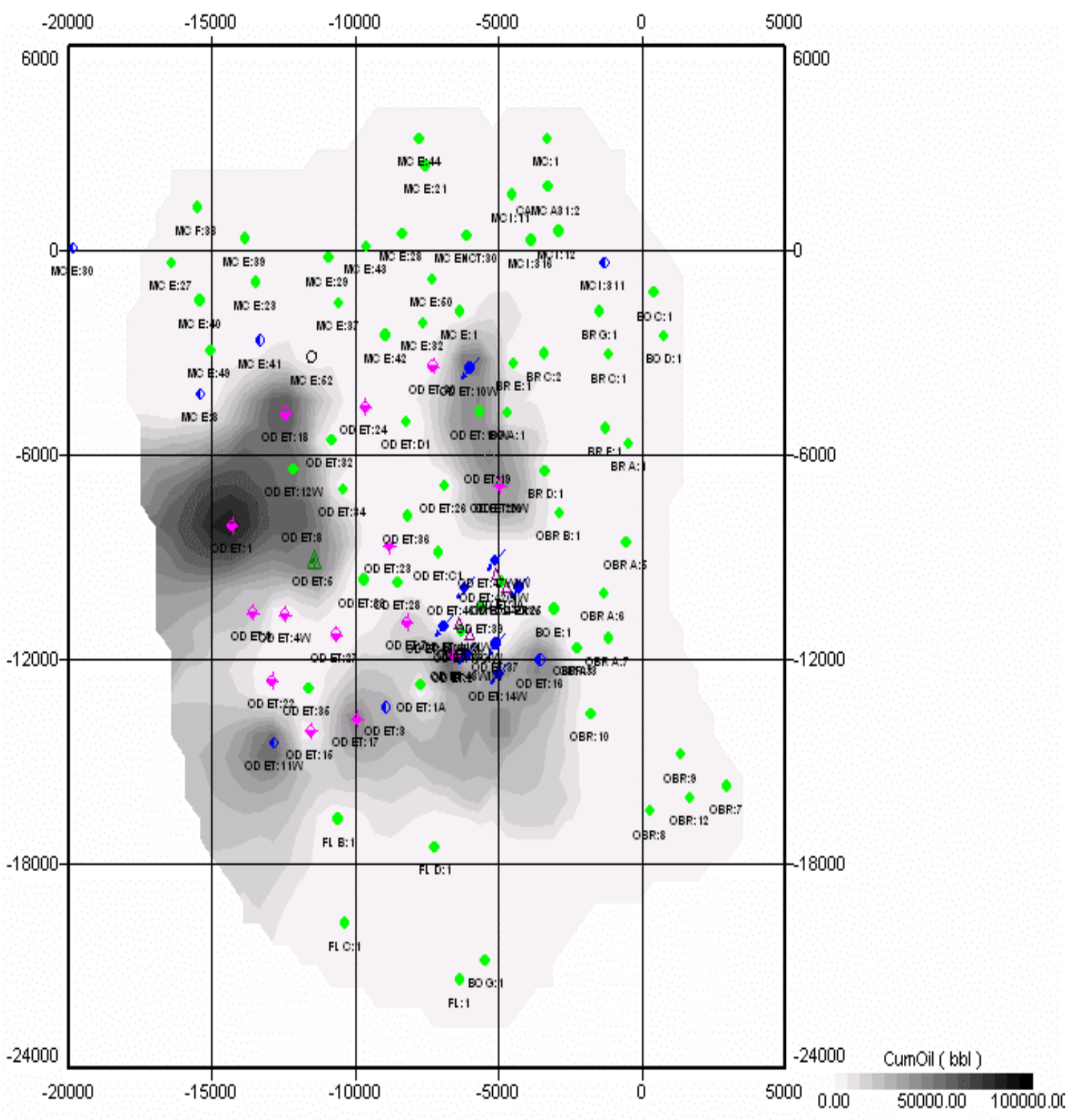

Fig. 2.3- Grid map showing cumulative oil production during 1951-1959 

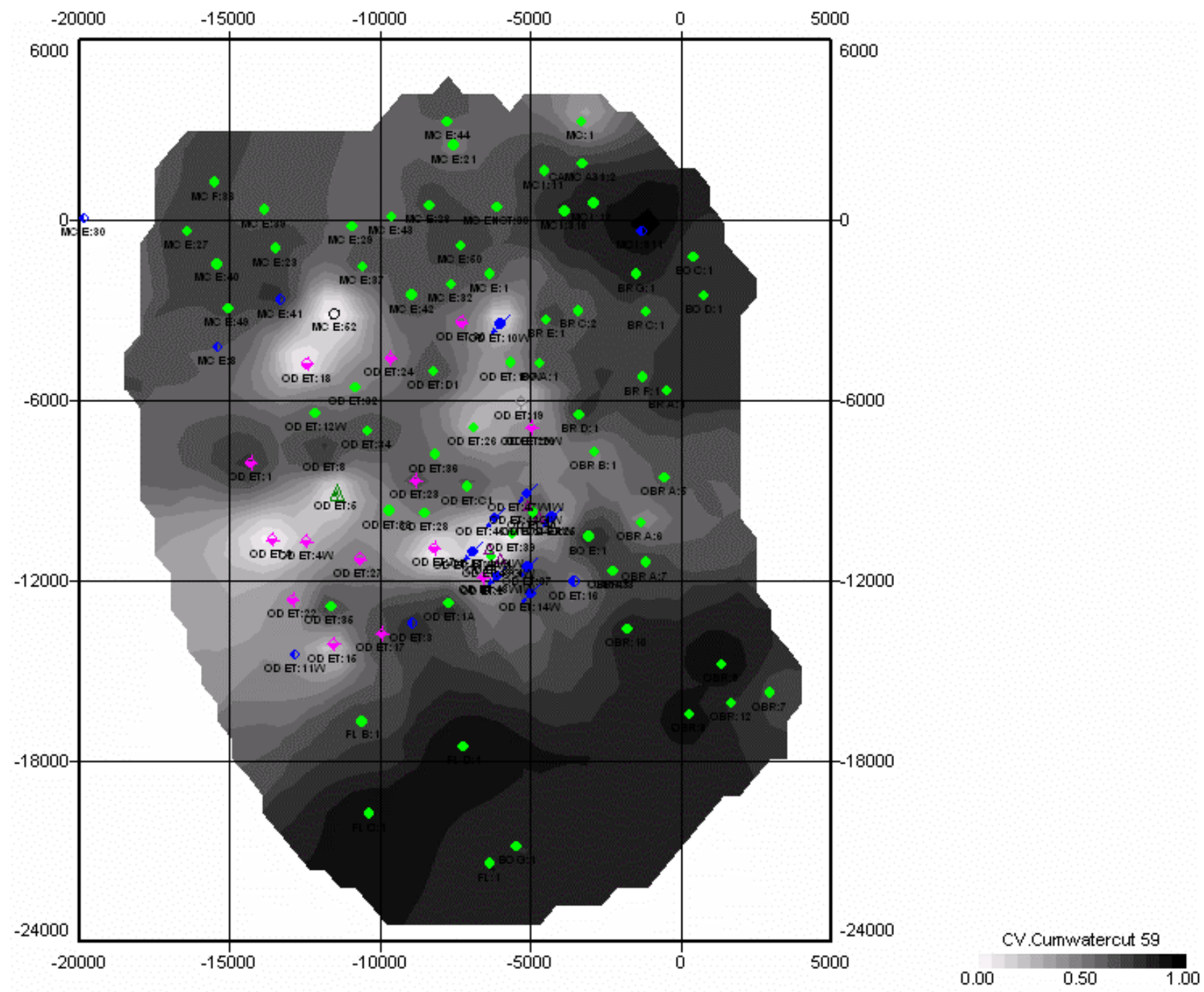

Fig. 2.4- Cumulative water cut grid map (1959-1999) 


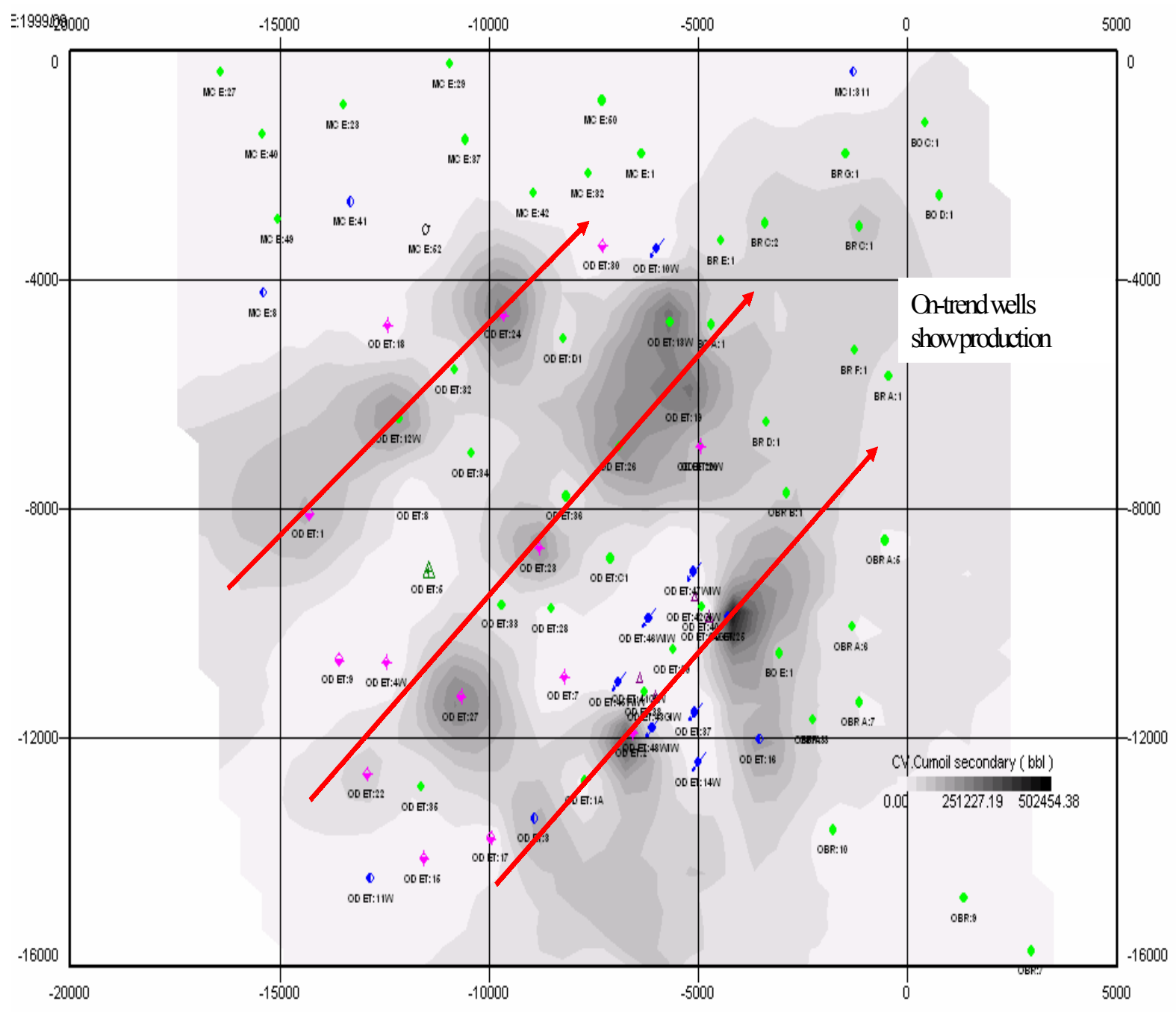

Fig. 2.5- Cumulative oil production (1959-1999) 


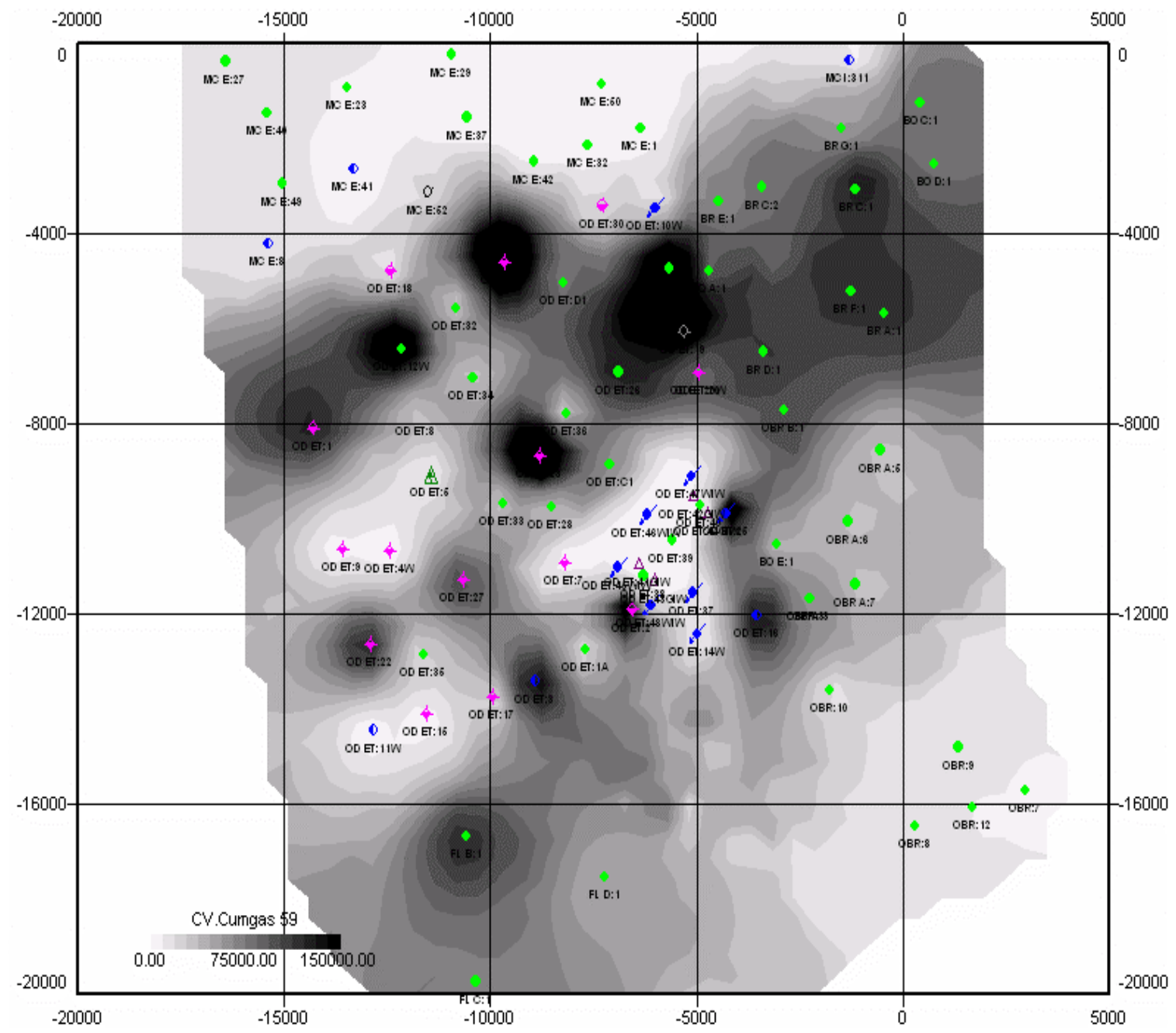

Fig. 2.6- Cumulative gas production (1959-1999) 


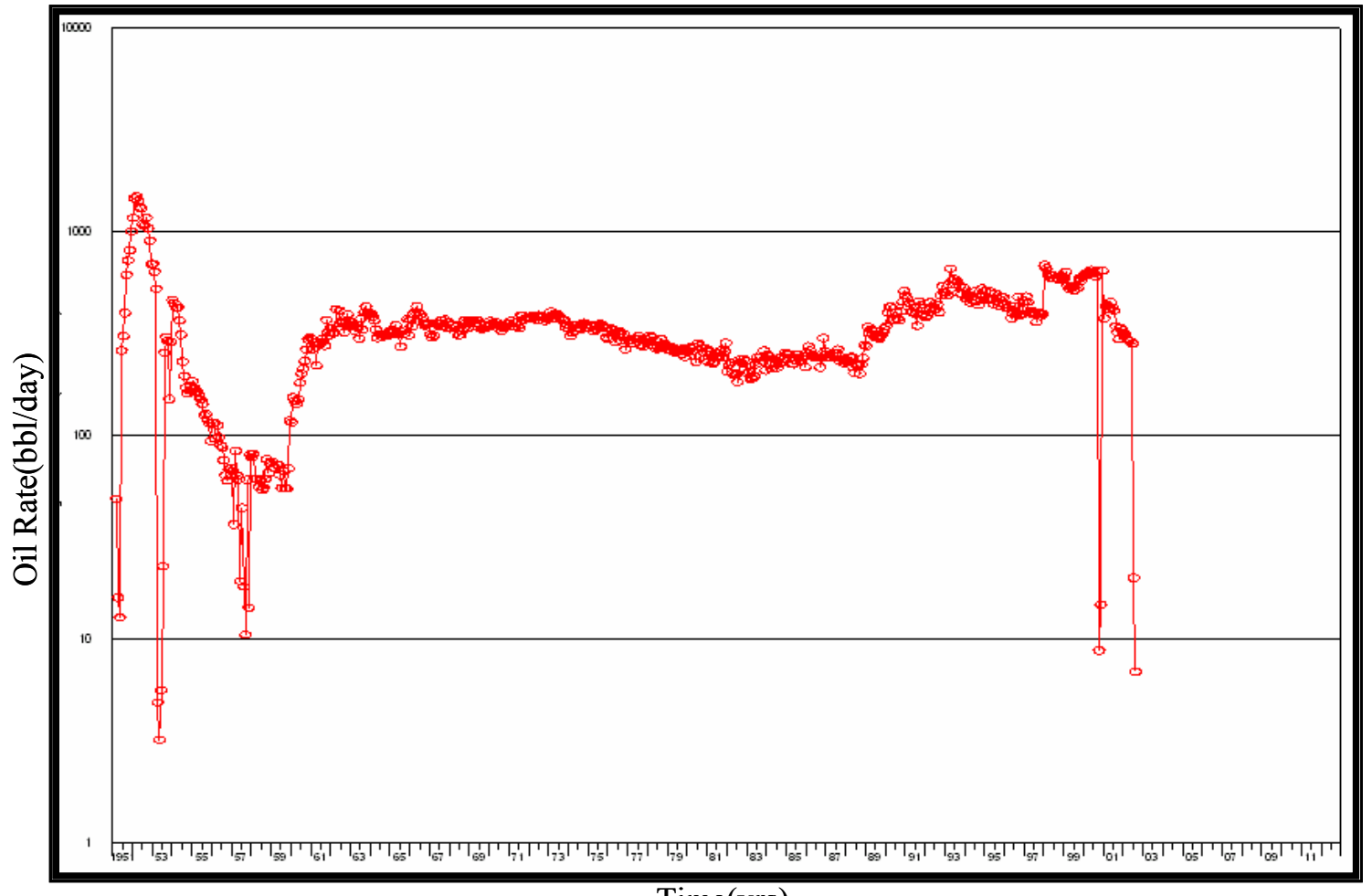

Time(yrs)

Fig. 2.7 - Historical Oil Production 

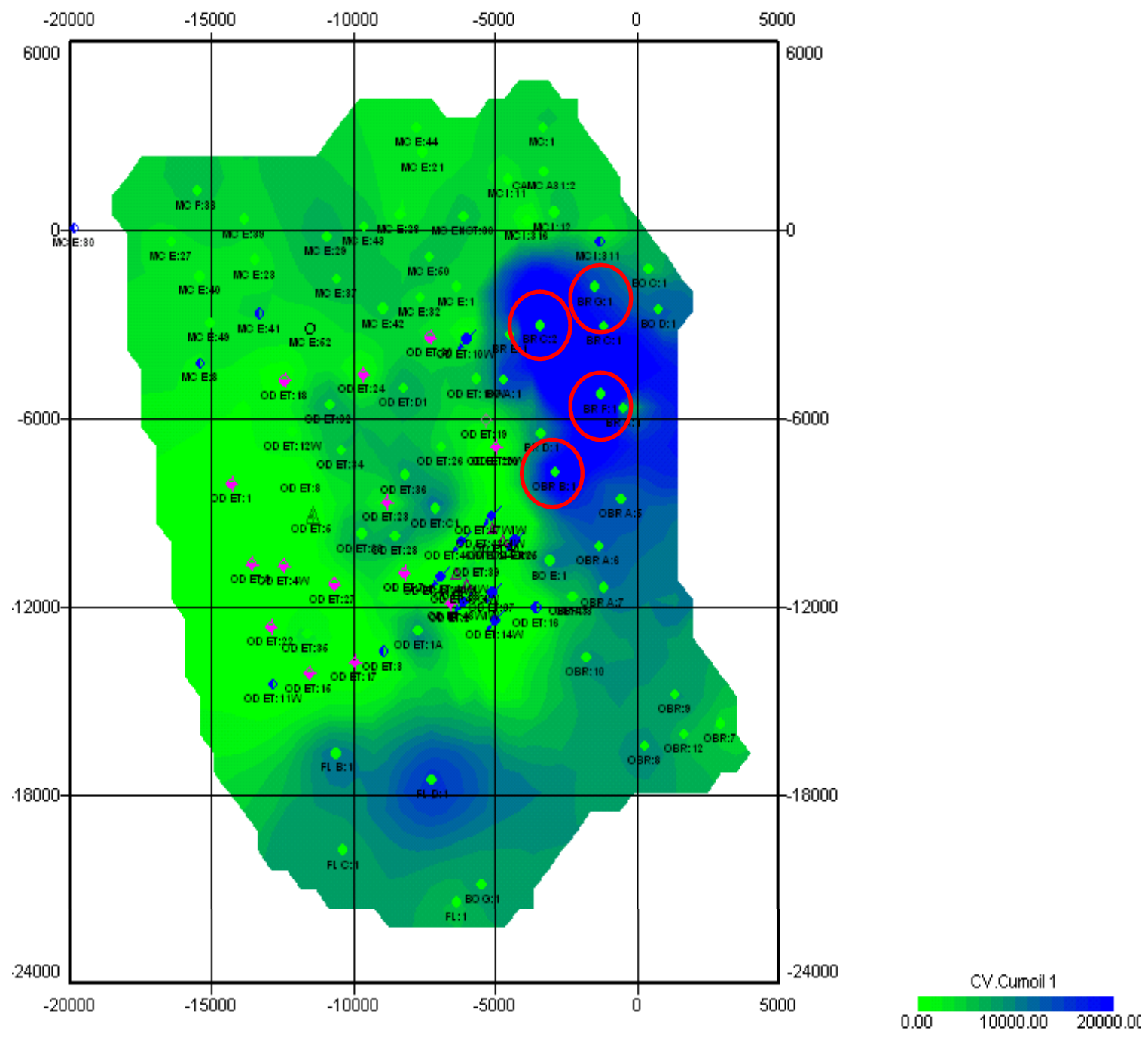

Fig. 2.8 - Oil response seen at on-trend wells (1999-2002) 


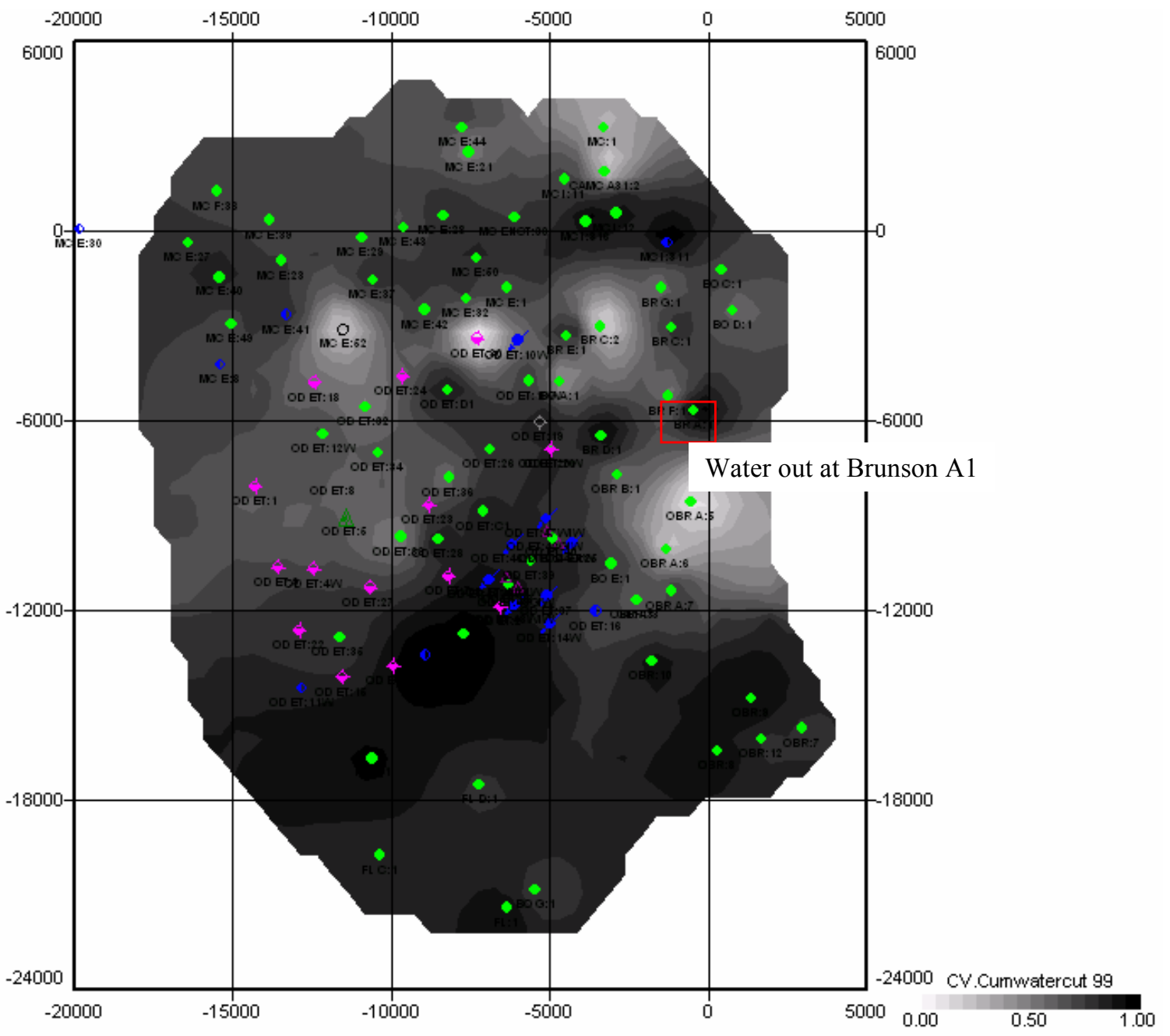

Fig. 2.9 - Water swept area (1999-2002) 


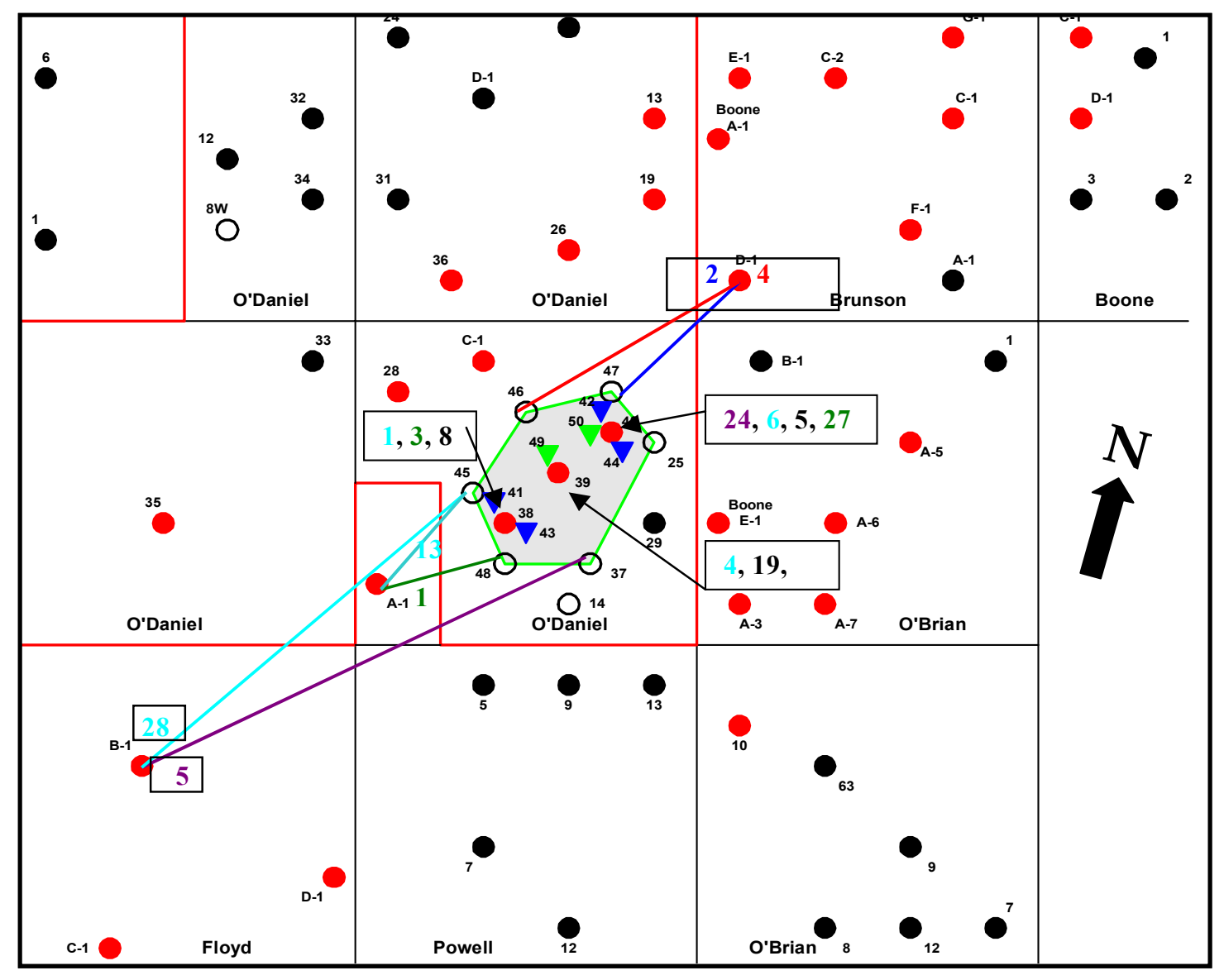

Fig. 2.10- Quickest tracer response (times of response shown in box) 


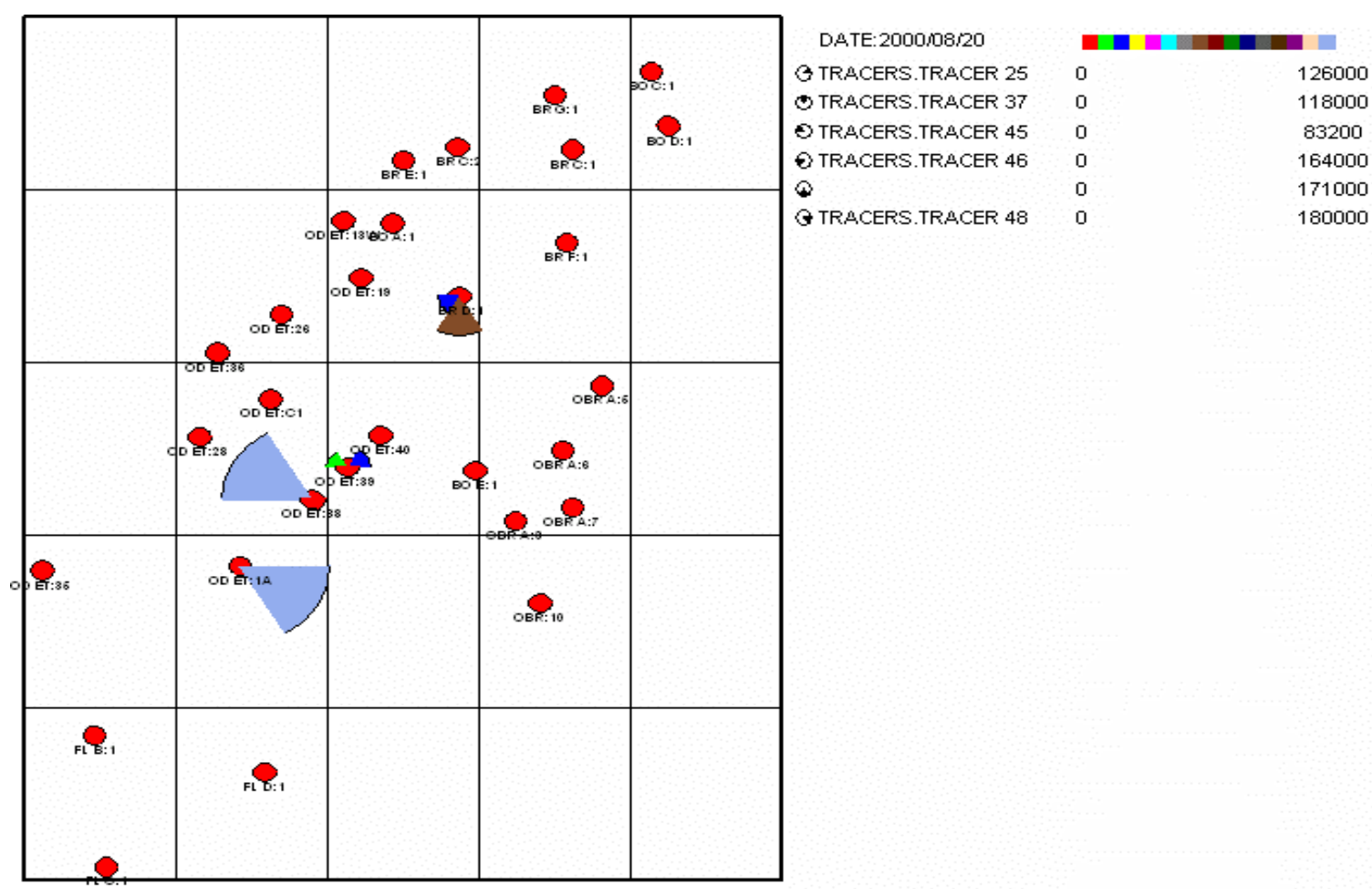

Fig. 2.11- Tracer response after 5 days

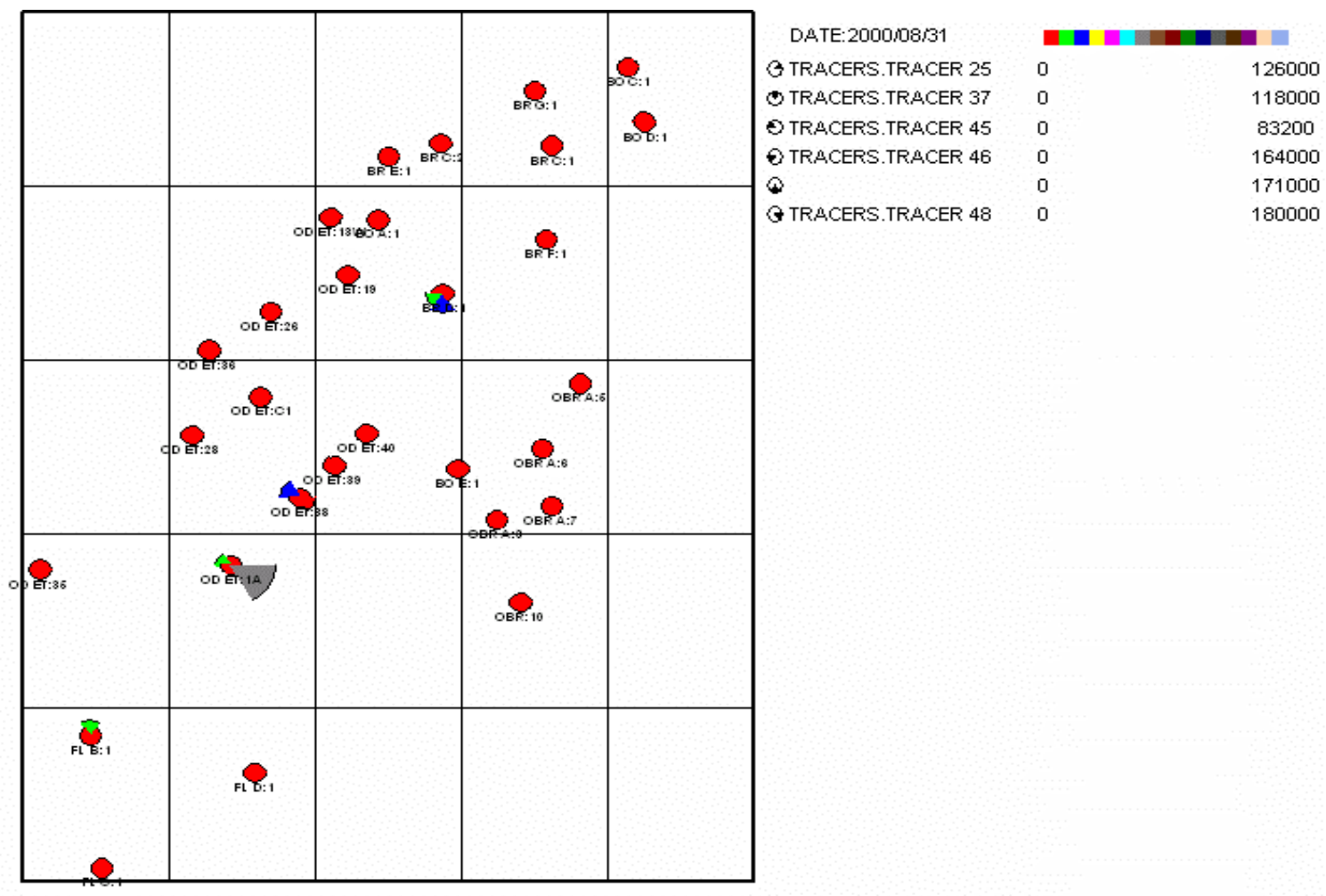

Fig. 2.12- Tracer response after 15 days 


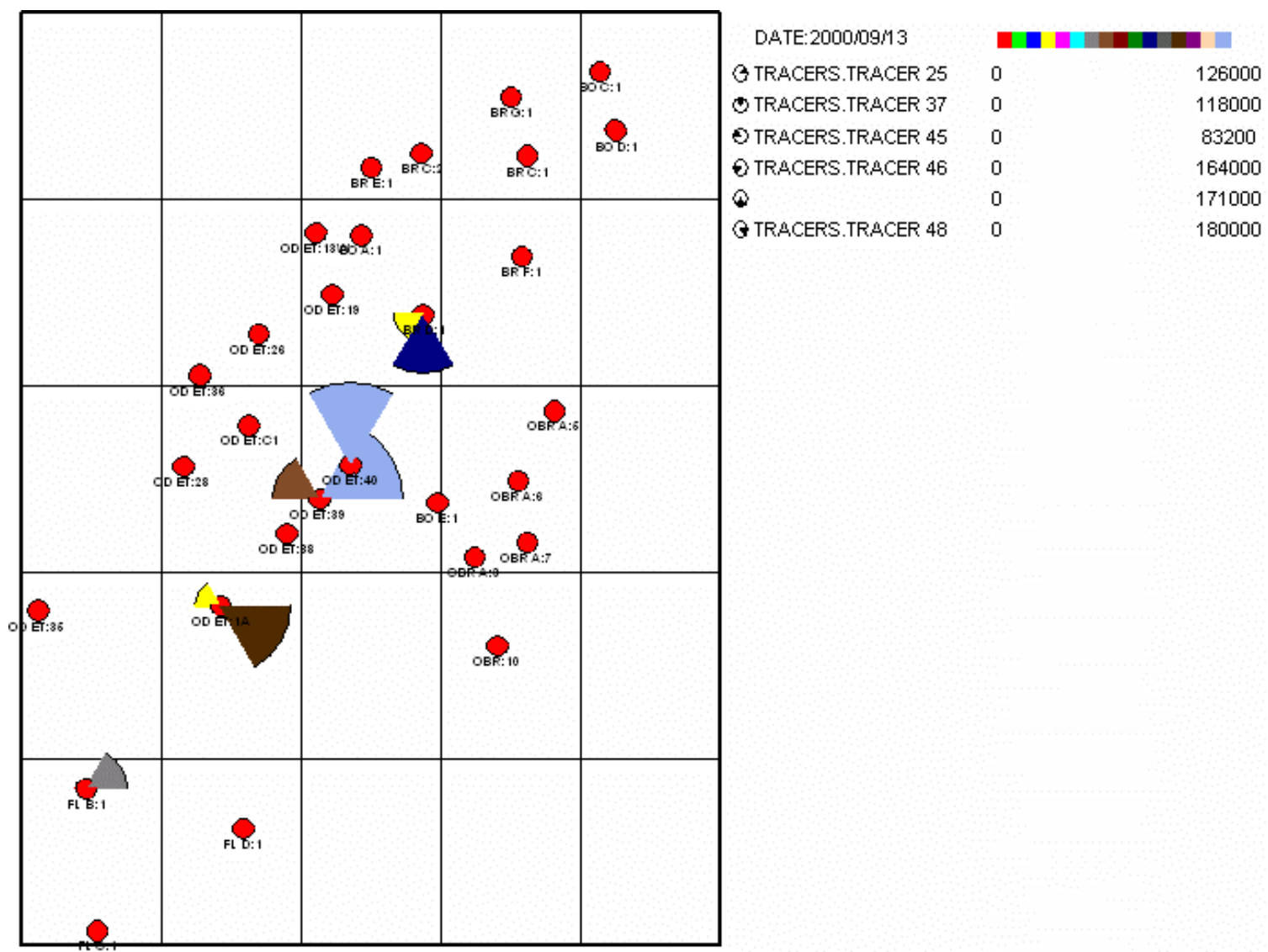

Fig. 2.13- Tracer response after 29 days

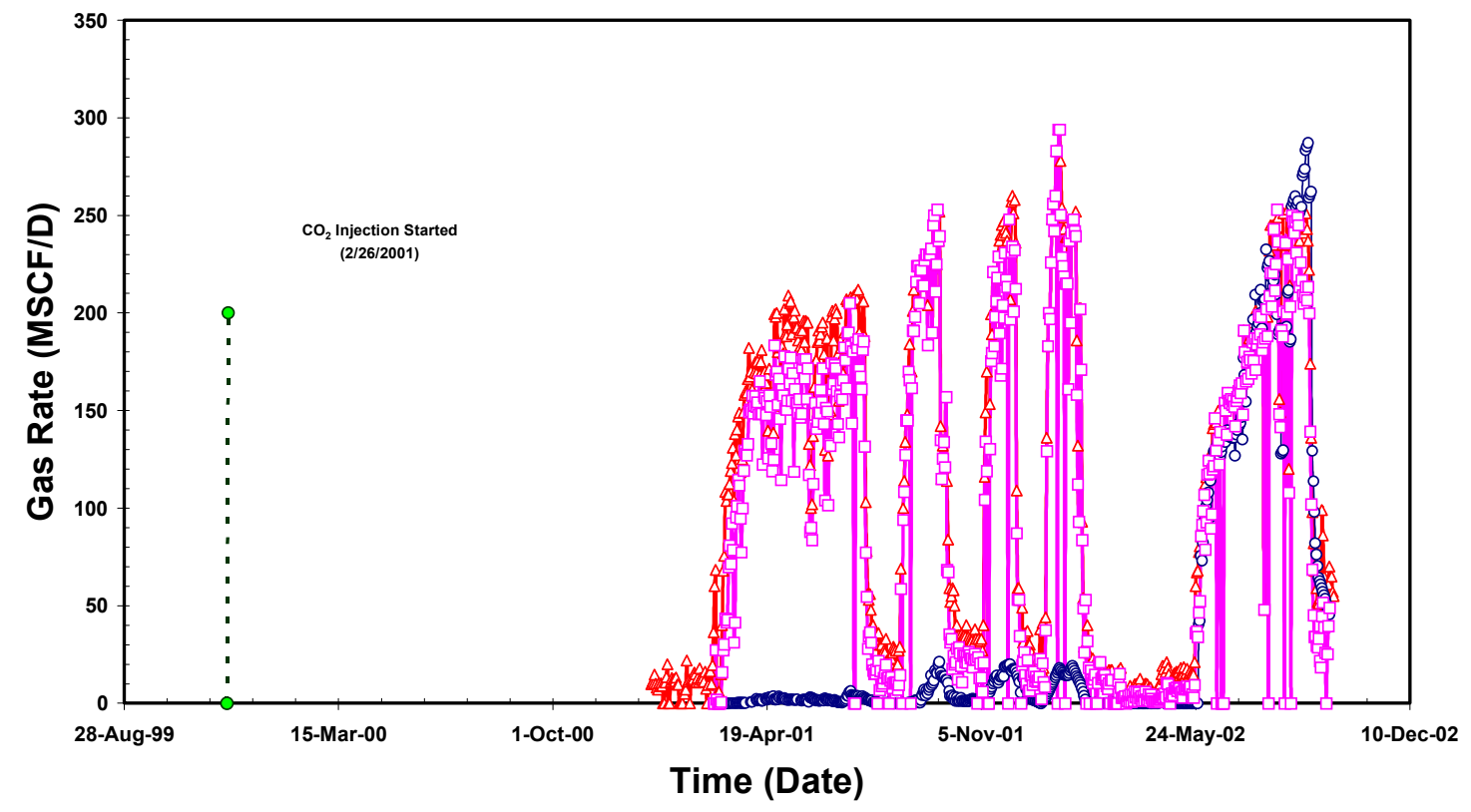

$\neg-$ Gas Rate (Mcf) - o- CO2 Started $\multimap-\mathrm{CO} 2$ Rate at A\#1 $\square-\mathrm{CO} 2$ Rate at \# 38,39, 40 and A\#1

Fig. 2.14 - The percentage of $\mathrm{CO}_{2}$ produced at the interior wells and ET O'Daniel A1 


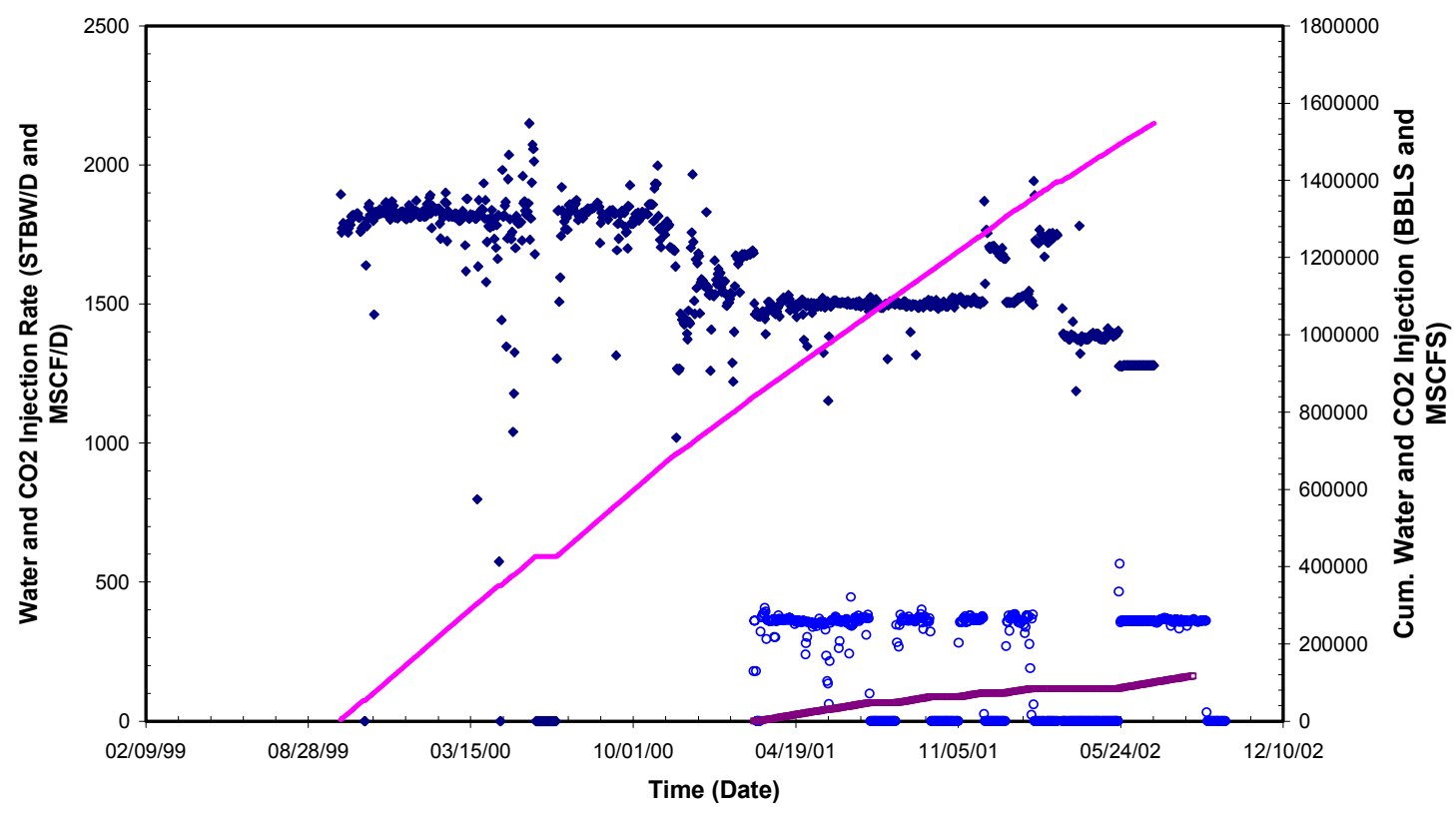

- Water Injection Rate CO2 Injection Rate —Cum. Water Injection - - Cum. CO2 Injection

Fig. 2.15 - Total water and $\mathrm{CO}_{2}$ injection is maintained in the pilot

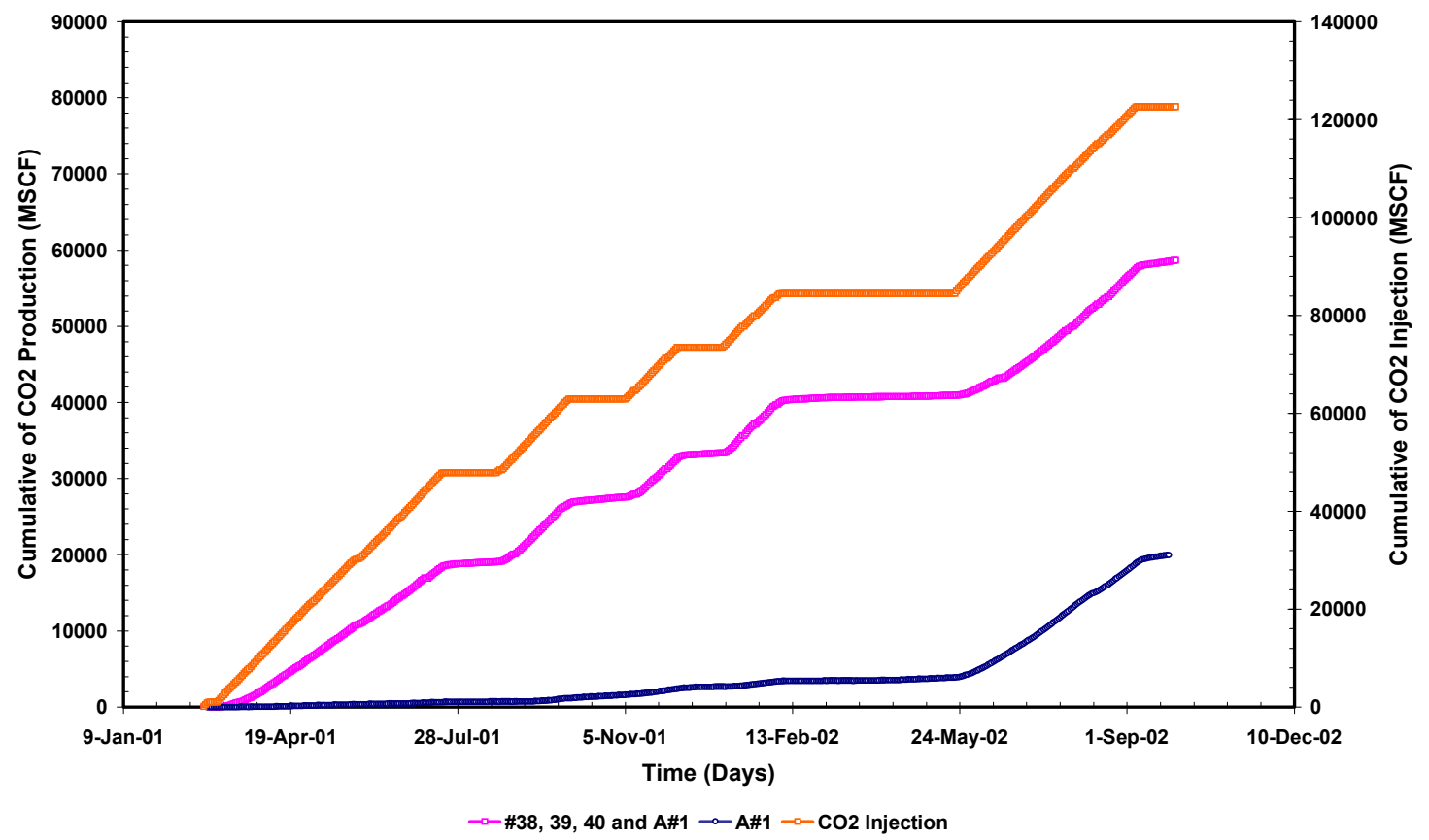

Fig. 2.16 - Comparison of $\mathrm{CO}_{2}$ injected and produced in the interior producers and ET O’Daniel A1 


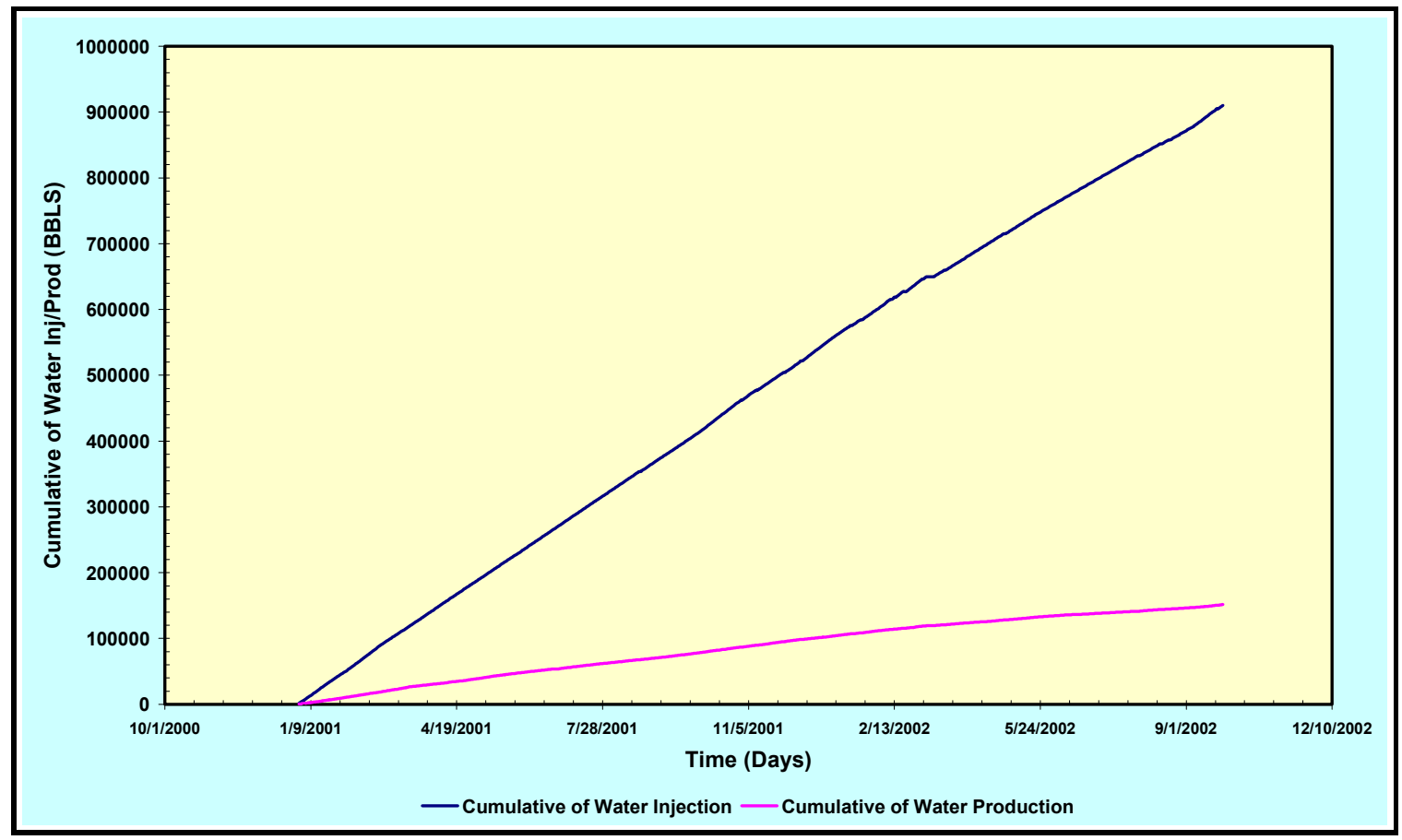

Fig. 2.17 - Cumulative water injection and production profile from ET O'Daniel A1 and interior producers.

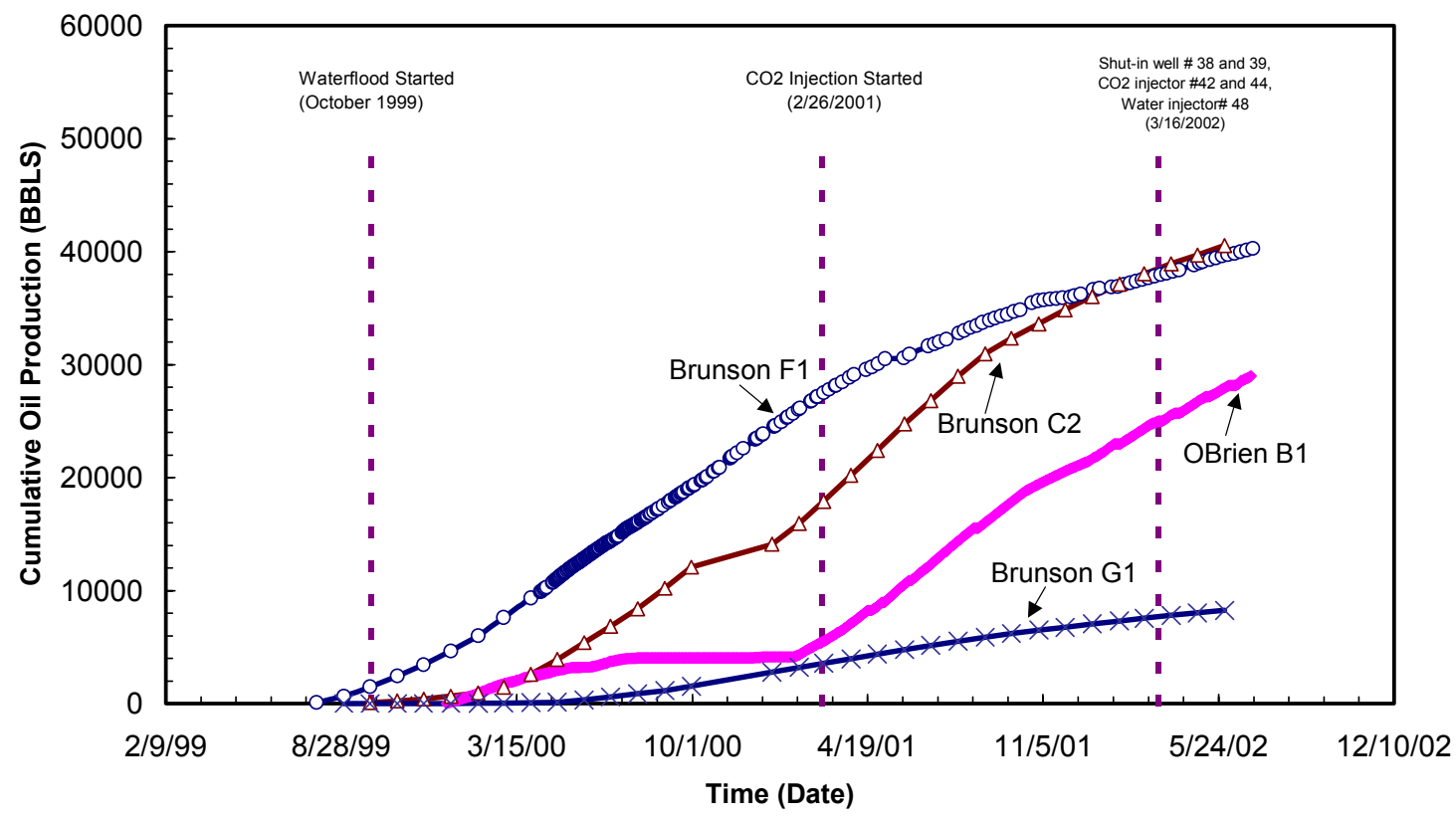

Fig. 2.18-Cumulative production profile from on trend wells 


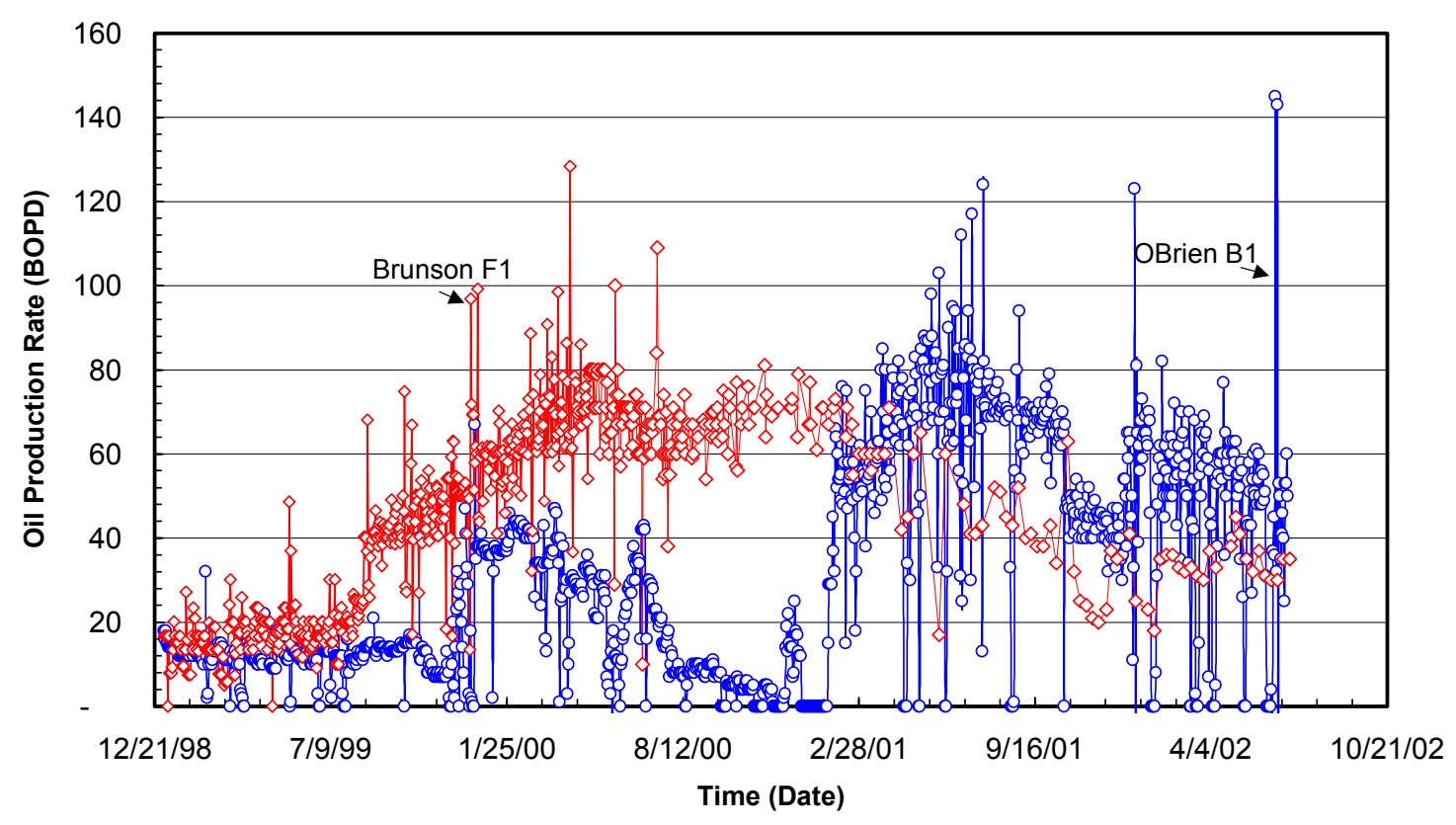

Fig. 2.19- Similar production trend in Brunson F1 and O'Brien

B1

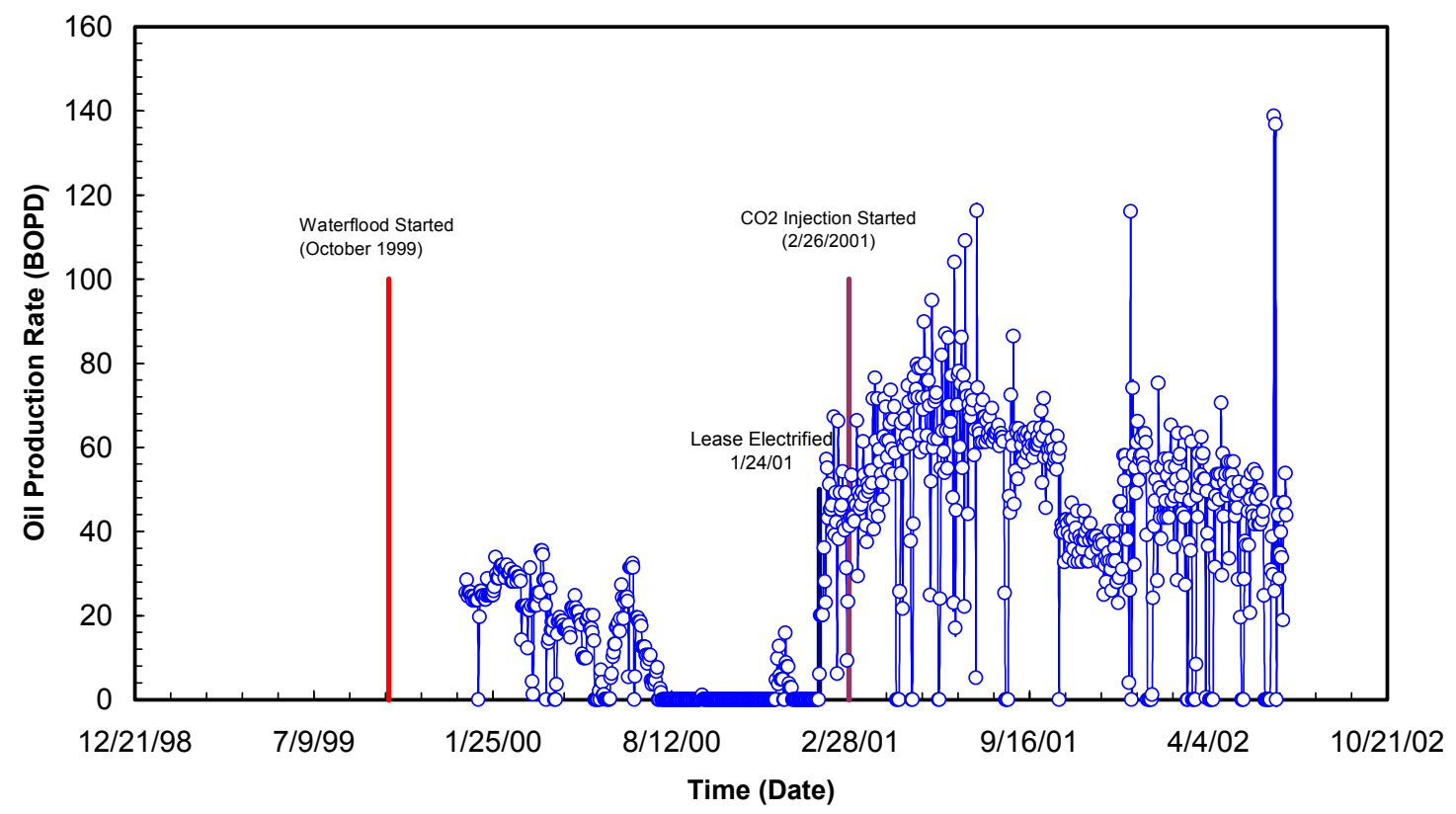

Fig. 2.20 - Production profile in O'Brien B1 


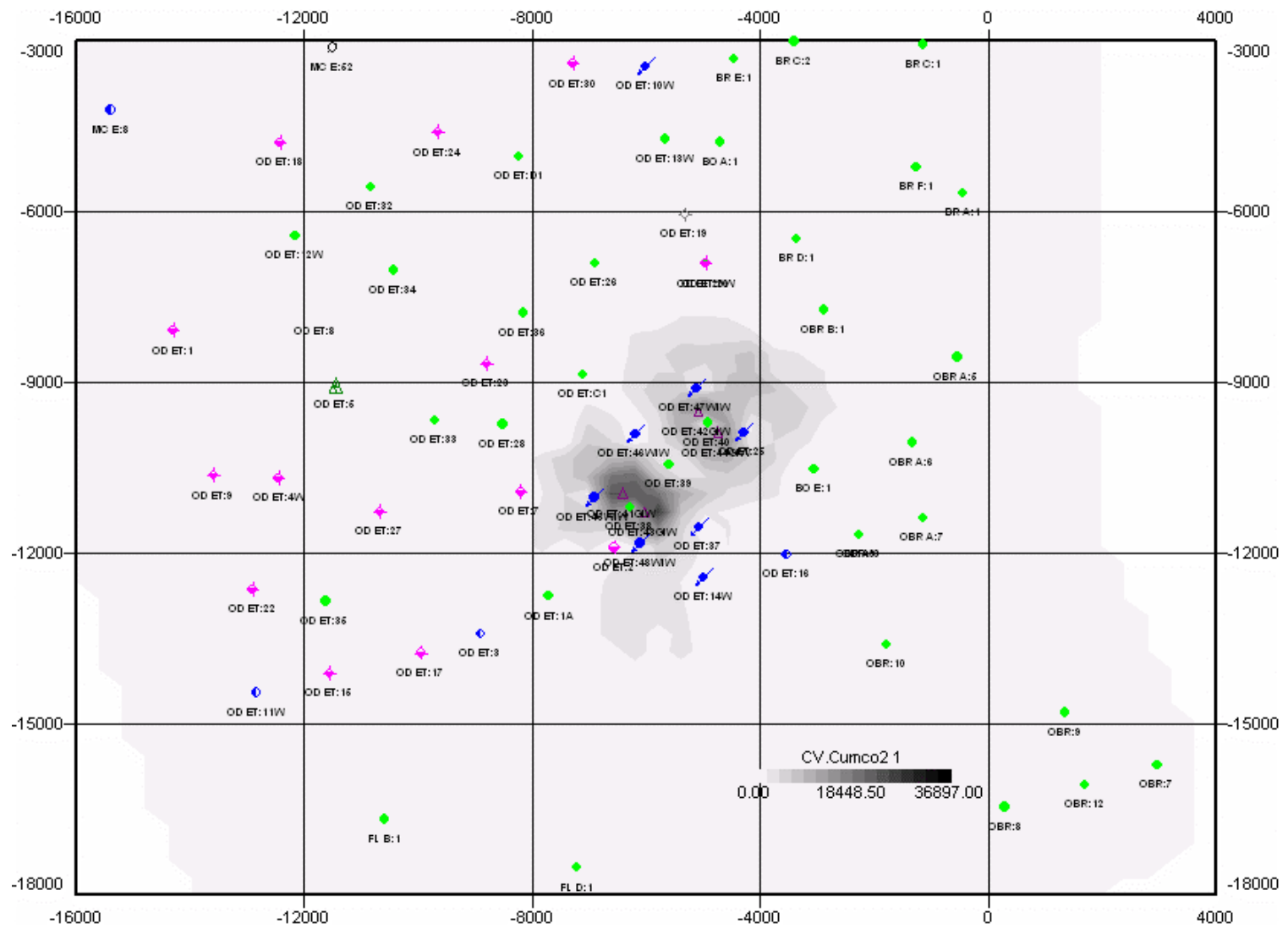

Fig. 2.21 - Cumulative $\mathrm{CO}_{2}$ Injected

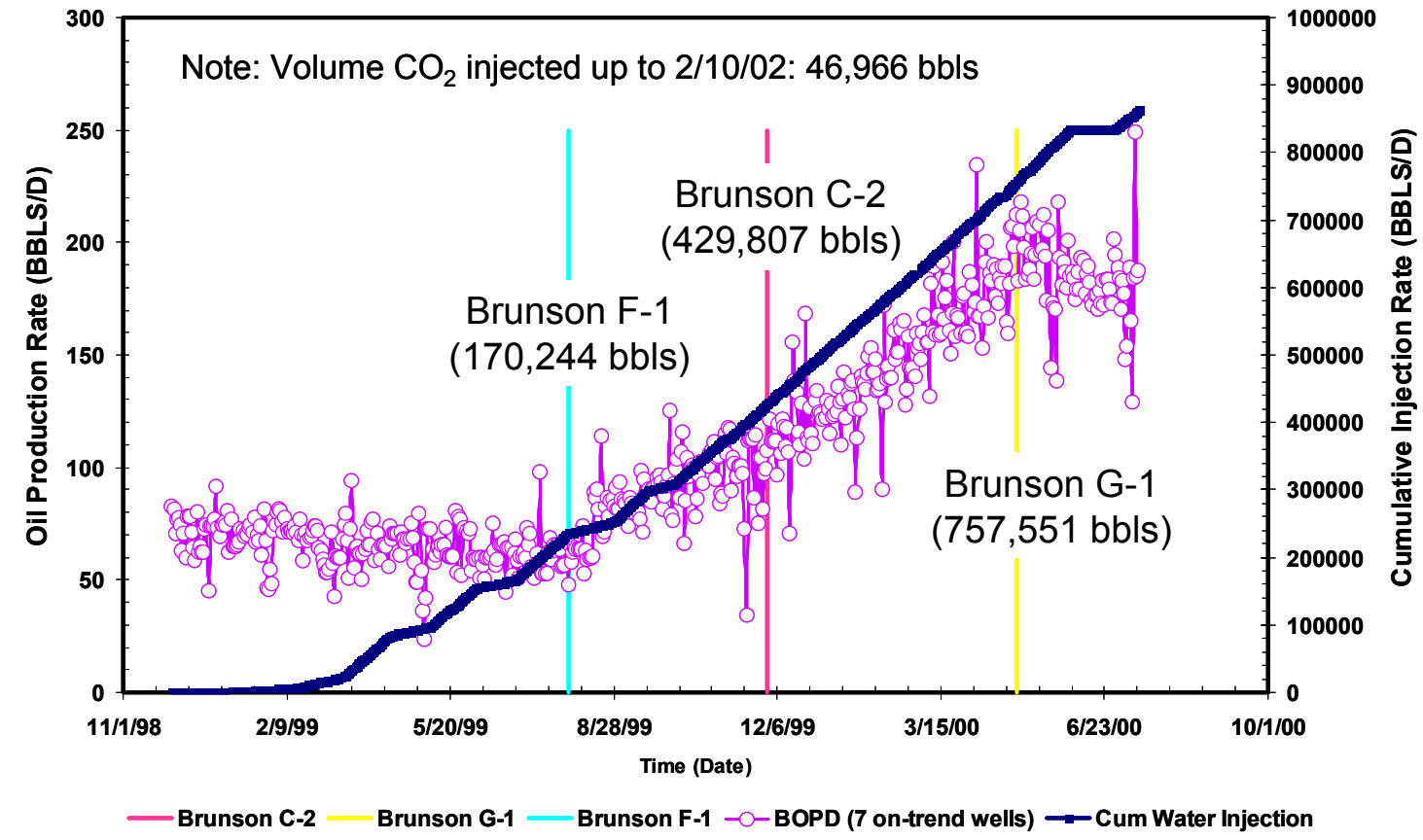

Fig. 2.22 - Production response at wells due to water injection alone 

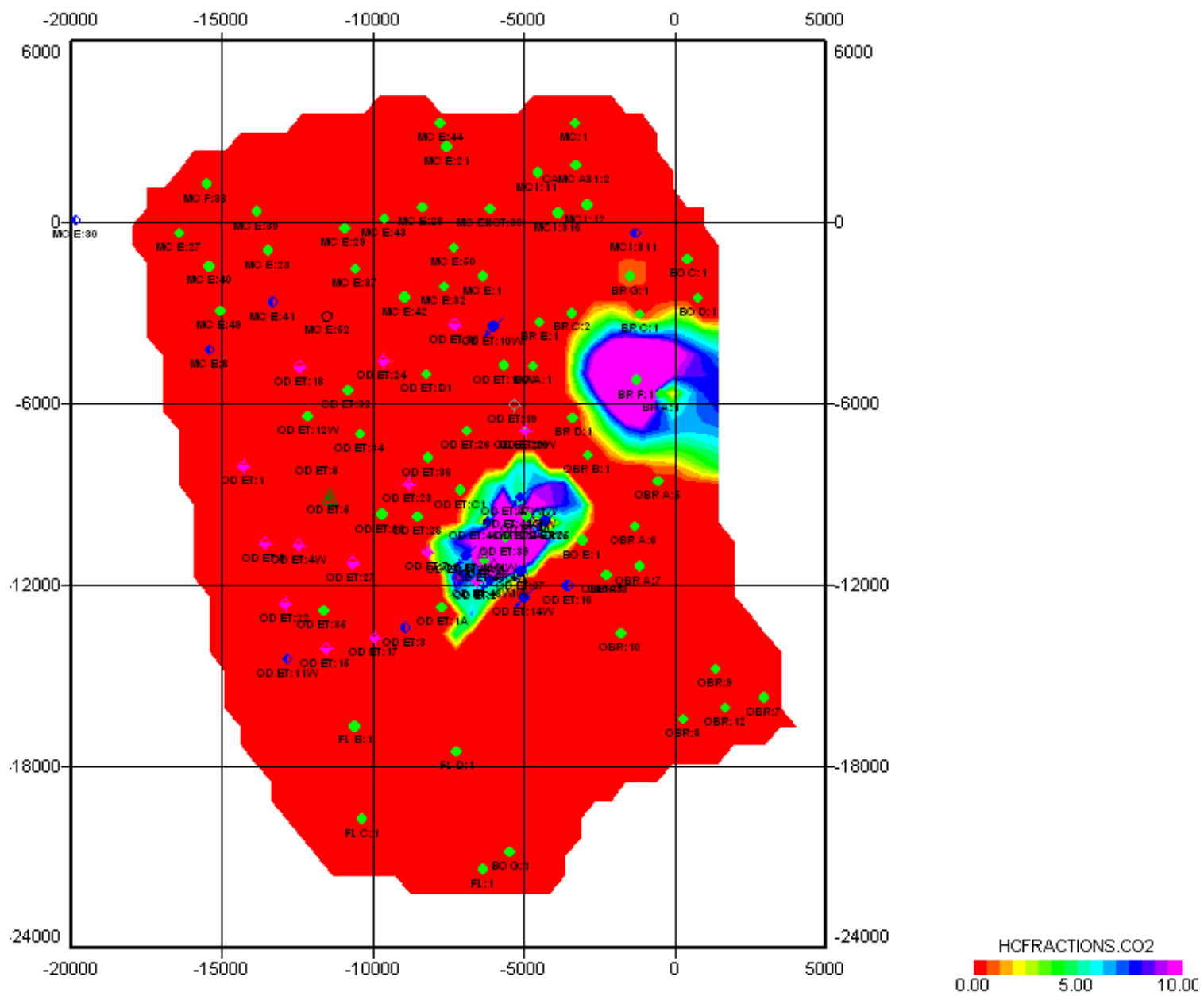

Fig. 2.23 - Cumulative produced $\mathrm{CO}_{2}$ fraction 


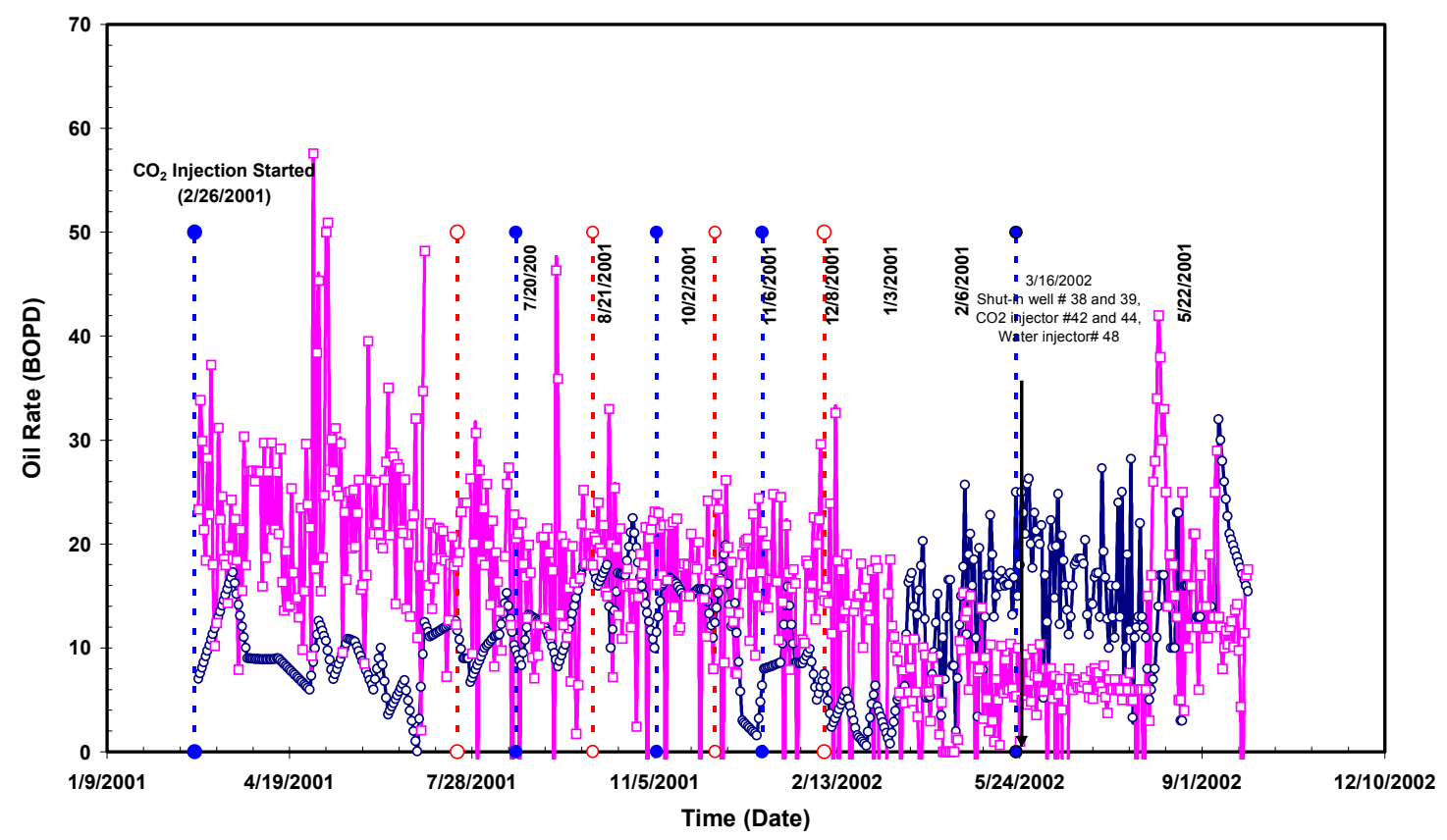

Fig. 2.24- Comparison of oil production between interior producers and ET O'Daniel A1

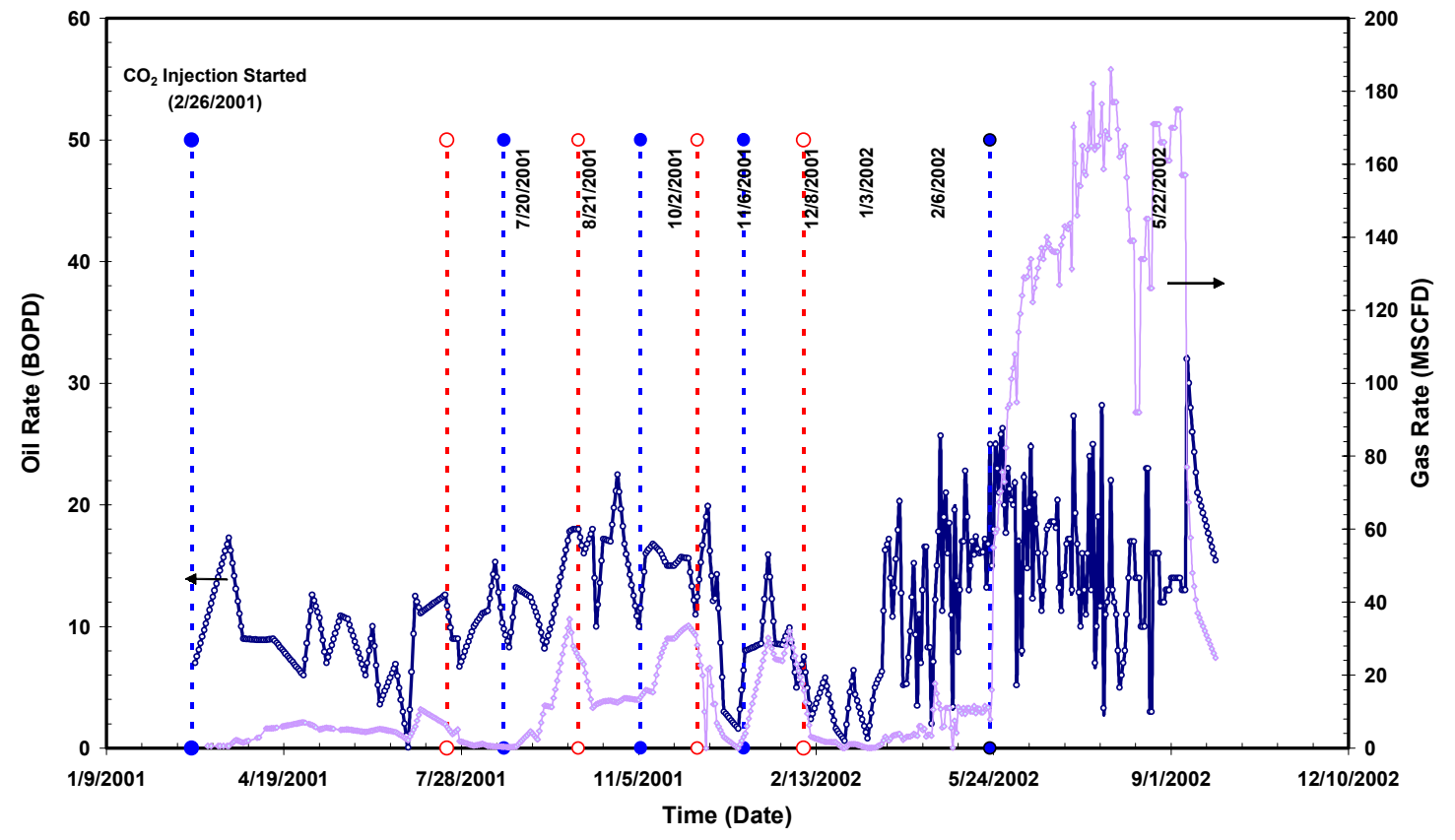

Fig. 2.25 - Comparison of oil rate and gas rate at ET O'Daniel A1 


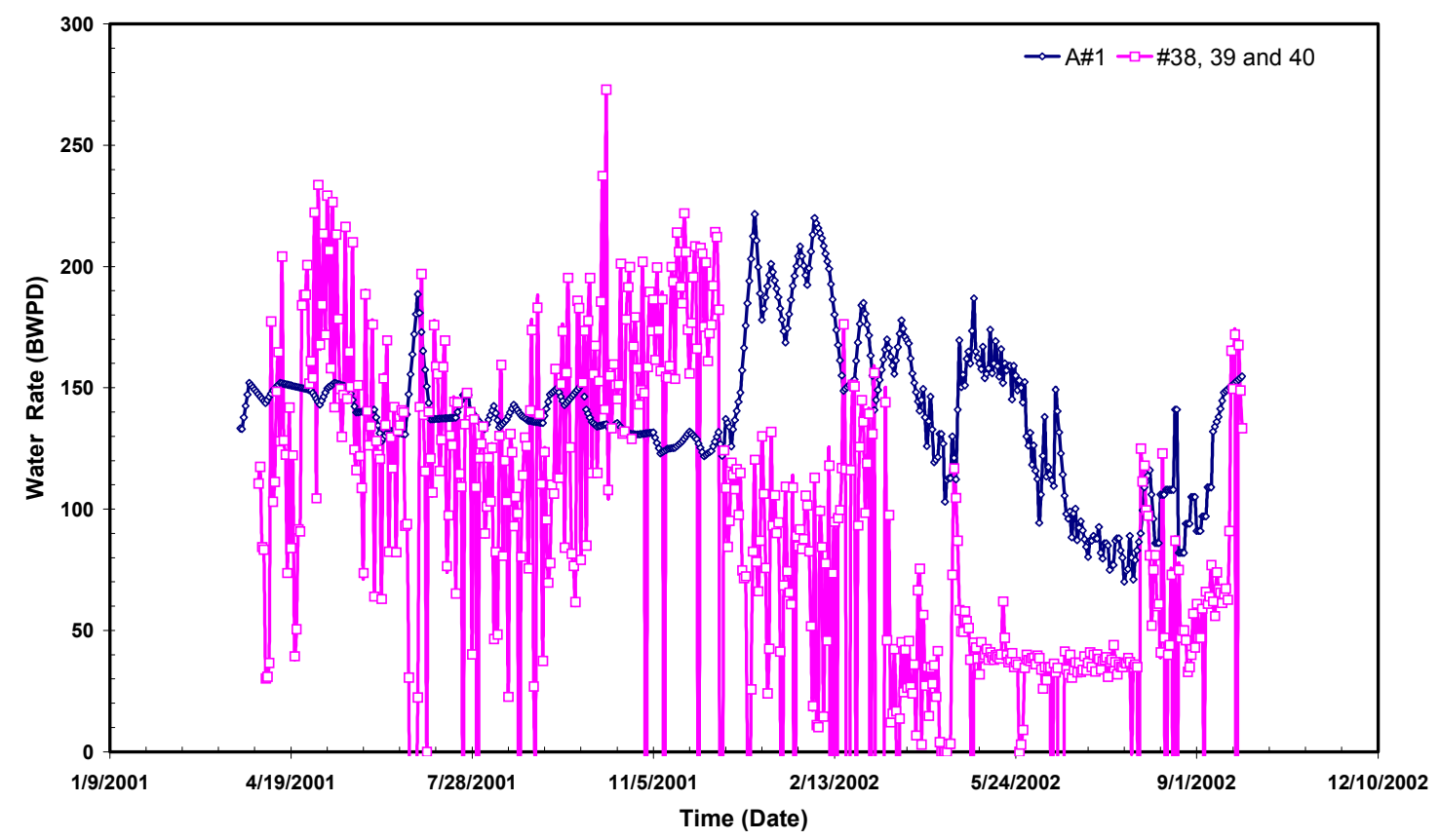

Fig. 2.26 - Water production at the interior producers and O'Daniel A1

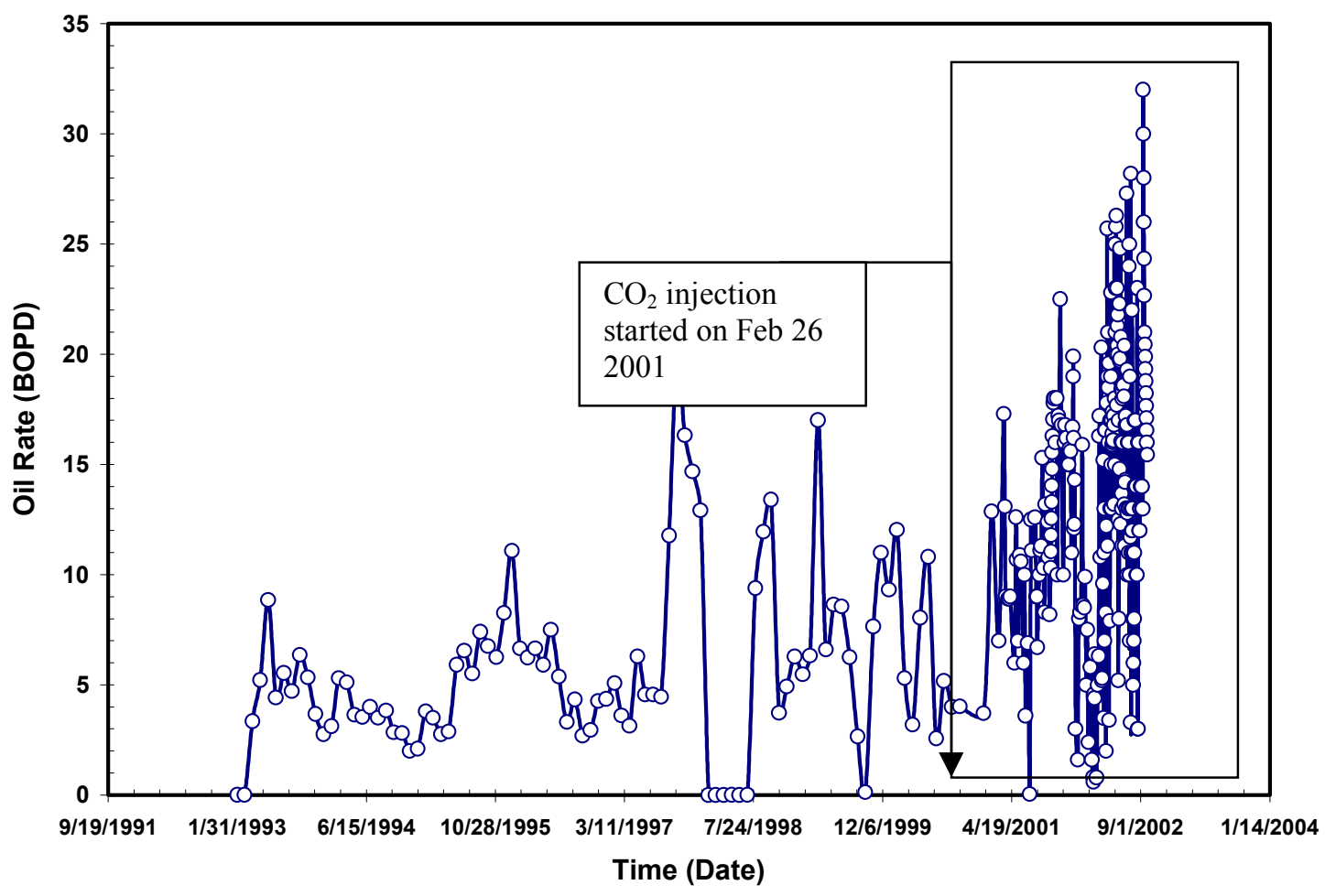

Fig. 2.27 - Oil production profile in O'Daniel A1 


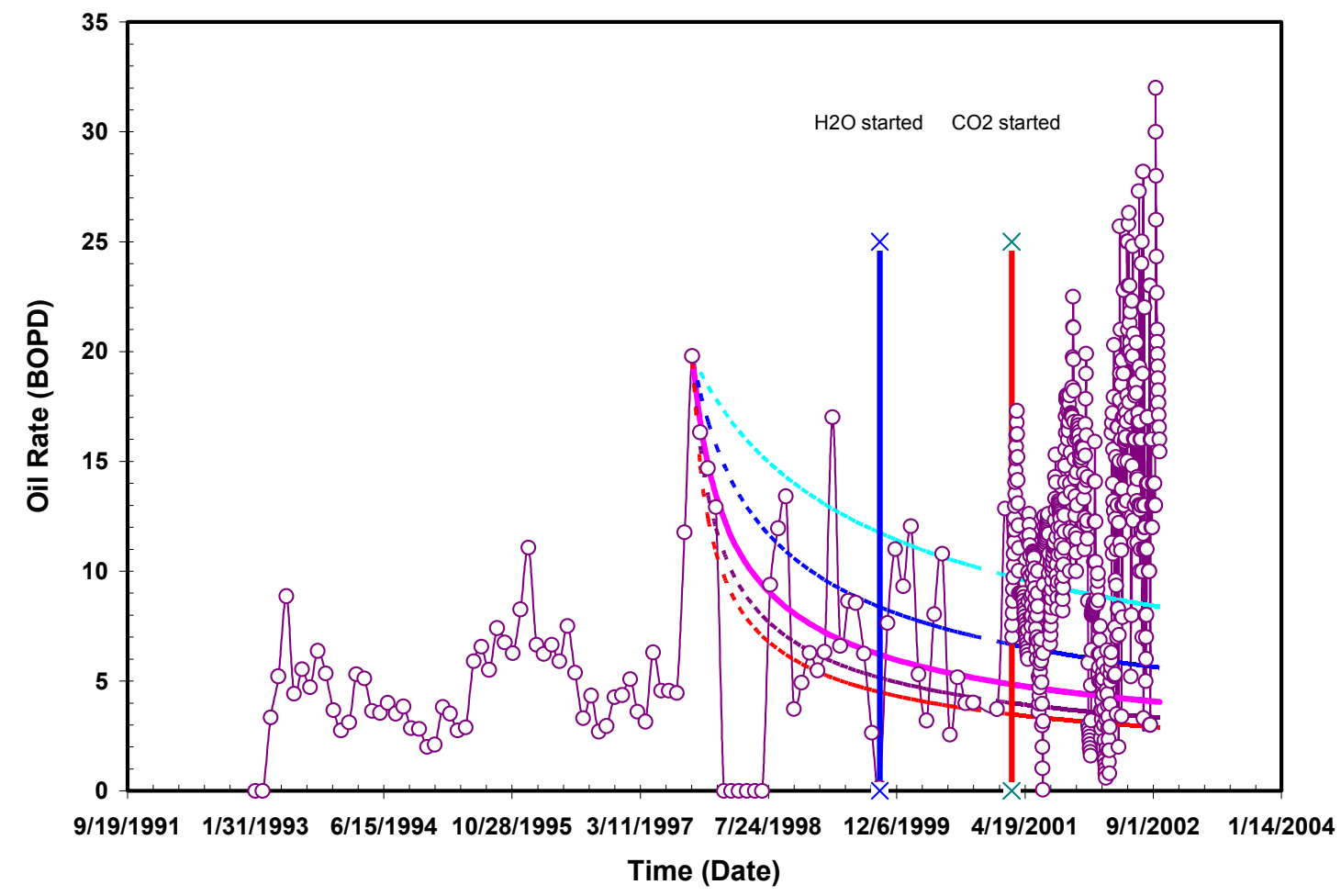

Fig. 2.28 - Decline curve scenarios when highest oil rate prior to waterflooding is used

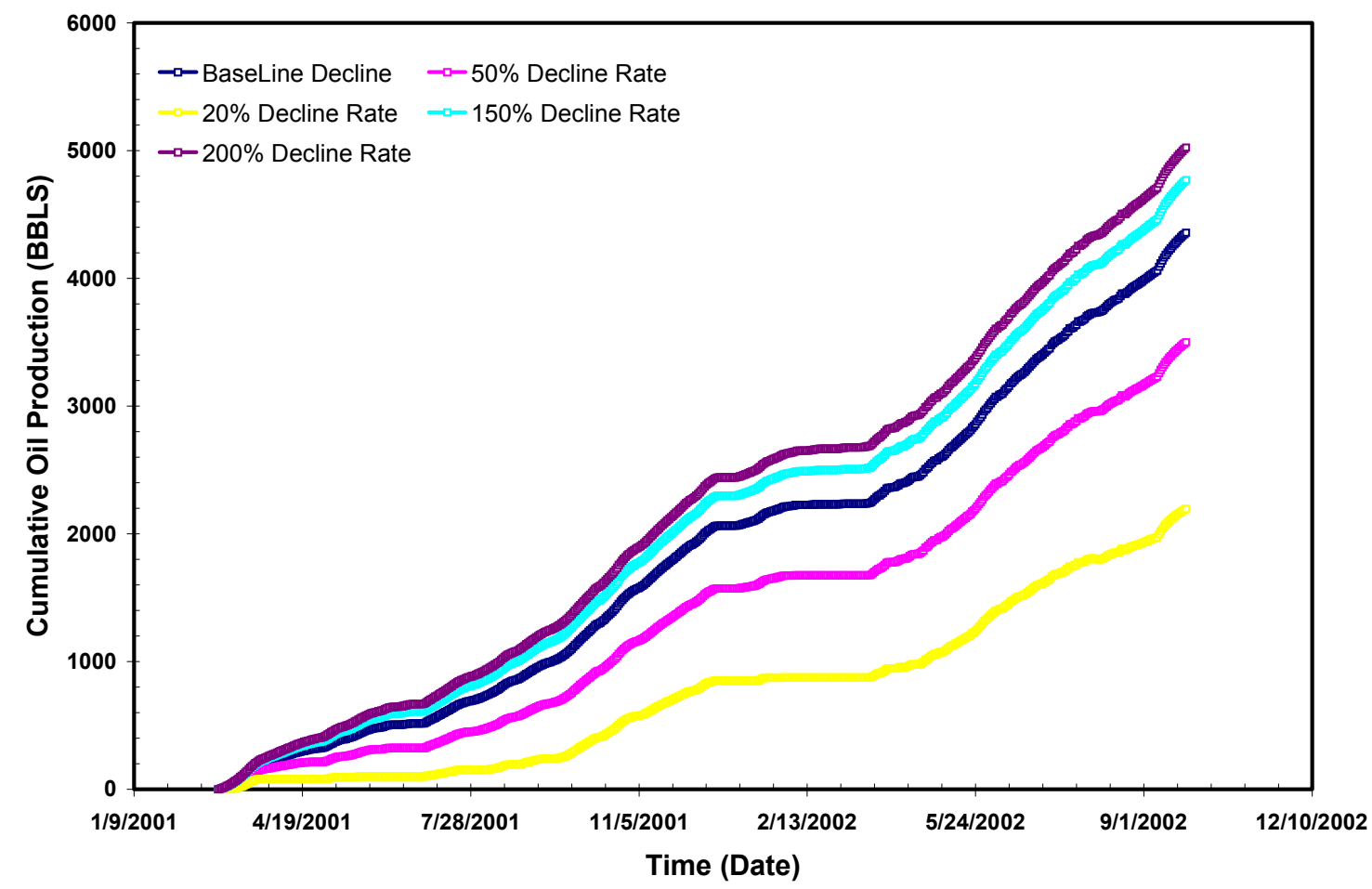

Fig. 2.29-Cumulative oil production for decline in production before waterflooding 


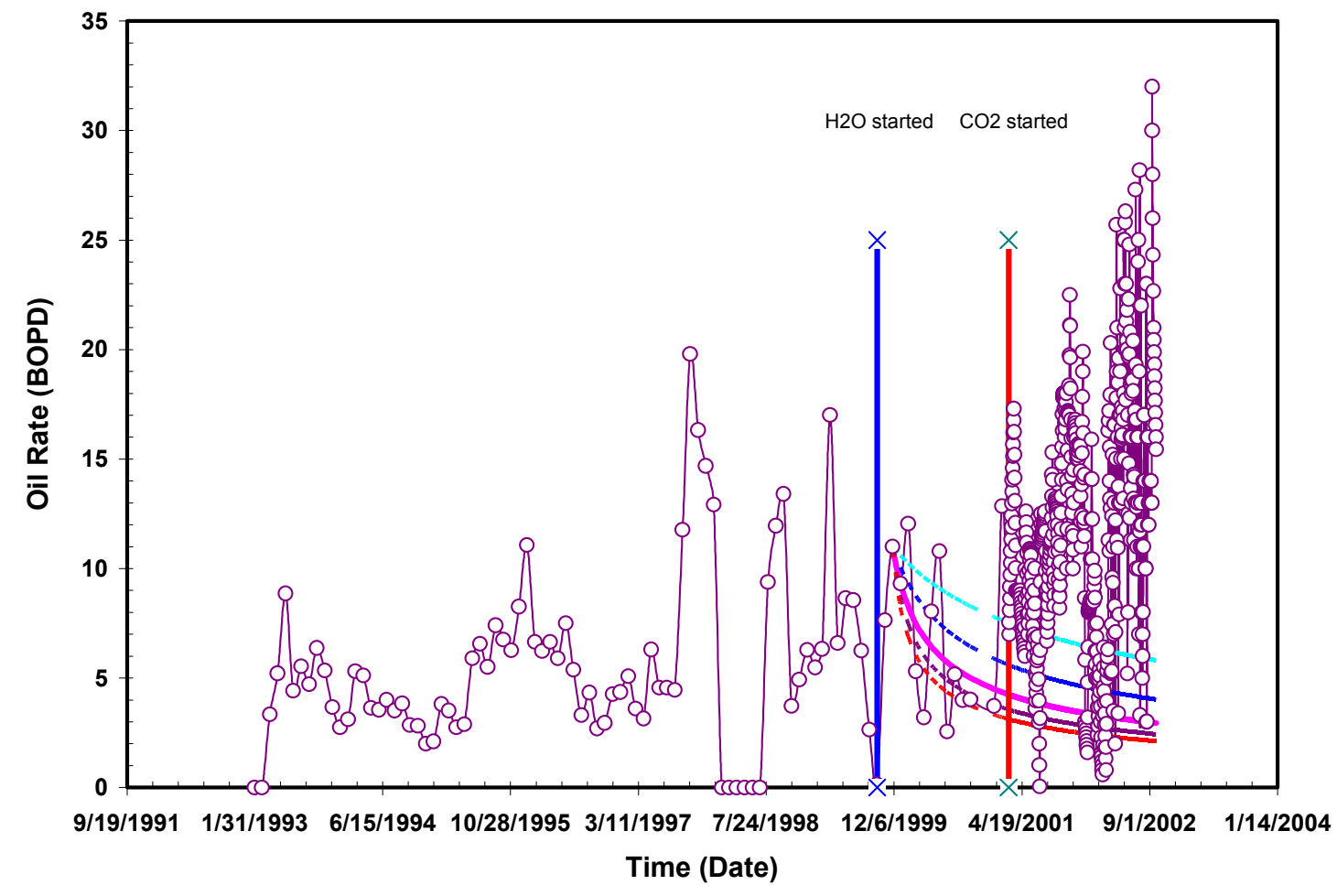

Fig. 2.30 - Decline curve analysis after waterflooding was started

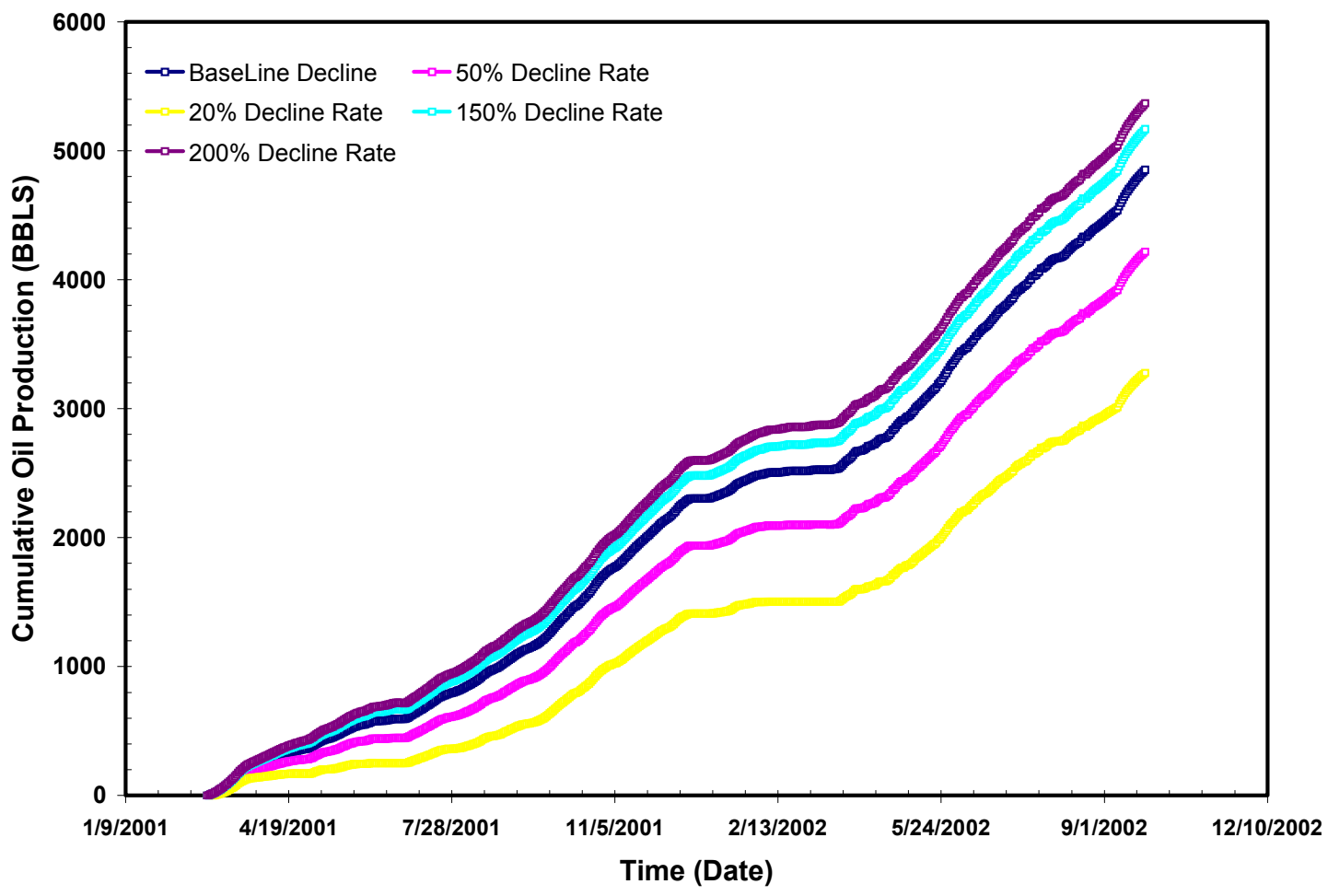

Fig. 2.31 - Cumulative production estimates for different rates after waterflooding 


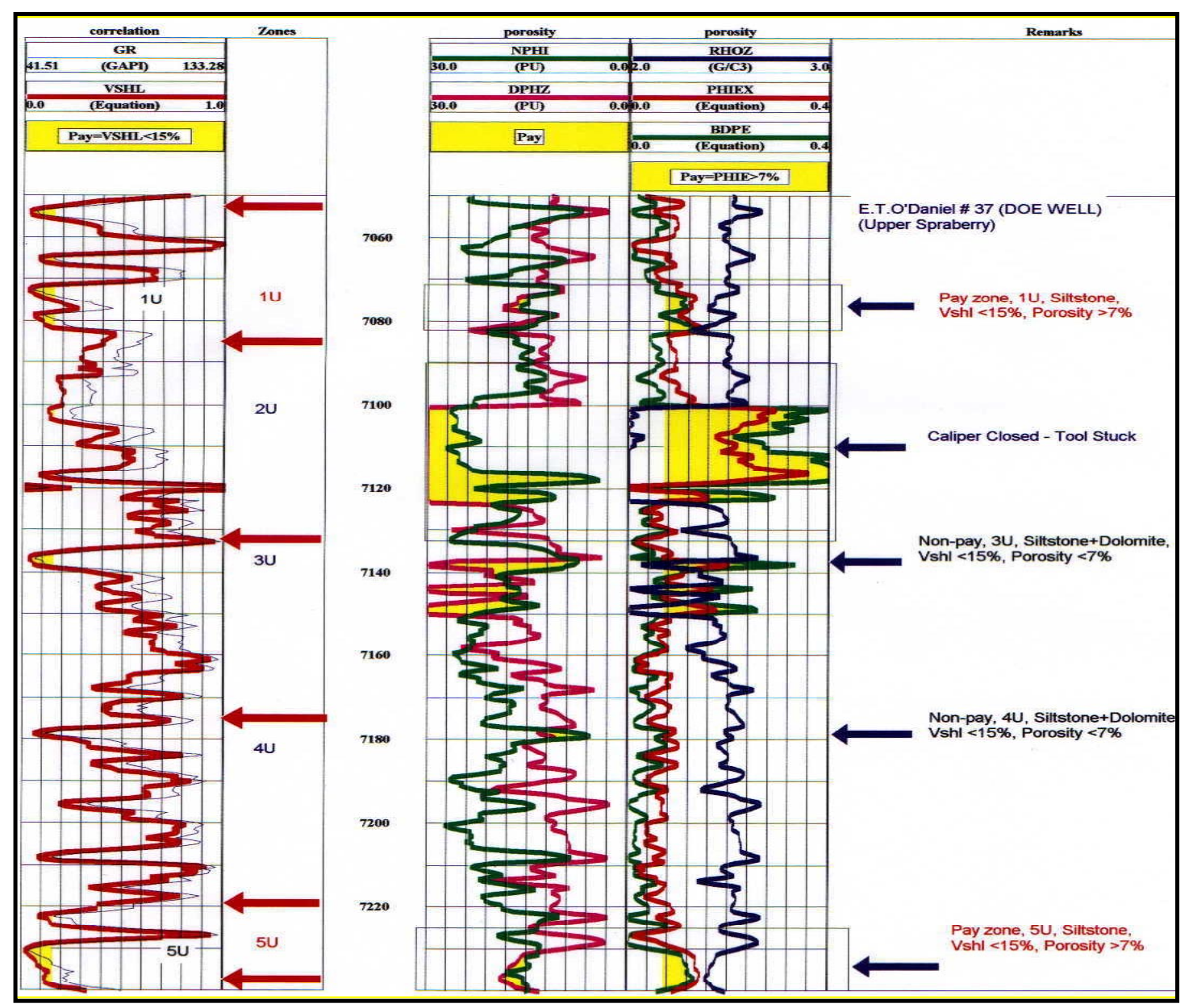

Fig. 2.32 - Upper Spraberry Interval (1U-5U) 


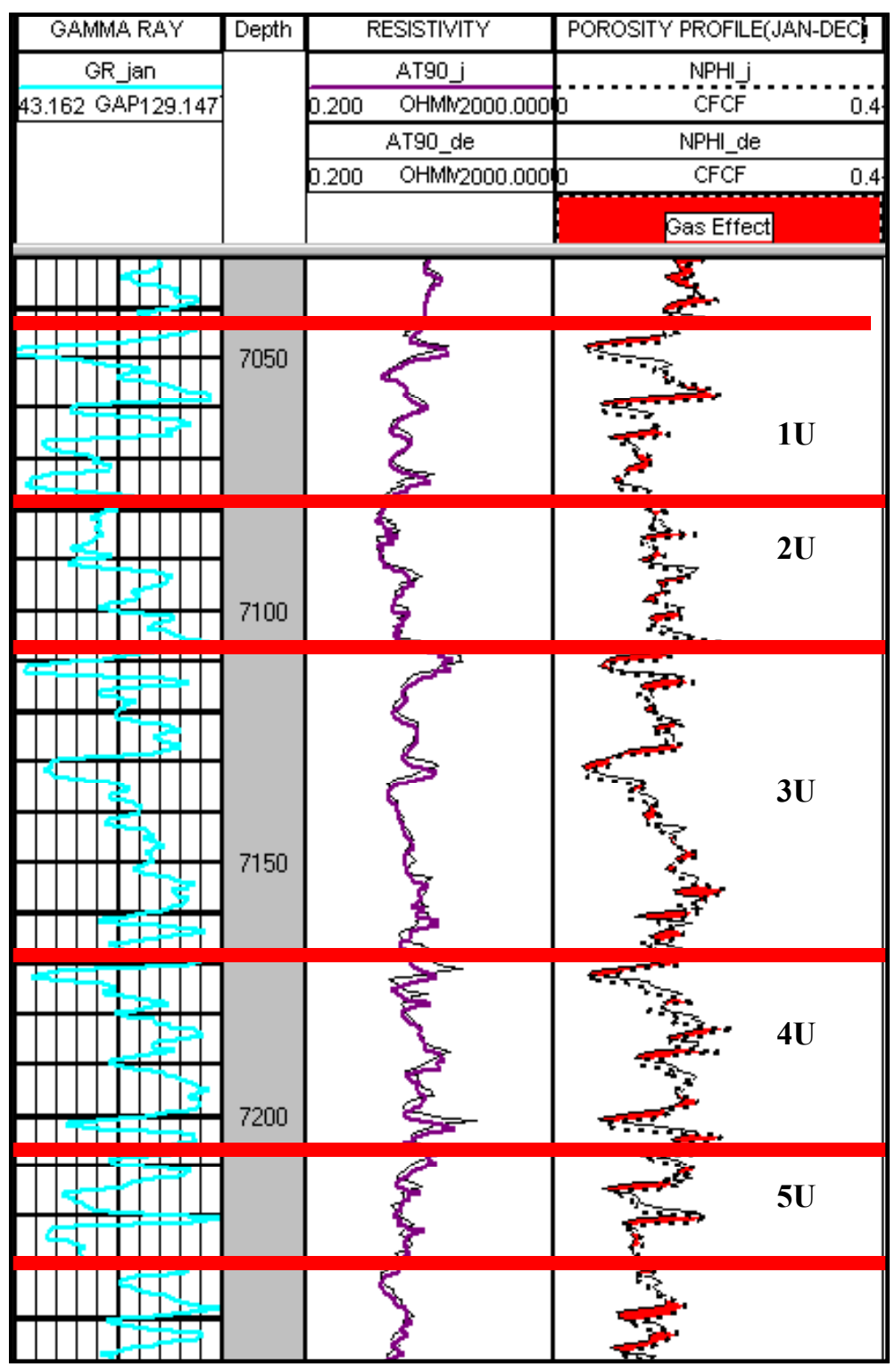

Fig. 2.33 - Comparison of neutron response at LOW 49(Jan/Dec 2001) 


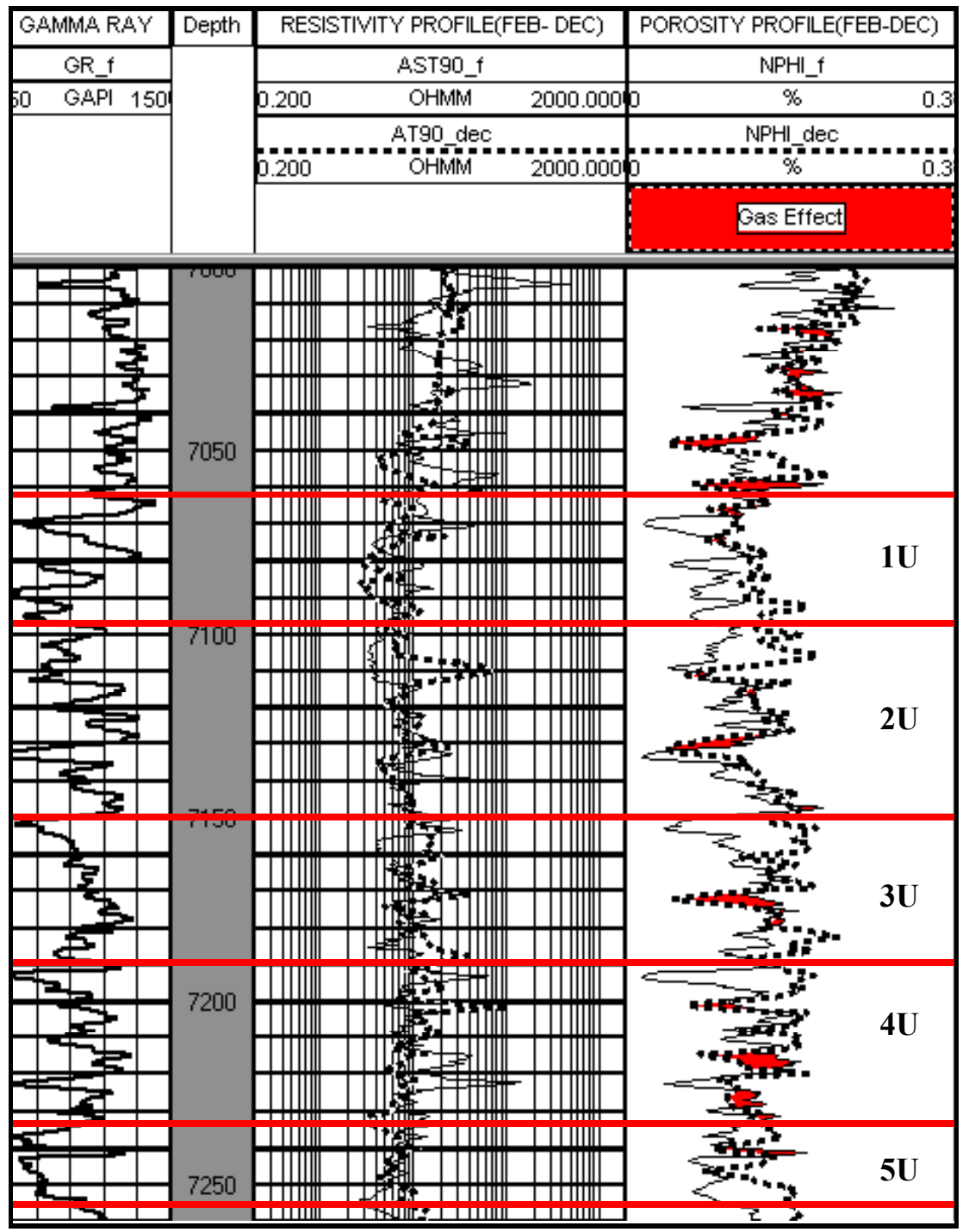

Fig. 2.34 - Comparison of neutron response at LOW 50(Feb/Dec 2001) 


\section{Well \#41}

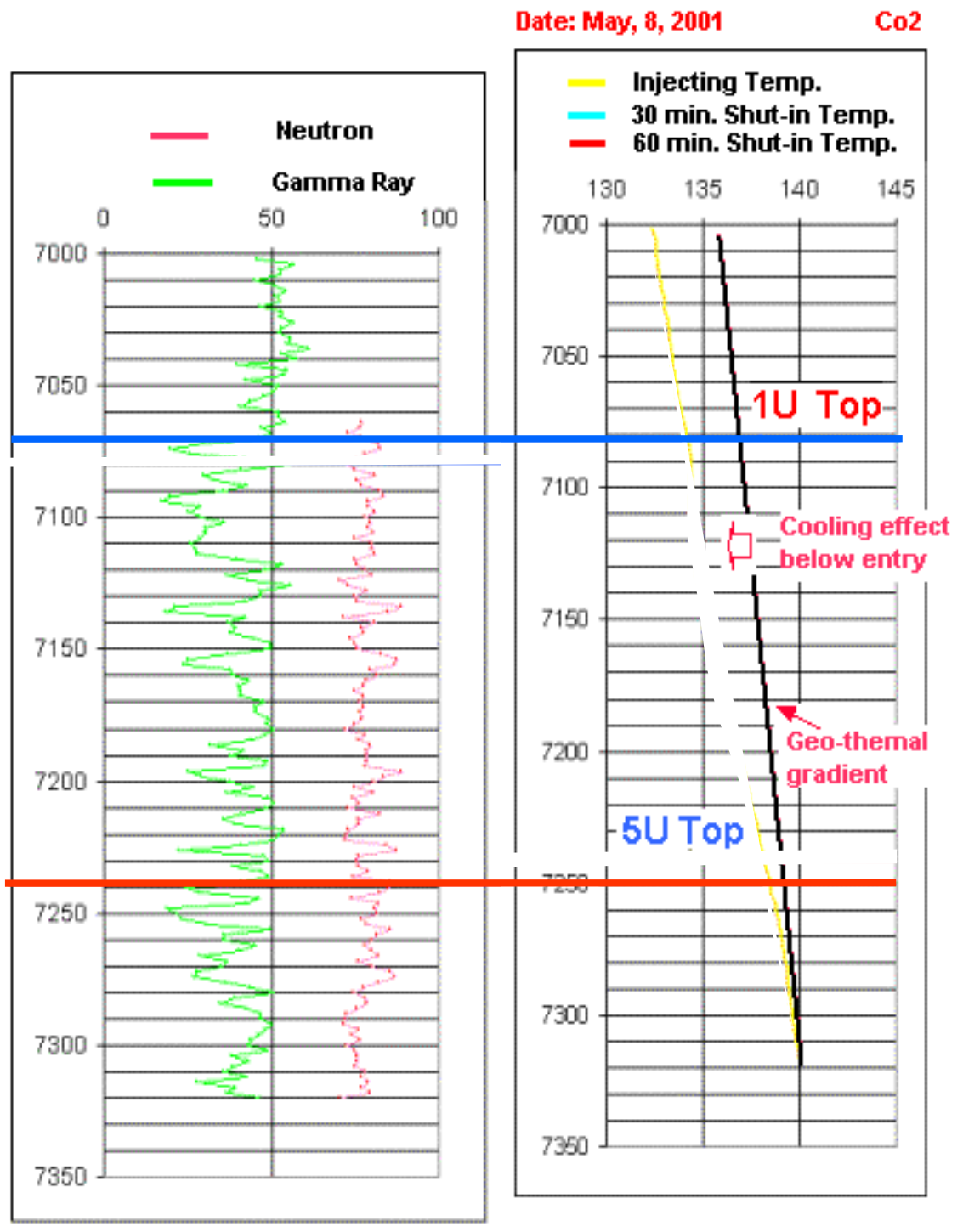

Fig. 2.35 - Temperature Log taken in ET O'Daniel 41 


\section{Well \#42}

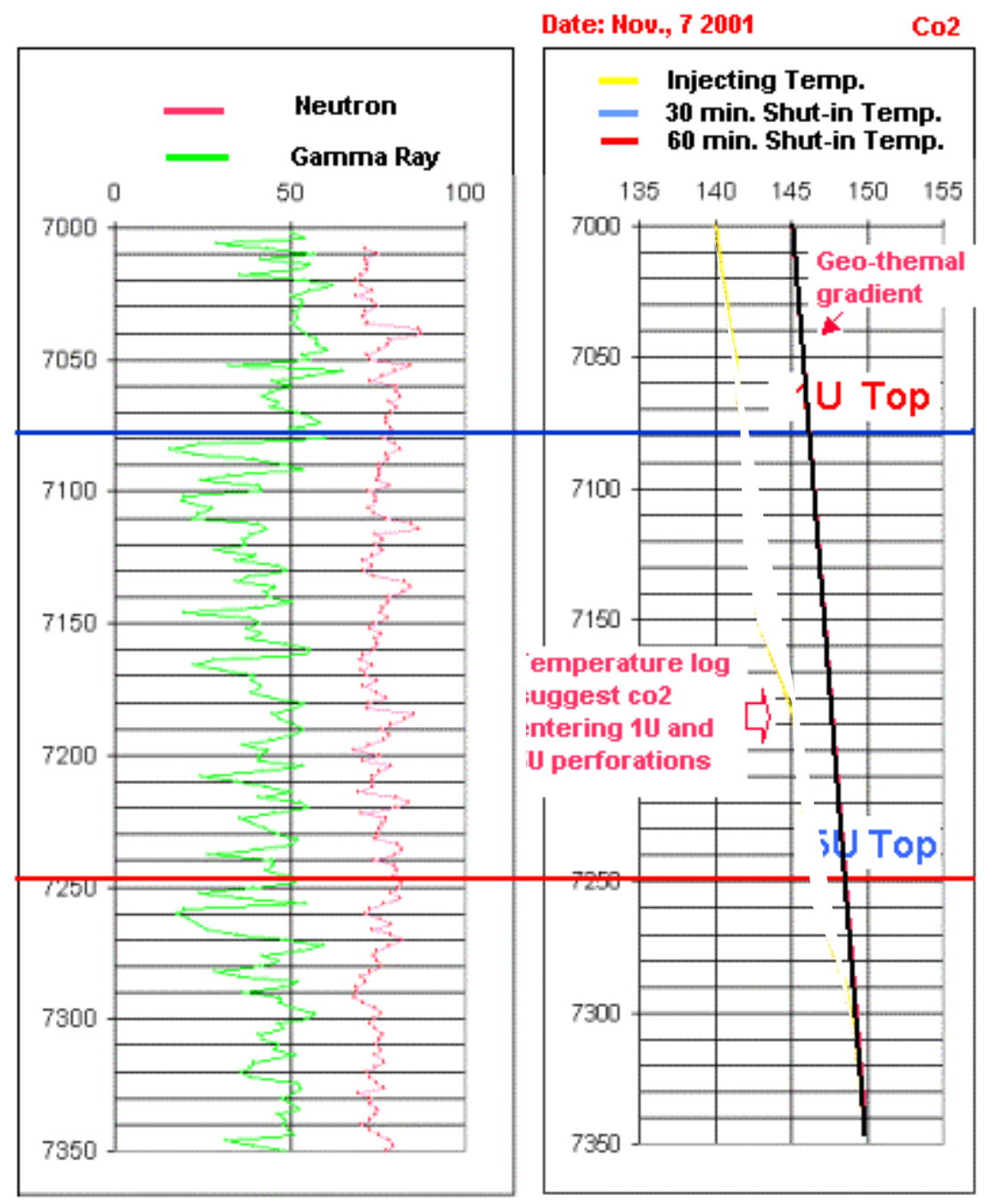

Fig. 2.36 - Temperature Log taken in ET O'Daniel 42 


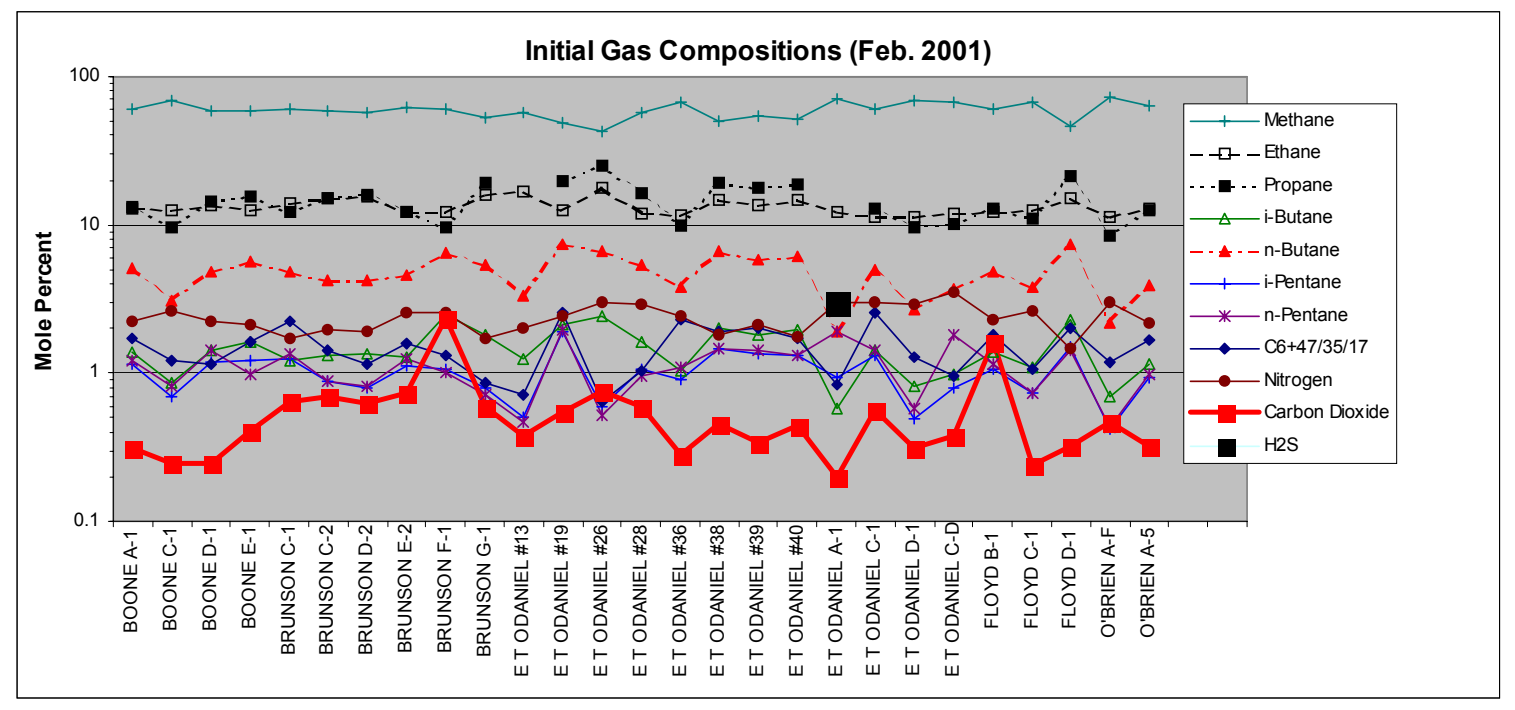

Fig. 2.37 - Initial gas compositions recorded in Feb 2001

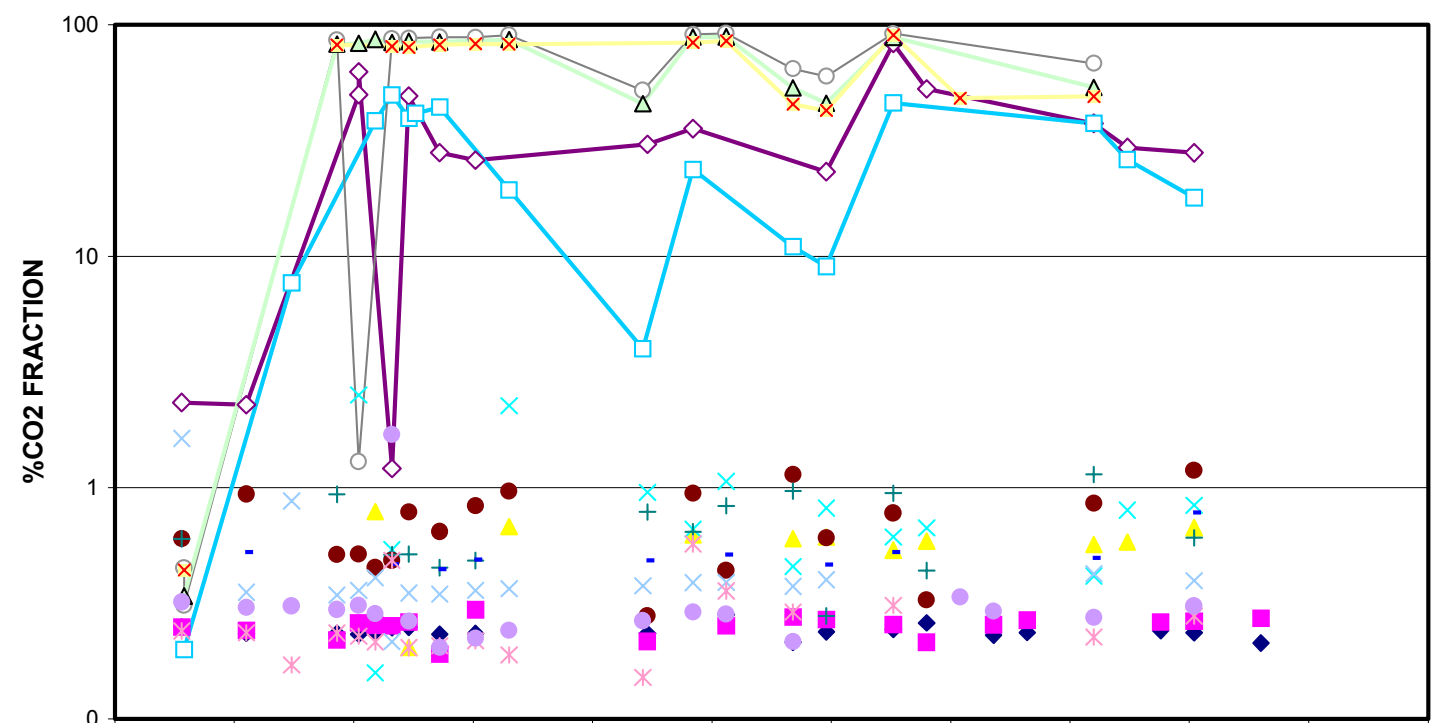

01/09/2001 02/28/2001 04/19/2001 06/08/2001 07/28/2001 09/16/2001 11/05/2001 $12 / 25 / 2001 \quad 02 / 13 / 2002 \quad 04 / 04 / 2002$ 05/24/2002 $07 / 13 / 2002$ SAMPLING DATE

- Boone C1

- Brunson G1

$\triangle$ OD 39
- Boone D1

+ Brunson $\mathrm{C} 2$

$\times$ OD 40 $\begin{array}{ll} & \text { Brunson D1 } \\ \text { - } & \text { Brunson C1,C2 } \\ \times & \text { Floyd B1 }\end{array}$ $\times$ Brunson A1
$-\square-O D$ A1
$* \quad$ Floyd C1 $\prec$ Brunson F1

$-0-$ OD38

- Floyd D1

Fig. 2.38 - Carbon dioxide fractions in on-trend wells 


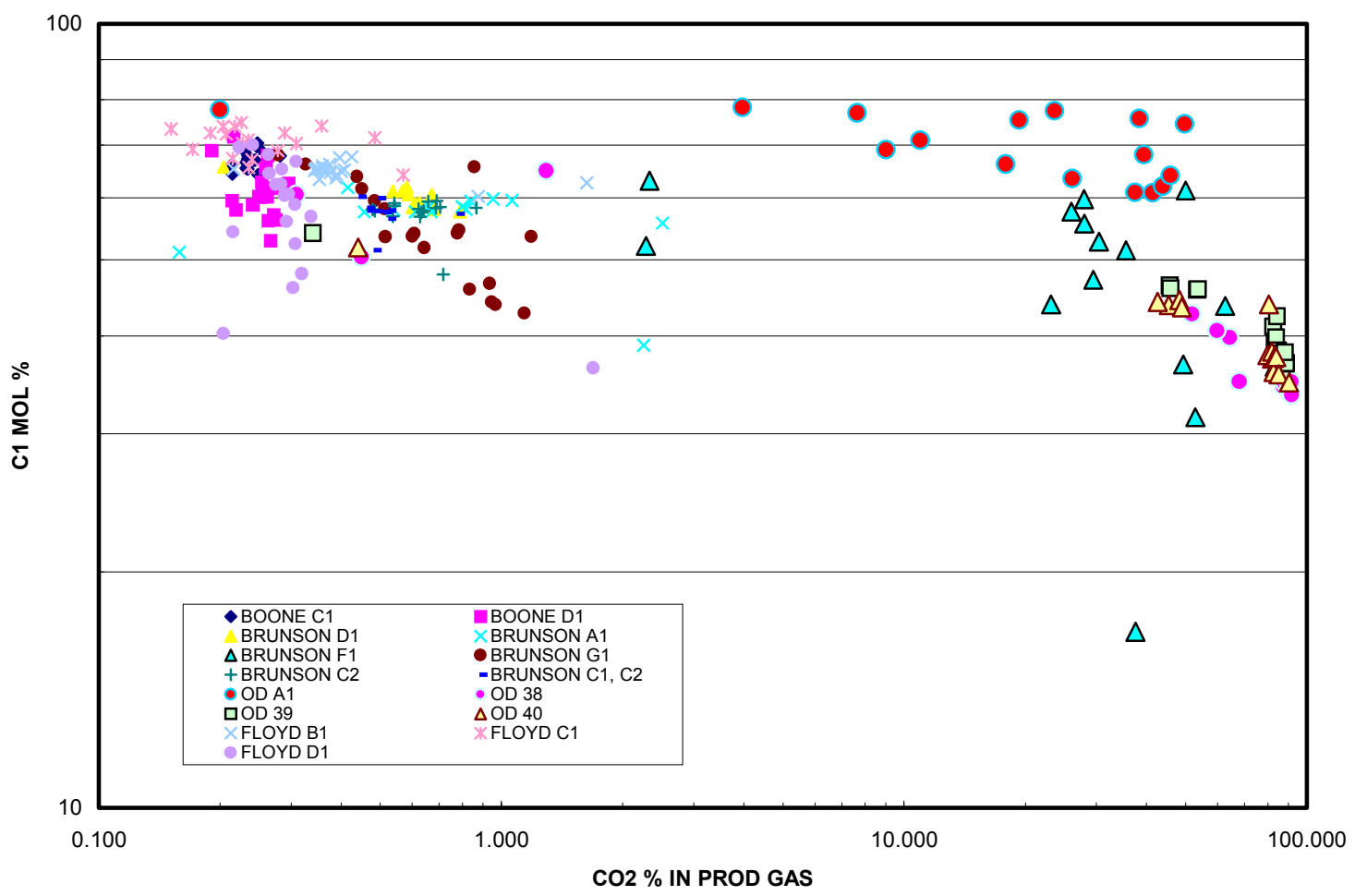

Fig. 2.39-Methane fractions in on-trend wells

C2 RELATIVE ENRICHMENT

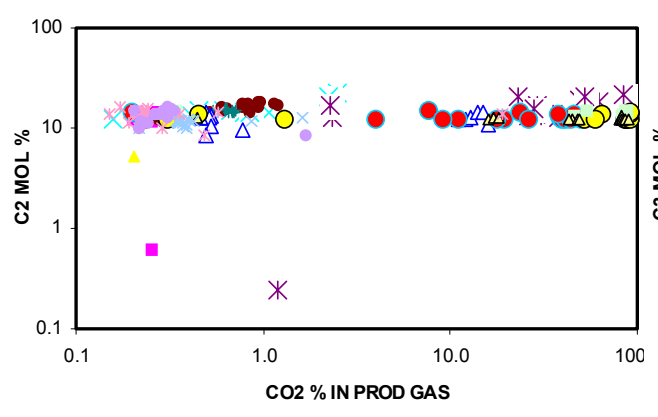

N-C4 RELATIVE ENRICHMENT

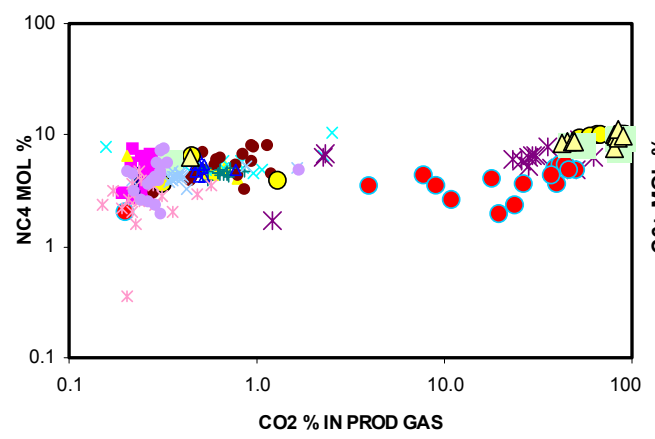

C3 RELATIVE ENRICHMENT

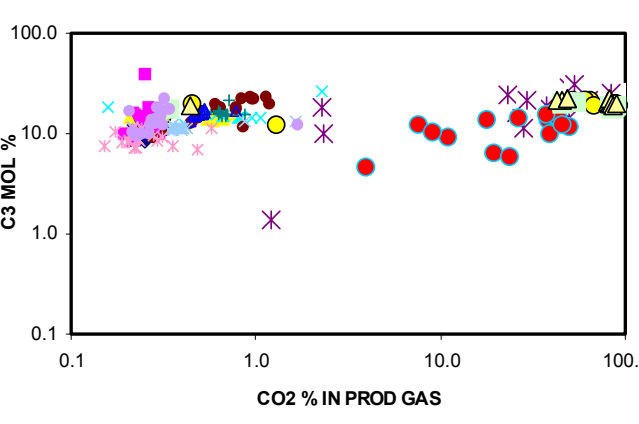

C6+ RELATIVE ENRICHMENT

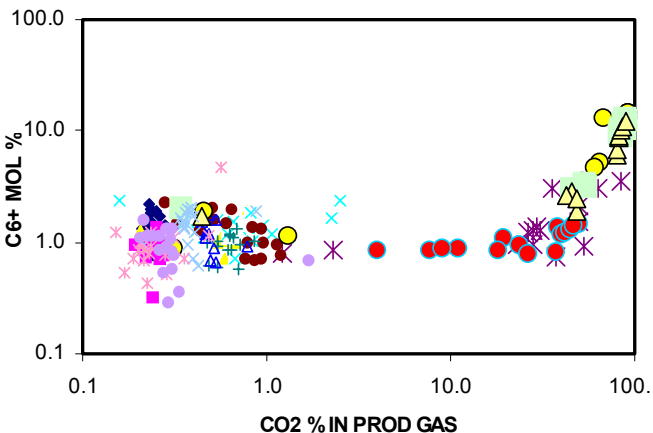

Fig. $2.40-\mathrm{C} 2, \mathrm{C} 3, \mathrm{n}-\mathrm{C} 4$ and $\mathrm{C} 6+$ fractions in on-trend wells 


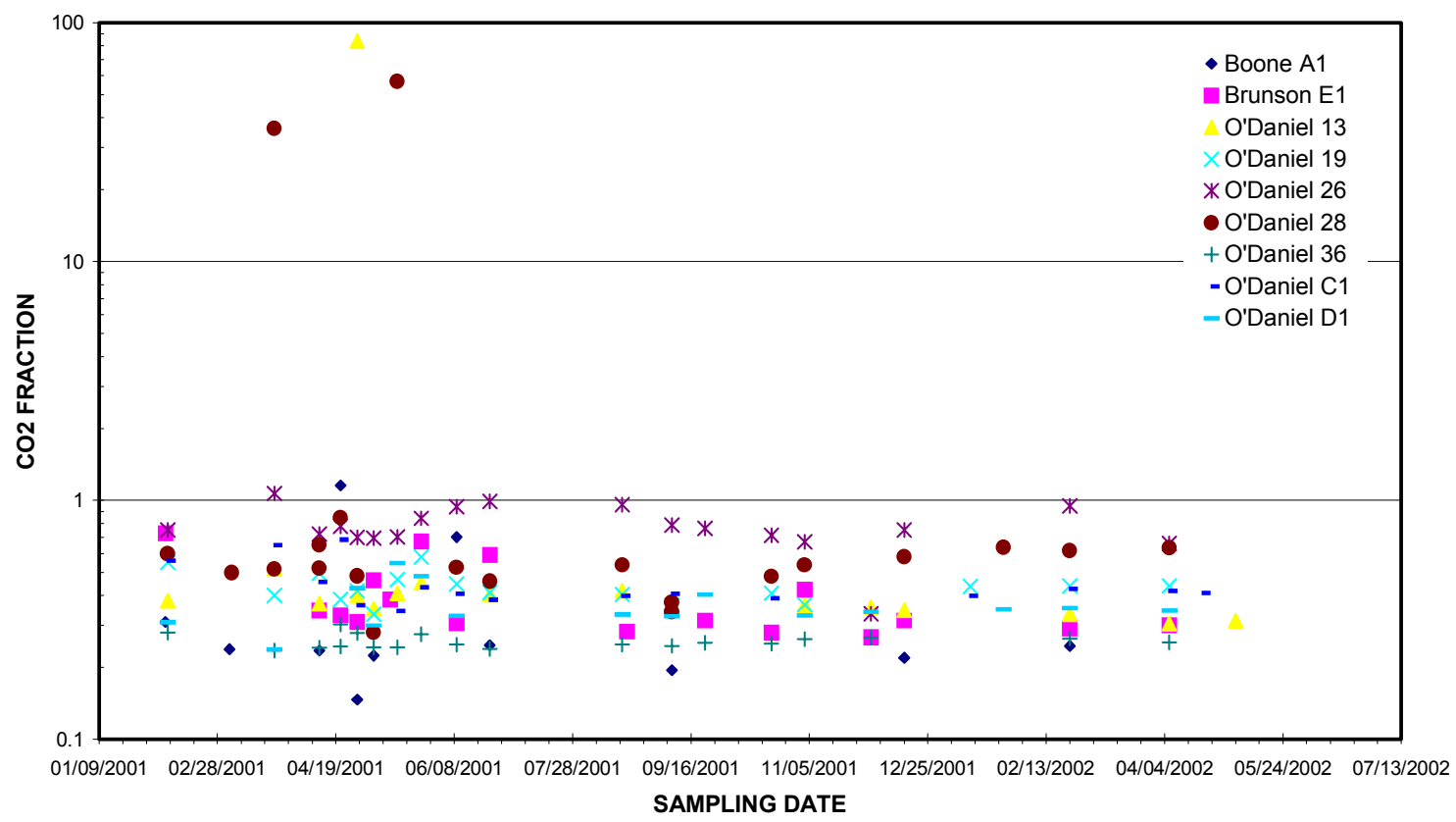

Fig. $2.41-\mathrm{CO}_{2}$ fractions in off-trend wells

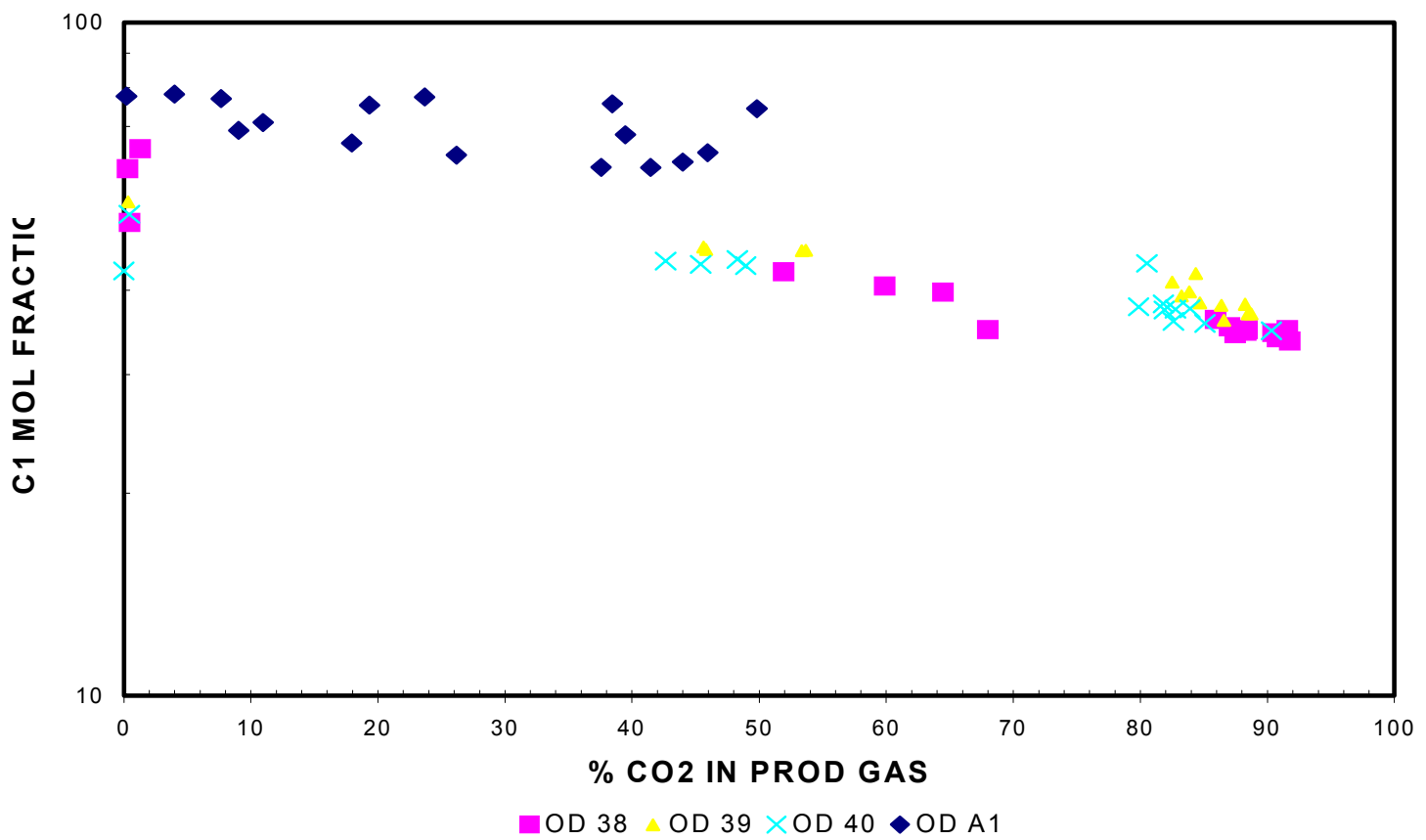

Fig. $2.42-\mathrm{C} 1$ mole fraction in ET O'Daniel A1 compared to interior producers 
C 2 RELATIVE ENRICHMENT

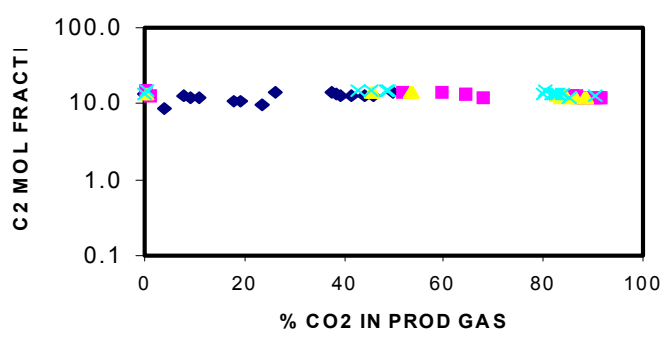

- OD A1 - OD $38 \triangle O D 39 \times$ OD 40

N-C 4 RELATIVE ENRICHMENT

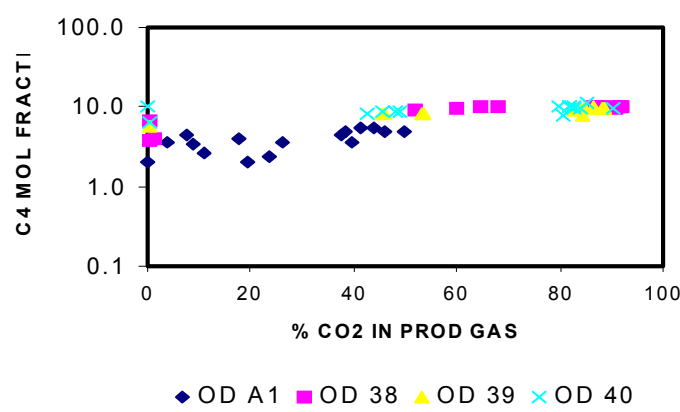

C 3 RELATIVE ENRICHMENT

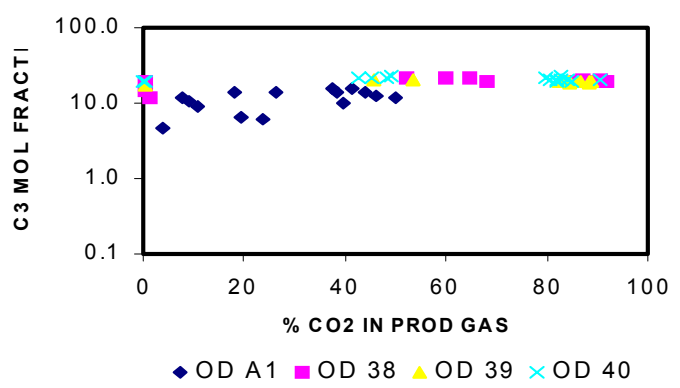

C 6+ RELATIVE ENRICHMENT

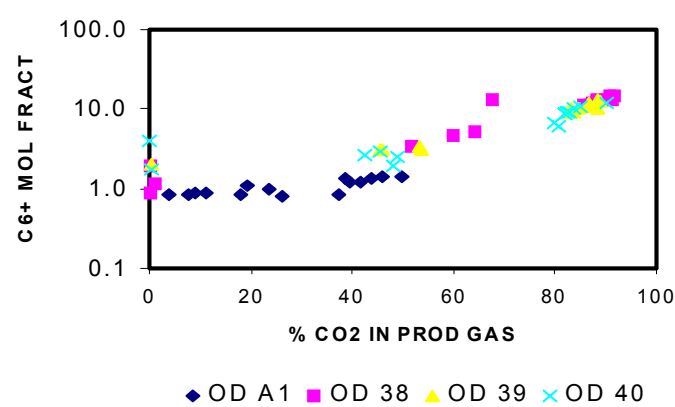

Fig. 2.43 - Relative enrichment of hydrocarbon fractions at O'Daniel A1 and interior producers 